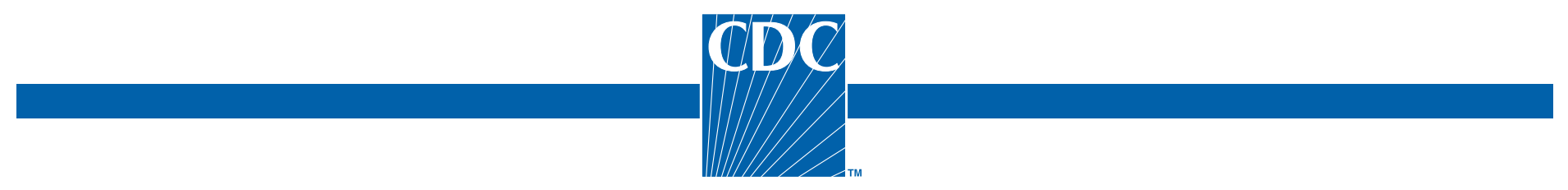

\title{
MWWR
}

Morbidity and Mortality Weekly Report

Weekly

January 3, 2003 / Vol. 51 / Nos. 51 \& 52

\section{Outbreaks of Salmonella Serotype Enteritidis Infection Associated with Eating Shell Eggs - United States, 1999-2001}

A Salmonella serotype Enteritidis (SE) epidemic emerged in the 1980s, when increasing numbers of infections were detected in the Northeastern and Mid-Atlantic regions of the United States (1). In the early 1990s, while SE rates in the Northeast began to decline, the SE epidemic expanded to the Pacific region (2). Nationwide, the number of SE isolates reported to CDC peaked at 3.8 per 100,000 population in 1995. Although rates of culture-confirmed SE infection reported to CDC declined to 1.9 by 1999 (Figure 1), rates did not decline further through 2001, and outbreaks continue to occur. Investigations of outbreaks and sporadic cases have indicated repeatedly that, when a food vehicle is identified, the most common sources of SE infection are undercooked and raw shell eggs $(3,4)$. This report describes two SE outbreaks associated with eating shell eggs and underscores the need to strengthen SE-control measures.

\section{South Carolina, 2001}

During February-March 2001, outbreaks of gastroenteritis occurred among inmates in four prison facilities of the South Carolina Department of Corrections (SCDC). The first outbreak occurred in a men's facility (M1) on February 6. The three other outbreaks, all occurring on March 2, affected a second men's facility (M2) and two women's facilities (F1 and F2). Among 2,317 inmates in the four prisons, 688 reported to prison infirmaries with gastrointestinal symptoms (e.g., abdominal cramps, diarrhea, and nausea). Stool specimens from ill inmates yielded SE phage types 2, 13a, and 23. No illness was reported among SCDC staff members.

The South Carolina Department of Health and Environmental Control conducted two case-control studies in M2 and F1, which shared a common kitchen. A case-patient was defined as any SCDC inmate who reported to the prison
FIGURE 1. Isolation rate* of Salmonella serotype Enteritidis (SE), by year — United States, 1990-2001

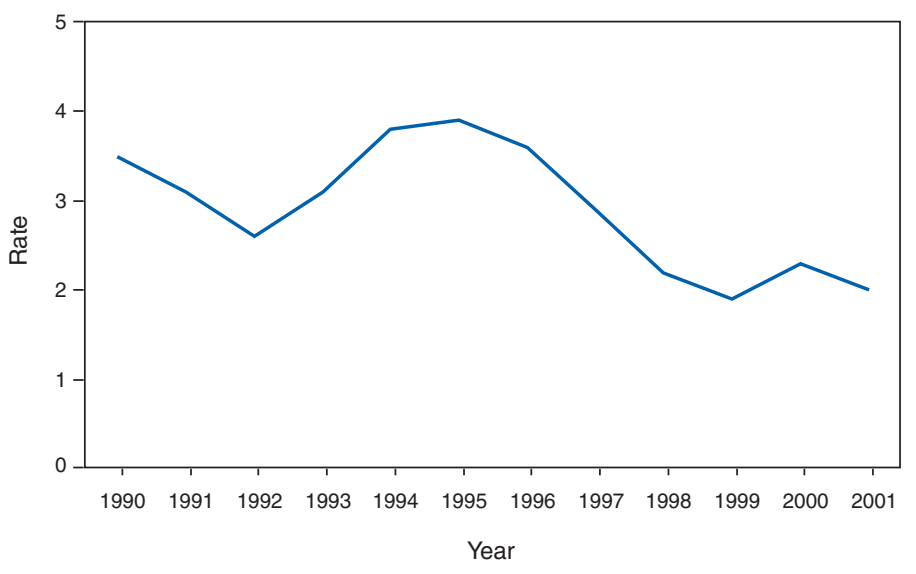

* Per 100,000 population.

infirmary with acute gastrointestinal symptoms. Case-patients were selected at random from a list of ill inmates. Controls were inmates without illness who were selected at random from an inmate roster provided by the prisons and who were matched by prison facility. A tuna salad served for lunch on March 2 was eaten by $88 \%$ of the male case-patients (odds ratio $[\mathrm{OR}]=7.0 ; 95 \%$ confidence interval $[\mathrm{CI}]=1.8-30.5)$ and by $89 \%$ of the female case-patients $(\mathrm{OR}=16.7 ; 95 \% \mathrm{CI}=4.1-$ 74.7). The tuna salad was prepared with eggs that were reportedly hard-boiled by kitchen staff, who also were inmates.

\section{INSIDE}

1152 Blood Safety Monitoring Among Persons with Bleeding Disorders - United States, May 1998-June 2002 
The $M M W R$ series of publications is published by the Epidemiology Program Office, Centers for Disease Control and Prevention (CDC), U.S. Department of Health and Human Services, Atlanta, GA 30333.

\section{SUGGESTED CITATION}

Centers for Disease Control and Prevention. [Article Title]. MMWR 2002;51:[inclusive page numbers].

\section{Centers for Disease Control and Prevention}

Julie L. Gerberding, M.D., M.P.H. Director

David W. Fleming, M.D. Deputy Director for Science and Public Health

Dixie E. Snider, Jr., M.D., M.P.H. Associate Director for Science

\section{Epidemiology Program Office}

Stephen B. Thacker, M.D., M.Sc. Director

Office of Scientific and Health Communications

John W. Ward, M.D. Director

Editor, MMWR Series

David C. Johnson Acting Managing Editor, MMWR (Weekly)

Jude C. Rutledge

Teresa F. Rutledge

Jeffrey D. Sokolow, M.A.

Writers/Editors, MMWR (Weekly)

Lynda G. Cupell

Malbea A. Heilman

Beverly J. Holland

Visual Information Specialists

Quang M. Doan

Erica R. Shaver

Information Technology Specialists

\section{Division of Public Health Surveillance and Informatics}

Notifiable Disease Morbidity and 122 Cities Mortality Data

Robert F. Fagan

Deborah A. Adams

Felicia J. Connor

Lateka Dammond

Patsy A. Hall

Pearl C. Sharp
At the time of the outbreaks, all eggs used by the four involved SCDC facilities were supplied from a single vendor. Eggs supplied to M2 and F1 were traced back to the vendor's farm (Farm A). In February 2001, eggs submitted from Farm A to the South Carolina Egg Quality Assurance Program tested positive for SE phage types 2,13a, 22, 23, and 28. Phage type 2 was the predominant SE strain isolated from both ill patients and eggs from Farm A. To protect the inmates, SCDC switched to pasteurized egg products in April 2001.

\section{North Carolina, 2001}

In June 2001, the Statistical Outbreak Detection Algorithm at CDC signaled an increase in SE cases reported from North Carolina. The Division of Public Health in North Carolina was alerted and began to review SE cases throughout the state. The North Carolina State Laboratory of Public Health reported 51 cases in July and 31 in August, compared with 11 cases in each of those months during 2000. Cases occurred throughout the state.

A case-control study was performed. A case was defined as culture-confirmed SE in a resident of North Carolina reported during July 1-September 7, 2001. One to two neighbor controls were matched to each case. SE isolates were subtyped by pulsed-field gel electrophoresis (PFGE) and phage typing. Analysis of 53 patients and 78 controls indicated that illness was associated with eating eggs (matched odds ratio $[\mathrm{MOR}]=2.8 ; 95 \% \mathrm{CI}=1.1-9.5)$. Isolates from $21(40 \%)$ of 53 patients had PFGE pattern A. Analysis restricted to patients with pattern $A$ indicated a stronger association with egg consumption $(\mathrm{MOR}=10.7 ; 95 \% \mathrm{CI}=1.3-88.1)$. PFGE pattern A also was identified in isolates from patients in the South Carolina SE outbreak. All isolates from SE patients in both outbreaks that were PFGE pattern A also were phage type 13a. Among 14 random, nonoutbreak phage type 13a $\mathrm{SE}$ isolates tested subsequently at $\mathrm{CDC}$, seven distinct PFGE patterns were identified; none was PFGE pattern A. A traceback of implicated eggs purchased from retail outlets in North Carolina was inconclusive for implicating a farm.

Reported by: D Drociuk, MSPH, S Carnesale, MD, G Elliot, LJ Bell, MD, JJ Gibson, MD, South Carolina Dept of Health and Environmental Control. L Wolf, D Briggs, B Jenkins, JM Maillard, MD, North Carolina Dept of Health and Human Svcs. M Huddle, MPH, F Virgin, C Braden, MD, Div of Bacterial and Mycotic Diseases, National Center for Infectious Diseases; P Srikantiah, MD, A Stoica, $M D, T$ Chiller, MD, EIS officers, CDC.

Editorial Note: During 1990-2001, state and territorial health departments reported 677 SE outbreaks, which accounted for 23,366 illnesses, 1,988 hospitalizations, and 33 deaths (CDC, unpublished data, 2002). Among the 309 
outbreaks reported with a confirmed vehicle of transmission, $241(78.0 \%)$ were associated with shell eggs, accounting for 14,319 illnesses. Of these, 10,406 illnesses occurred during 1990-1995, and 3,913 occurred during 1996-2001. The overall decrease in SE incidence and the decrease in the number of illnesses related to egg-associated SE outbreaks during the last decade might be attributed in part to the implementation of prevention measures, including on-farm control programs, egg refrigeration, and consumer and food worker education. However, reported cases did not decline during 1999-2001, and outbreaks associated with shell eggs continue to occur.

In the South Carolina outbreak, eggs from a farm that tested positive for SE in February 2001 were distributed to the prisons in March, despite the farm's participation in a voluntary, state-sponsored SE-control program. This farm withdrew from the state program in April 2001. Phage type 2 was the most common SE strain isolated in the South Carolina outbreak. This uncommon phage type, which has accounted for 3\% of SE outbreaks with reported phage type since 1985, also was found on Farm A. Cases in the outbreak in North Carolina shared the same SE PFGE pattern and phage type (13a) as some of the South Carolina outbreak cases, suggesting a possible link to the same farm.

Eggs that reportedly were hard-boiled and used in a tuna salad were the implicated vehicle in the South Carolina outbreak. A recent study demonstrated that unless SE-containing eggs are exposed to boiling water until the yolk is completely solidified, SE can survive the cooking process (5). Cross contamination of the tuna salad by inmate food handlers also was possible.

To achieve sustained decreases in egg-associated SE illnesses, a concerted prevention effort is needed from farmers to consumers (6). A key factor in this effort is the implementation of farm-based measures to reduce SE contamination of eggs during production. The implementation of such control programs in Northeastern states in the early 1990s might have contributed to subsequent decreases in human SE isolation rates in New England and Mid-Atlantic regions (7). One important control measure is microbiologic testing of hen houses for the presence of SE. If SE is found on a farm during routine environmental testing, eggs may be diverted to pasteurization. Evidence suggests that proper implementation and oversight of farm-based control programs can result in a reduction of SE infections among flocks in poultry houses (8). Farm participation in current SE-control programs is voluntary, and the components of programs vary. Future shellegg safety measures should include greater participation in farm-based control programs with microbiologic testing.
Both outbreaks described in this report occurred in the Southeastern region of the United States. Compared with declining rates of $S E$ infections in other regions of the United States, the incidence of SE in Southeastern states increased by $50 \%$ from 2000 to 2001 (Figure 2). Ongoing surveillance of SE outbreaks will be necessary to detect changes in trends of SE infection in this region. Expansion of SE-prevention measures will be an important part of efforts to prevent SE infections in the Southeast. This includes actively encouraging farms to participate in SE-control programs, promotion of proper refrigeration of eggs during storage and transportation, and education of food handlers and consumers about food preparation (see box). Retail and consumer buyers can specify that suppliers provide only eggs produced from farms managed under an SE-control program that is recognized by a state regulatory agency or a state poultry association.

The outbreak in South Carolina prisons was the largest SE outbreak in 2001. Because persons residing in institutions depend entirely on their institutions for meals, the supply of contaminated foods to these settings can place large populations at risk for developing foodborne diseases. Persons residing in institutions, especially elderly persons in nursing homes or assisted living facilities, are at higher risk for dying from outbreak-associated SE infections (9). During 1990-2001, a total of 83 SE outbreaks occurred in institutional settings*, representing $12 \%$ of reported SE outbreaks. Of the 33 outbreak-associated deaths, 22 (67\%) occurred in institutional

\footnotetext{
*Institutional settings include nursing homes, independent living facilities, assisted living facilities, childcare settings, campus cafeterias, prisons and correctional facilities, and shelters.
}

FIGURE 2. Isolation rate* of Salmonella serotype Enteritidis (SE), by year - Southeastern region ${ }^{\dagger}$, 1990-2001

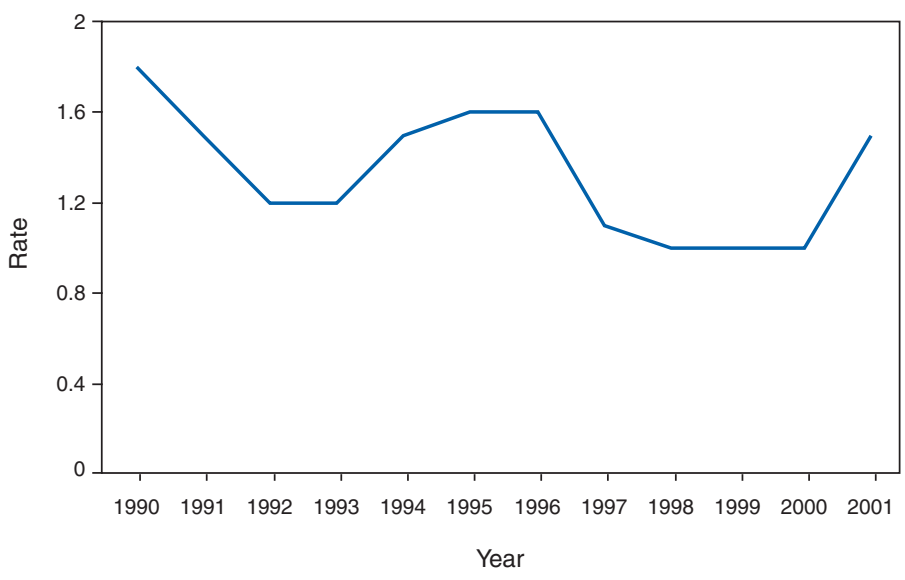

\footnotetext{
* Per 100,000 population.

${ }^{\dagger}$ Alabama, Delaware, Florida, Georgia, Kentucky, Maryland, Mississippi, North Carolina, South Carolina, Tennessee, Virginia, and West Virginia.
} 
BOX. Recommendations for preventing Salmonella serotype Enteritidis (SE) infections associated with eggs

\section{For egg producers:}

- Flock-based SE-control programs that include routine microbiologic testing should be adopted and implemented by industry nationwide.

For retail and food service establishments and institutional settings:

- In retail and food service establishments, pasteurized egg products or pasteurized in-shell eggs are recommended in place of pooled eggs or raw or undercooked shell eggs. If used, raw shell eggs should be fully cooked. If shell eggs are served undercooked, a consumer advisory should be posted in accordance with the Food Code.

- In hospitals, nursing homes, adult or childcare facilities, and senior centers, pasteurized egg products or pasteurized in-shell eggs should be used in place of pooled eggs or raw or undercooked eggs.

- Eggs should be purchased or received from a distributor refrigerated and stored refrigerated at $\leq 45^{\circ} \mathrm{F}\left(\leq 7^{\circ} \mathrm{C}\right)$ at all times.

\section{For egg consumers:}

- Consumption of raw or undercooked eggs should be avoided, especially by young children, elderly persons, and persons with weakened immune systems or debilitating illness.

- Eggs should be cooked until both the white and the yolk are firm and eaten promptly after cooking.

- Hands, cooking utensils, and food-preparation surfaces should be washed with soap and water after contact with raw eggs.

- Eggs should be purchased or received from a retail store or distributor refrigerated and stored refrigerated at $\leq 45^{\circ} \mathrm{F}\left(\leq 7^{\circ} \mathrm{C}\right)$ at all times.

facilities, underscoring the importance of using pasteurized egg products or in-shell pasteurized eggs for all recipes requiring pooled, raw, or undercooked shell eggs for institutionalized persons.

Additional information about preventing SE infections associated with eating raw or undercooked shell eggs is available at http://www.cdc.gov/ncidod/dbmd/diseaseinfo/ salment_g.htm, http://www.cfsan.fda.gov/ -dms/fs-eggs.html, http://www.cfsan.fda.gov/-dms/fs-eggs2.html, and http:// www.cfsan.fda.gov/-dms/fs-eggs4.html. Information for retail and food service establishments and institutional facilities about handling and cooking shell eggs is available in the Food Code at http://www.cfsan.fda.gov/ dms/ foodcode.html.

\section{References}

1. Mishu B, Koehler J, Lee LA, et al. Outbreaks of Salmonella Enteritidis infections in the United States, 1985-1991. J Infect Dis 1994;169: 547-52.

2. Angulo FJ, Swerdlow DL. Salmonella Enteritidis infections in the United States. J Am Vet Med Assoc 1998;213:1729-31.

3. St. Louis ME, Morse DL, Potter ME, et al. The emergence of grade A eggs as a major source of Salmonella Enteritidis infections: new implications for the control of salmonellosis. JAMA 1988;259:2103-7.

4. Angulo F, Swerdlow DL. Epidemiology of human Salmonella enterica serovar Enteritidis infections in the United States. In: Saeed A, ed. Salmonella enterica Serovar Enteritidis in Humans and Animals. 1st ed. Ames, Iowa: Iowa State University Press, 1999.

5. Chantarapanont W, Slutsker L, Tauxe RV, Beuchat LR. Factors influencing inactivation of Salmonella Enteritidis in hard-cooked eggs. J Food Prot 2000;63:36-43.

6. President's Council on Food Safety. Egg safety from production to consumption: an action plan to eliminate Salmonella Enteritidis illnesses due to eggs. Washington, DC: President's Council on Food Safety, 1999.

7. Hogue A, White P, Guard-Petter J, et al. Epidemiology and control of egg-associated Salmonella Enteritidis in the United States of America. Rev Sci Tech 1997;16:542-53.

8. White P, Schlosser W, Benson CE, Maddox C, Hogue A. Environmental survey by manure drag sampling for Salmonella Enteritidis in chicken layer houses. J Food Prot 1997;60:1189-93.

9. Levine WC, Smart JF, Archer DL, Bean NH, Tauxe RV. Foodborne disease outbreaks in nursing homes, 1975 through 1987. JAMA 1991;266:2105-9.

\section{Blood Safety Monitoring Among Persons with Bleeding Disorders - United States, May 1998-June 2002}

Since 1998, CDC has collaborated with approximately 140 federally funded hemophilia treatment centers (HTCs) in the United States and its territories through the Universal Data Collection (UDC) surveillance project to monitor blood product safety and detect new viral hepatitis and human immunodeficiency virus (HIV) infections. This report presents findings of investigations conducted during May 1998-June 2002 of 1,149 seroconversions* for hepatitis viruses identified among persons with bleeding disorders who were enrolled voluntarily in UDC; $99 \%$ of hepatitis A virus (HAV) seroconversions and $90 \%$ of hepatitis B virus (HBV) seroconversions were attributed to vaccination programs against HAV or HBV. None of these cases was attributable to blood products received during this time, which indicates that the virally inactivated blood factor concentrates used to treat

\footnotetext{
* A change of test results from negative in year one of testing to positive in the subsequent year of testing for any reason (e.g., vaccination or other risk factors). Seroconversion is an expected outcome for vaccination.
} 
bleeding disorders are unlikely to transmit viral hepatitis. Regular monitoring of patients ensures the continued safety of blood and blood products.

HTC staff obtain informed consent from each UDC participant and collect a standard set of clinical data and a plasma specimen. Data presented on standardized registration, annual, and laboratory forms are sent to CDC along with annual blood specimens from all UDC patients. Specimen remainders are stored in a blood-safety repository for future investigations of blood safety. All plasma specimens are tested for hepatitis viruses at Baylor College of Medicine. UDC participants are tested for hepatitis at enrollment according to algorithms that determine whether patients have been exposed to or infected with a virus. Participants who test negative for a virus are retested in subsequent years to monitor for seroconversions. Possible seroconversions are evaluated for HAV by testing for IgM antibody to HAV and total antibody to HAV; for HBV by testing for antibody to hepatitis B surface antigen (anti-HBs), antibody to hepatitis B core antigen (anti-HBc), and hepatitis B surface antigen ( $\mathrm{HBsAg}$ ); and for hepatitis $\mathrm{C}$ virus (HCV) by testing for antibody to hepatitis $\mathrm{C}$ (anti-HCV), which is confirmed with recombinant immunoblot assay and/or HCV-RNA by polymerase chain reaction when needed.

Systematic investigations were conducted when patients were confirmed as seropositive after having tested seronegative in a previous UDC specimen. Laboratory results were compared with information about past infections and vaccinations and with data about exposure to blood components or plasma derivatives. If the change in laboratory results could not be explained on the basis of these data, CDC contacted HTC staff for additional information on other potential risk factors for infection and on the setting of potential transmission, including blood-product manufacturer and lot number. Resolution of discrepancies generally required repeat testing of previously drawn specimens; less often, repeat testing was performed on newly drawn specimens. Patients' identities were not disclosed by HTCs.

During May 1998-June 2002, a total of 11,171 patients with hemophilia and other bleeding disorders were enrolled in UDC; 6,931 (62\%) had hemophilia A, 1,866 (16\%) had hemophilia B, 2,078 (19\%) had von Willebrand disease, and $296(3 \%)$ had other congenital bleeding disorders. A total of $6,219(56 \%)$ patients were newly enrolled in UDC and so had been tested only once; these persons will be tested again in subsequent years. Of the 4,952 (44\%) patients who had blood testing in $\geq 2$ years, 1,149 (23\%) had seroconversions to hepatitis viruses: $896(18 \%)$ to anti-HAV; $252(5 \%)$ to anti-HBs, anti-HBc, or HBsAg; and one $(<1 \%)$ to anti-HCV. Because 896 (99\%) HAV seroconversions and 227 (90\%)
HBV seroconversions could be attributed to vaccination programs, and the remainder could be attributed to other sources, no seroconversions were attributed to exposure to blood derivatives used during the surveillance interval.

No participants who seroconverted to anti-HAV were IgMpositive when the tests were performed. Being IgM-positive is a marker of acute infection with HAV that persists for 3-6 months in the majority of patients (1).

Of 896 persons who seroconverted to total anti-HAV in the second year of testing, 890 (99\%) had completed the hepatitis A vaccination series, had received a booster injection, or were in the process of being vaccinated. Because none of the six participants who seroconverted in the absence of vaccination had received blood products between tests, these infections were presumed to be community-acquired.

Of 252 persons who seroconverted to one or more HBV markers, 227 (90\%) who seroconverted only to anti-HBs had received either a full, partial, or booster vaccination between their first- and second-year tests. The remaining 25 who tested negative in initial UDC testing for anti-HBs, anti-HBc, or HBsAg and then tested positive subsequently were documented by HTC staff to have a previous history of HBV infection caused by past exposure to blood products. All these 25 participants also were HIV-infected from blood products used before enrollment in UDC.

One seroconversion for HCV occurred 6 months after collection of an initial negative UDC specimen. Local health authorities investigated this seroconversion and determined that the most likely source of this infection was injectiondrug use; the patient's HIV status was negative.

Reported by: FB Hollinger, MD, Baylor College of Medicine, Houston, Texas. A Kirtava, MD, M Oakley, DVM, M Soucie, PhD, B Evatt, $M D$, Div of AIDS, STD, and TB Laboratory Research, National Center for Infectious Diseases, $C D C$.

Editorial Note: HTCs provide care to $70 \%$ of persons in the United States with bleeding disorders. UDC is the largest data collection system monitoring persons receiving plasma derivatives, and infections transmitted by blood and blood products often are identified first in this sentinel population (2). A high risk for bloodborne viral infections (including $\mathrm{HBV}$ and $\mathrm{HCV}$ ) among persons with bleeding disorders was associated with the use of clotting factor concentrates prepared from large pools of human plasma manufactured during the 1970s and early 1980s before the development of viral inactivation procedures $(3,4)$. In the early 1990 s, several outbreaks of HAV associated with the receipt of clotting factors were reported in Europe and the United States $(5,6)$.

Investigations of seroconversions during May 1998-July 2002 did not document new cases of viral hepatitis infections that were attributed to blood products received during the 
time interval between laboratory tests. The majority of seroconversions for HAV and HBV were associated with vaccination (99\% and 90\%, respectively). The other seroconversions probably were caused either by communityacquired infection (for the six HAV infections) or by fluctuations in antibody levels that occur among HIV-infected patients (for the 25 persons with HBV seroconversions who also were infected with HIV) (7).

This report suggests that currently available blood factor concentrates most likely do not transmit HBV or HCV. Transmission of HAV remains a remote risk because the viral inactivation procedures used for plasma derivatives are unable to inactivate non-enveloped viruses such as HAV completely (8). Sporadic cases occur when plasma obtained from an asymptomatic donor who is incubating the infection is added inadvertently to a plasma pool used to manufacture derivatives. Because of the wide distribution of these products, such sporadic product-related cases can be identified only by monitoring large populations for clusters of cases that occur at the same time and that are associated with the use of a single product lot.

The findings in this report are subject to at least two limitations. First, because not all persons with bleeding disorders participated in the surveillance, some seroconversions might have been missed. Second, because patient or health-care provider reports of vaccination were used instead of medical record documentation, some seroconversions might have been attributed incorrectly to vaccination.

UDC promotes prevention and reduction of the complications of bleeding disorders and provides health agencies with timely risk data to support policy decision making. In addition, UDC has led to high levels of vaccination coverage, which is recommended for persons with bleeding disorders $(9,10)$.
Regular testing of patients with bleeding disorders through UDC monitors the safety of blood and blood products and provides the national repository of stored serum for assessment of potential new threats to the blood supply.

\section{Acknowledgment}

This article is based on data supplied by the staff of federally funded hemophilia treatment centers who enrolled patients in the surveillance system and assisted with the investigations.

\section{References}

1. Kao HW, Ashcavai M, Redeker AG. The persistence of hepatitis A IgM antibody after acute clinical hepatitis A. Hepatology 1984;4:933-6.

2. Soucie JM, Jackson D, Evatt B. The occurrence of hemophilia in the United States. Am J Hematol 1998;59:288-94.

3. Gjerset GF, Clements MJ, Counts RB, Halvorsen AS, Thompson AR. Treatment type and amount influenced human immunodeficiency virus seroprevalence of patients with congenital bleeding disorders. Blood 1991;78:1623-7.

4. Kasper CK, Kipnis SA. Hepatitis and clotting factor concentrates. JAMA 1972;221:510.

5. Mannucci PM, Gdovin S, Gringeri A, et al. Transmission of hepatitis A to patients with hemophilia by factor VIII concentrates treated with organic solvent and detergent to inactivate viruses. Ann Intern Med 1994;120:1-7.

6. Soucie JM, Robertson BH, Bell BP, McCaustland KA, Evatt BL. Hepatitis A virus infections associated with clotting factor concentrate in the United States. Transfusion 1998;38:573-9.

7. Kisker CT, Mahoney EM, Arkin S, Maeder MA, Donfield SM, Evatt BL. Changes in hepatitis B serologic titers in HIV+ and HIV- children with hemophilia. Hemophilia 1999;5:354-9.

8. Richardson LC, Evatt BL. Risk of hepatitis A virus in persons with hemophilia receiving plasma-derived products. Transfusion 2000;14:64-73.

9. CDC. Hepatitis B virus: a comprehensive strategy for eliminating transmission in the United States through universal childhood vaccination: recommendations of the Immunization Practices Advisory Committee. MMWR 1991;40(No. RR-13).

10. CDC. Prevention of hepatitis A through active or passive immunization: recommendations of the Advisory Committee on Immunization Practices. MMWR 1999;48(No. RR-12). 
FIGURE I. Selected notifiable disease reports, United States, comparison of provisional 4-week totals ending December 21, 2002, with historical data

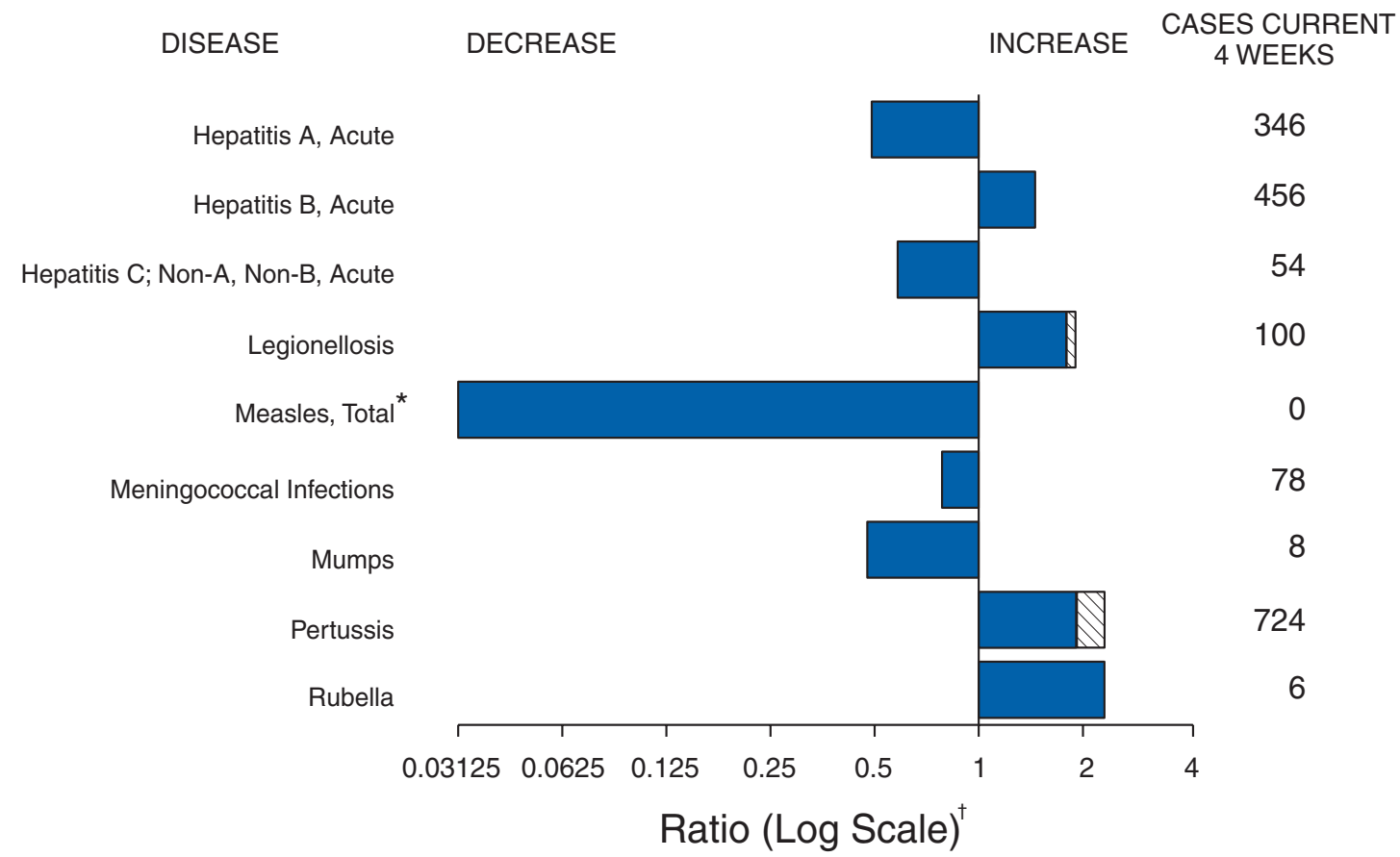

No measles cases were reported for the current 4-week period yielding a ratio for week 51 of zero (0).

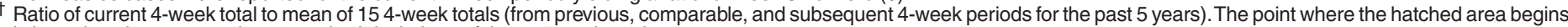
is based on the mean and two standard deviations of these 4-week totals.

TABLE I. Summary of provisional cases of selected notifiable diseases, United States, cumulative, week ending December 21,2002 (51st Week)

Anthrax

Botulism:

foodborne

infant

other (wound \& unspecified)

Brucellosis $^{\dagger}$

Chancroid

Cholera

Cyclosporiasis $^{\dagger}$

Diphtheria

Ehrlichiosis:

human granulocytic (HGE) ${ }^{\dagger}$ human monocytic (HME) ${ }^{\dagger}$

other and unspecified

Encephalitis: California serogroup viral ${ }^{\dagger}$ eastern equine ${ }^{\dagger}$

Powassan $^{\dagger}$

St. Louis ${ }^{\dagger}$ western equine ${ }^{\dagger}$

\begin{tabular}{|r|r|}
\hline Cum. & Cum. \\
$\mathbf{2 0 0 2}$ & $\mathbf{2 0 0 1}$ \\
\hline 2 & 22 \\
13 & 34 \\
55 & 91 \\
28 & 19 \\
80 & 129 \\
67 & 37 \\
5 & 5 \\
156 & 143 \\
1 & 2 \\
375 & 221 \\
167 & 116 \\
14 & 6 \\
131 & 117 \\
7 & 8 \\
1 & - \\
13 & 79 \\
3 & - \\
\hline
\end{tabular}

Encephalitis: West Nile ${ }^{\dagger}$

Hansen disease (leprosy) ${ }^{\dagger}$

Hantavirus pulmonary syndrome ${ }^{\dagger}$

Hemolytic uremic syndrome, postdiarrheal ${ }^{\dagger}$

HIV infection, pediatric ${ }^{\dagger \S}$

Plague

Poliomyelitis, paralytic

Psittacosis ${ }^{\dagger}$

Q fever ${ }^{\dagger}$

Rabies, human

Streptococcal toxic-shock syndrome ${ }^{\dagger}$

Tetanus

Toxic-shock syndrome

Trichinosis

Tularemia ${ }^{\dagger}$

Yellow fever

\begin{tabular}{|r|r|}
\hline Cum. & Cum. \\
$\mathbf{2 0 0 2}$ & $\mathbf{2 0 0 1}$ \\
\hline 1,770 & 57 \\
73 & 72 \\
16 & 8 \\
183 & 184 \\
163 & 203 \\
1 & 2 \\
- & - \\
17 & 24 \\
49 & 24 \\
2 & 1 \\
84 & 76 \\
22 & 33 \\
112 & 118 \\
13 & 21 \\
60 & 128 \\
1 & - \\
& \\
\hline
\end{tabular}

-:No reported cases.

* Incidence data for reporting year 2001 and 2002 are provisional and cumulative (year-to-date).

${ }^{\dagger}$ Not notifiable in all states.

$\S$ Updated monthly from reports to the Division of HIV/AIDS Prevention — Surveillance and Epidemiology, National Center for HIV, STD, and TB Prevention (NCHSTP). Last update November 24, 2002. 
TABLE II. Provisional cases of selected notifiable diseases, United States, weeks ending December 21, 2002, and December 22, 2001 (51st Week)*

\begin{tabular}{|c|c|c|c|c|c|c|c|c|c|c|}
\hline \multirow[b]{3}{*}{ Reporting Area } & \multirow{2}{*}{\multicolumn{2}{|c|}{ AIDS }} & \multirow{2}{*}{\multicolumn{2}{|c|}{ Chlamydia $^{\dagger}$}} & \multirow{2}{*}{\multicolumn{2}{|c|}{ Cryptosporidiosis }} & \multicolumn{4}{|c|}{ Escherichia coli, Enterohemorrhagic } \\
\hline & & & & & & & \multicolumn{2}{|c|}{ 0157:H7 } & \multicolumn{2}{|c|}{$\begin{array}{l}\text { Shiga Toxin Positive, } \\
\text { Serogroup non-0157 }\end{array}$} \\
\hline & $\begin{array}{l}\text { Cum. } \\
2002^{\S}\end{array}$ & $\begin{array}{l}\text { Cum. } \\
2001\end{array}$ & $\begin{array}{l}\text { Cum. } \\
2002\end{array}$ & $\begin{array}{l}\text { Cum. } \\
2001\end{array}$ & $\begin{array}{l}\text { Cum. } \\
2002\end{array}$ & $\begin{array}{l}\text { Cum. } \\
2001\end{array}$ & $\begin{array}{l}\text { Cum. } \\
2002\end{array}$ & $\begin{array}{l}\text { Cum. } \\
2001\end{array}$ & $\begin{array}{l}\text { Cum. } \\
2002\end{array}$ & $\begin{array}{l}\text { Cum. } \\
2001\end{array}$ \\
\hline UNITED STATES & 38,878 & 40,344 & 754,858 & 762,547 & 2,721 & 3,700 & 3,529 & 3,172 & 159 & 159 \\
\hline $\begin{array}{l}\text { NEW ENGLAND } \\
\text { Maine } \\
\text { N.H. } \\
\text { Vt. } \\
\text { Mass. } \\
\text { R.I. } \\
\text { Conn. }\end{array}$ & $\begin{array}{r}1,488 \\
28 \\
35 \\
12 \\
754 \\
97 \\
562\end{array}$ & $\begin{array}{r}1,461 \\
48 \\
38 \\
26 \\
749 \\
93 \\
507\end{array}$ & $\begin{array}{r}26,678 \\
1,733 \\
1,529 \\
917 \\
10,775 \\
2,782 \\
8,942\end{array}$ & $\begin{array}{r}23,883 \\
1,306 \\
1,362 \\
632 \\
10,155 \\
2,869 \\
7,559\end{array}$ & $\begin{array}{r}176 \\
12 \\
29 \\
33 \\
63 \\
21 \\
18\end{array}$ & $\begin{array}{r}149 \\
18 \\
17 \\
34 \\
55 \\
8 \\
17\end{array}$ & $\begin{array}{r}261 \\
40 \\
32 \\
14 \\
116 \\
14 \\
45\end{array}$ & $\begin{array}{r}245 \\
27 \\
36 \\
14 \\
114 \\
16 \\
38\end{array}$ & $\begin{array}{r}32 \\
5 \\
- \\
1 \\
9 \\
- \\
17\end{array}$ & $\begin{array}{r}42 \\
1 \\
3 \\
1 \\
10 \\
1 \\
26\end{array}$ \\
\hline $\begin{array}{l}\text { MID. ATLANTIC } \\
\text { Upstate N.Y. } \\
\text { N.Y. City } \\
\text { N.J. } \\
\text { Pa. }\end{array}$ & $\begin{array}{r}8,998 \\
946 \\
5,290 \\
1,304 \\
1,458\end{array}$ & $\begin{array}{r}11,403 \\
1,421 \\
6,570 \\
1,672 \\
1,740\end{array}$ & $\begin{array}{l}82,262 \\
16,527 \\
25,921 \\
11,501 \\
28,313\end{array}$ & $\begin{array}{l}85,787 \\
15,042 \\
29,179 \\
15,394 \\
26,172\end{array}$ & $\begin{array}{r}349 \\
142 \\
131 \\
11 \\
65\end{array}$ & $\begin{array}{r}351 \\
108 \\
123 \\
24 \\
96\end{array}$ & $\begin{array}{r}251 \\
179 \\
17 \\
55 \\
\mathrm{~N}\end{array}$ & $\begin{array}{r}237 \\
149 \\
16 \\
72 \\
\mathrm{~N}\end{array}$ & $\begin{array}{l}- \\
- \\
- \\
-\end{array}$ & $\begin{array}{l}- \\
- \\
- \\
-\end{array}$ \\
\hline $\begin{array}{l}\text { E.N. CENTRAL } \\
\text { Ohio } \\
\text { Ind. } \\
\text { III. } \\
\text { Mich. } \\
\text { Wis. }\end{array}$ & $\begin{array}{r}4,221 \\
766 \\
482 \\
2,094 \\
701 \\
178\end{array}$ & $\begin{array}{r}2,835 \\
531 \\
342 \\
1,254 \\
527 \\
181\end{array}$ & $\begin{array}{r}129,963 \\
30,399 \\
16,468 \\
35,843 \\
31,539 \\
15,714\end{array}$ & $\begin{array}{r}140,998 \\
37,084 \\
15,126 \\
42,889 \\
29,637 \\
16,262\end{array}$ & $\begin{array}{r}872 \\
120 \\
59 \\
88 \\
122 \\
483\end{array}$ & $\begin{array}{r}1,582 \\
181 \\
82 \\
482 \\
181 \\
656\end{array}$ & $\begin{array}{r}830 \\
151 \\
78 \\
171 \\
135 \\
295\end{array}$ & $\begin{array}{r}803 \\
226 \\
85 \\
171 \\
102 \\
219\end{array}$ & $\begin{array}{r}19 \\
15 \\
1 \\
- \\
3 \\
-\end{array}$ & $\begin{array}{r}12 \\
10 \\
- \\
- \\
2 \\
-\end{array}$ \\
\hline $\begin{array}{l}\text { W.N. CENTRAL } \\
\text { Minn. } \\
\text { lowa } \\
\text { Mo. } \\
\text { N. Dak. } \\
\text { S. Dak. } \\
\text { Nebr. } \\
\text { Kans. }\end{array}$ & $\begin{array}{r}716 \\
149 \\
85 \\
337 \\
3 \\
10 \\
64 \\
68\end{array}$ & $\begin{array}{r}838 \\
130 \\
86 \\
421 \\
2 \\
23 \\
77 \\
99\end{array}$ & $\begin{array}{r}41,588 \\
9,444 \\
5,144 \\
15,049 \\
801 \\
2,163 \\
2,633 \\
6,354\end{array}$ & $\begin{array}{r}38,864 \\
8,221 \\
4,927 \\
13,768 \\
1,025 \\
1,794 \\
3,176 \\
5,953\end{array}$ & $\begin{array}{r}410 \\
215 \\
47 \\
34 \\
20 \\
31 \\
47 \\
16\end{array}$ & $\begin{array}{r}528 \\
183 \\
81 \\
54 \\
13 \\
8 \\
8 \\
185 \\
4\end{array}$ & $\begin{array}{r}503 \\
167 \\
122 \\
69 \\
17 \\
40 \\
54 \\
34\end{array}$ & $\begin{array}{r}505 \\
210 \\
79 \\
66 \\
19 \\
43 \\
60 \\
28\end{array}$ & $\begin{array}{r}38 \\
33 \\
- \\
\mathrm{N} \\
- \\
2 \\
3 \\
-\end{array}$ & $\begin{array}{r}40 \\
30 \\
- \\
N \\
3 \\
6 \\
1 \\
-\end{array}$ \\
\hline $\begin{array}{l}\text { S. ATLANTIC } \\
\text { Del. } \\
\text { Md. } \\
\text { D.C. } \\
\text { Va. } \\
\text { W. Va. } \\
\text { N.C. } \\
\text { S.C. } \\
\text { Ga. } \\
\text { Fla. }\end{array}$ & $\begin{array}{r}11,487 \\
180 \\
1,676 \\
769 \\
816 \\
80 \\
971 \\
792 \\
1,536 \\
4,667\end{array}$ & $\begin{array}{r}11,910 \\
247 \\
1,831 \\
778 \\
985 \\
94 \\
915 \\
684 \\
1,521 \\
4,855\end{array}$ & $\begin{array}{r}147,018 \\
2,612 \\
16,501 \\
3,251 \\
16,993 \\
2,203 \\
24,516 \\
11,378 \\
30,593 \\
38,971\end{array}$ & $\begin{array}{r}145,855 \\
2,752 \\
15,093 \\
3,252 \\
17,746 \\
2,336 \\
21,056 \\
15,316 \\
31,619 \\
36,685\end{array}$ & $\begin{array}{r}315 \\
3 \\
22 \\
5 \\
31 \\
3 \\
36 \\
6 \\
107 \\
102\end{array}$ & $\begin{array}{r}377 \\
6 \\
40 \\
14 \\
27 \\
2 \\
31 \\
7 \\
160 \\
90\end{array}$ & $\begin{array}{r}448 \\
9 \\
26 \\
3 \\
63 \\
9 \\
226 \\
5 \\
42 \\
65\end{array}$ & $\begin{array}{r}249 \\
4 \\
29 \\
- \\
50 \\
10 \\
57 \\
23 \\
45 \\
31\end{array}$ & $\begin{array}{r}40 \\
- \\
- \\
- \\
10 \\
- \\
- \\
- \\
9 \\
21\end{array}$ & $\begin{array}{r}38 \\
1 \\
- \\
- \\
6 \\
- \\
- \\
- \\
10 \\
21\end{array}$ \\
\hline $\begin{array}{l}\text { E.S. CENTRAL } \\
\text { Ky. } \\
\text { Tenn. } \\
\text { Ala. } \\
\text { Miss. }\end{array}$ & $\begin{array}{r}1,844 \\
288 \\
764 \\
388 \\
404\end{array}$ & $\begin{array}{r}1,769 \\
332 \\
583 \\
438 \\
416\end{array}$ & $\begin{array}{r}47,165 \\
8,597 \\
15,575 \\
12,945 \\
10,048\end{array}$ & $\begin{array}{r}49,569 \\
8,797 \\
14,997 \\
14,168 \\
11,607\end{array}$ & $\begin{array}{r}123 \\
10 \\
59 \\
44 \\
10\end{array}$ & $\begin{array}{r}54 \\
5 \\
16 \\
18 \\
15\end{array}$ & $\begin{array}{r}110 \\
30 \\
48 \\
21 \\
11\end{array}$ & $\begin{array}{r}141 \\
64 \\
47 \\
18 \\
12\end{array}$ & $\begin{array}{l}- \\
- \\
- \\
-\end{array}$ & $\begin{array}{l}1 \\
1 \\
- \\
- \\
-\end{array}$ \\
\hline $\begin{array}{l}\text { W.S. CENTRAL } \\
\text { Ark. } \\
\text { La. } \\
\text { Okla. } \\
\text { Tex. }\end{array}$ & $\begin{array}{r}3,867 \\
223 \\
905 \\
181 \\
2,558\end{array}$ & $\begin{array}{r}4,094 \\
199 \\
797 \\
244 \\
2,854\end{array}$ & $\begin{array}{r}103,322 \\
7,041 \\
18,084 \\
10,484 \\
67,713\end{array}$ & $\begin{array}{r}104,647 \\
7,245 \\
17,720 \\
10,458 \\
69,224\end{array}$ & $\begin{array}{r}36 \\
8 \\
6 \\
16 \\
6\end{array}$ & $\begin{array}{r}129 \\
10 \\
8 \\
15 \\
96\end{array}$ & $\begin{array}{r}74 \\
12 \\
2 \\
23 \\
37\end{array}$ & $\begin{array}{r}217 \\
16 \\
8 \\
34 \\
159\end{array}$ & $\begin{array}{l}- \\
- \\
- \\
-\end{array}$ & $\begin{array}{l}- \\
- \\
- \\
- \\
-\end{array}$ \\
\hline $\begin{array}{l}\text { MOUNTAIN } \\
\text { Mont. } \\
\text { Idaho } \\
\text { Wyo. } \\
\text { Colo. } \\
\text { N. Mex. } \\
\text { Ariz. } \\
\text { Utah } \\
\text { Nev. }\end{array}$ & $\begin{array}{r}1,319 \\
11 \\
28 \\
8 \\
286 \\
81 \\
559 \\
63 \\
283\end{array}$ & $\begin{array}{r}1,333 \\
15 \\
19 \\
4 \\
299 \\
147 \\
489 \\
107 \\
253\end{array}$ & $\begin{array}{r}47,338 \\
2,355 \\
2,484 \\
927 \\
13,413 \\
6,319 \\
14,199 \\
2,680 \\
4,961\end{array}$ & $\begin{array}{r}45,707 \\
1,852 \\
1,990 \\
817 \\
13,117 \\
6,054 \\
14,140 \\
2,957 \\
4,780\end{array}$ & $\begin{array}{r}159 \\
6 \\
30 \\
9 \\
57 \\
20 \\
18 \\
15 \\
4\end{array}$ & $\begin{array}{r}240 \\
37 \\
23 \\
7 \\
43 \\
30 \\
11 \\
82 \\
7\end{array}$ & $\begin{array}{r}360 \\
31 \\
49 \\
15 \\
101 \\
13 \\
36 \\
87 \\
28\end{array}$ & $\begin{array}{r}292 \\
20 \\
76 \\
10 \\
87 \\
16 \\
30 \\
35 \\
18\end{array}$ & $\begin{array}{r}22 \\
- \\
11 \\
2 \\
5 \\
3 \\
1 \\
- \\
-\end{array}$ & $\begin{array}{r}20 \\
- \\
5 \\
2 \\
7 \\
6 \\
- \\
- \\
-\end{array}$ \\
\hline $\begin{array}{l}\text { PACIFIC } \\
\text { Wash. } \\
\text { Oreg. } \\
\text { Calif. } \\
\text { Alaska } \\
\text { Hawaii }\end{array}$ & $\begin{array}{r}4,937 \\
449 \\
311 \\
4,039 \\
30 \\
108\end{array}$ & $\begin{array}{r}4,701 \\
473 \\
216 \\
3,869 \\
19 \\
124\end{array}$ & $\begin{array}{r}129,524 \\
14,630 \\
6,760 \\
100,312 \\
3,590 \\
4,232\end{array}$ & $\begin{array}{r}127,237 \\
13,361 \\
7,297 \\
99,966 \\
2,632 \\
3,981\end{array}$ & $\begin{array}{r}281 \\
43 \\
40 \\
195 \\
1 \\
2\end{array}$ & $\begin{array}{r}290 \\
U \\
58 \\
228 \\
1 \\
3\end{array}$ & $\begin{array}{r}692 \\
144 \\
223 \\
276 \\
8 \\
41\end{array}$ & $\begin{array}{r}483 \\
130 \\
85 \\
243 \\
4 \\
21\end{array}$ & $\begin{array}{l}8 \\
- \\
8 \\
- \\
- \\
-\end{array}$ & $\begin{array}{l}6 \\
- \\
6 \\
- \\
- \\
-\end{array}$ \\
\hline $\begin{array}{l}\text { Guam } \\
\text { P.R. } \\
\text { V.I. } \\
\text { Amer. Samoa } \\
\text { C.N.M.I. }\end{array}$ & $\begin{array}{r}3 \\
1,045 \\
74 \\
U \\
3\end{array}$ & $\begin{array}{r}11 \\
1,111 \\
11 \\
U \\
U\end{array}$ & $\begin{array}{r}- \\
1,997 \\
125 \\
U \\
154\end{array}$ & $\begin{array}{r}389 \\
2,710 \\
142 \\
\cup \\
U\end{array}$ & $\begin{array}{l}- \\
- \\
- \\
\end{array}$ & $\begin{array}{l}- \\
- \\
\\
U\end{array}$ & $\begin{array}{l}\mathrm{N} \\
- \\
\bar{U} \\
-\end{array}$ & $\begin{array}{c}N \\
2 \\
- \\
U \\
U\end{array}$ & $\begin{array}{l}- \\
- \\
\text { U } \\
-\end{array}$ & $\begin{array}{l}- \\
- \\
\\
U\end{array}$ \\
\hline
\end{tabular}

$\mathrm{N}$ : Not notifiable. U: Unavailable.

$-:$ No reported cases.

C.N.M.I: Commonwealth of Northern Mariana Islands.

* Incidence data for reporting year 2001 and 2002 are provisional and cumulative (year-to-date).

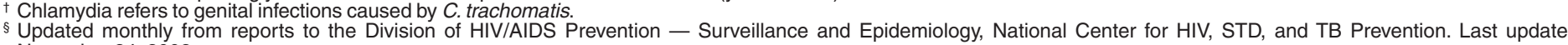
November 24, 2002. 
TABLE II. (Continued) Provisional cases of selected notifiable diseases, United States, weeks ending December 21, 2002, and December 22, 2001 (51st Week)*

\begin{tabular}{|c|c|c|c|c|c|c|c|c|c|}
\hline \multirow[b]{4}{*}{ Reporting Area } & \multirow{2}{*}{\multicolumn{2}{|c|}{$\begin{array}{c}\text { Escherichia coli } \\
\text { Enterohemorrhagic }\end{array}$}} & \multirow[b]{3}{*}{ Giardiasis } & \multirow{3}{*}{\multicolumn{2}{|c|}{ Gonorrhea }} & \multicolumn{4}{|c|}{$\begin{array}{c}\text { Haemophilus influenzae, } \\
\text { Invasive }\end{array}$} \\
\hline & & & & & & \multirow{2}{*}{\multicolumn{2}{|c|}{$\begin{array}{l}\text { All Ages, } \\
\text { All Serotypes }\end{array}$}} & \multirow{2}{*}{\multicolumn{2}{|c|}{$\begin{array}{c}\text { Age }<5 \text { Years } \\
\text { Serotype } \\
\text { B }\end{array}$}} \\
\hline & \multicolumn{2}{|c|}{$\begin{array}{c}\text { Shiga Toxin Positive, } \\
\text { Not Serogrouped }\end{array}$} & & & & & & & \\
\hline & $\begin{array}{l}\text { Cum. } \\
2002\end{array}$ & $\begin{array}{l}\text { Cum. } \\
2001\end{array}$ & $\begin{array}{l}\text { Cum. } \\
2002\end{array}$ & $\begin{array}{l}\text { Cum. } \\
2002\end{array}$ & $\begin{array}{l}\text { Cum. } \\
2001\end{array}$ & $\begin{array}{l}\text { Cum. } \\
2002 \\
\end{array}$ & $\begin{array}{l}\text { Cum. } \\
2001\end{array}$ & $\begin{array}{l}\text { Cum. } \\
2002\end{array}$ & $\begin{array}{l}\text { Cum. } \\
2001\end{array}$ \\
\hline UNITED STATES & 37 & 19 & 16,631 & 318,796 & 352,511 & 1,445 & 1,448 & 27 & 23 \\
\hline $\begin{array}{l}\text { NEW ENGLAND } \\
\text { Maine } \\
\text { N.H. } \\
\text { Vt. } \\
\text { Mass. } \\
\text { R.I. } \\
\text { Conn. }\end{array}$ & $\begin{array}{l}1 \\
- \\
- \\
1 \\
- \\
- \\
-\end{array}$ & $\begin{array}{l}1 \\
- \\
- \\
1 \\
- \\
- \\
-\end{array}$ & $\begin{array}{r}1,646 \\
212 \\
43 \\
145 \\
830 \\
156 \\
260\end{array}$ & $\begin{array}{r}7,439 \\
140 \\
121 \\
96 \\
3,212 \\
914 \\
2,956\end{array}$ & $\begin{array}{r}6,832 \\
141 \\
176 \\
75 \\
3,133 \\
818 \\
2,489\end{array}$ & $\begin{array}{r}125 \\
2 \\
10 \\
7 \\
50 \\
10 \\
46\end{array}$ & $\begin{array}{r}111 \\
2 \\
7 \\
5 \\
42 \\
7 \\
48\end{array}$ & $\begin{array}{l}- \\
- \\
- \\
- \\
- \\
- \\
-\end{array}$ & $\begin{array}{l}1 \\
- \\
- \\
- \\
1 \\
- \\
-\end{array}$ \\
\hline $\begin{array}{l}\text { MID. ATLANTIC } \\
\text { Upstate N.Y. } \\
\text { N.Y. City } \\
\text { N.J. } \\
\text { Pa. }\end{array}$ & $\begin{array}{l}- \\
- \\
- \\
- \\
-\end{array}$ & $\begin{array}{l}3 \\
- \\
- \\
- \\
3\end{array}$ & $\begin{array}{r}3,637 \\
1,226 \\
1,319 \\
351 \\
741\end{array}$ & $\begin{array}{r}38,005 \\
8,492 \\
10,903 \\
6,705 \\
11,905\end{array}$ & $\begin{array}{r}42,895 \\
8,709 \\
12,422 \\
8,545 \\
13,219\end{array}$ & $\begin{array}{r}258 \\
117 \\
63 \\
48 \\
30\end{array}$ & $\begin{array}{r}224 \\
79 \\
58 \\
48 \\
39\end{array}$ & $\begin{array}{l}6 \\
2 \\
- \\
- \\
4\end{array}$ & $\begin{array}{l}3 \\
- \\
- \\
- \\
3\end{array}$ \\
\hline $\begin{array}{l}\text { E.N. CENTRAL } \\
\text { Ohio } \\
\text { Ind. } \\
\text { III. } \\
\text { Mich. } \\
\text { Wis. }\end{array}$ & $\begin{array}{r}13 \\
12 \\
- \\
- \\
1 \\
-\end{array}$ & $\begin{array}{l}7 \\
7 \\
- \\
- \\
- \\
-\end{array}$ & $\begin{array}{r}3,186 \\
934 \\
- \\
736 \\
904 \\
612\end{array}$ & $\begin{array}{r}63,621 \\
17,173 \\
7,116 \\
19,060 \\
14,415 \\
5,857\end{array}$ & $\begin{array}{r}73,930 \\
20,808 \\
6,901 \\
23,521 \\
16,713 \\
5,987\end{array}$ & $\begin{array}{r}202 \\
77 \\
42 \\
58 \\
17 \\
8\end{array}$ & $\begin{array}{r}271 \\
74 \\
51 \\
99 \\
13 \\
34\end{array}$ & $\begin{array}{l}4 \\
- \\
2 \\
- \\
2 \\
-\end{array}$ & $\begin{array}{l}2 \\
1 \\
- \\
- \\
- \\
1\end{array}$ \\
\hline $\begin{array}{l}\text { W.N. CENTRAL } \\
\text { Minn. } \\
\text { lowa } \\
\text { Mo. } \\
\text { N. Dak. } \\
\text { S. Dak. } \\
\text { Nebr. } \\
\text { Kans. }\end{array}$ & $\begin{array}{l}4 \\
- \\
- \\
N \\
2 \\
- \\
- \\
2\end{array}$ & $\begin{array}{l}4 \\
- \\
- \\
N \\
4 \\
- \\
- \\
-\end{array}$ & $\begin{array}{r}2,025 \\
821 \\
307 \\
485 \\
28 \\
73 \\
133 \\
178\end{array}$ & $\begin{array}{r}16,194 \\
2,887 \\
1,229 \\
8,471 \\
47 \\
262 \\
723 \\
2,575\end{array}$ & $\begin{array}{r}16,723 \\
2,657 \\
1,330 \\
8,595 \\
55 \\
280 \\
1,153 \\
2,653\end{array}$ & $\begin{array}{r}70 \\
47 \\
1 \\
12 \\
- \\
- \\
1 \\
9\end{array}$ & $\begin{array}{r}78 \\
46 \\
- \\
20 \\
7 \\
- \\
3 \\
2\end{array}$ & $\begin{array}{l}1 \\
1 \\
- \\
- \\
- \\
- \\
- \\
-\end{array}$ & $\begin{array}{l}1 \\
- \\
- \\
- \\
- \\
- \\
1 \\
-\end{array}$ \\
\hline $\begin{array}{l}\text { S. ATLANTIC } \\
\text { Del. } \\
\text { Md. } \\
\text { D.C. } \\
\text { Va. } \\
\text { W.Va. } \\
\text { N.C. } \\
\text { S.C. } \\
\text { Ga. } \\
\text { Fla. }\end{array}$ & $\begin{array}{l}1 \\
- \\
- \\
- \\
- \\
1 \\
- \\
- \\
- \\
-\end{array}$ & $\begin{array}{l}- \\
- \\
- \\
- \\
- \\
- \\
- \\
- \\
- \\
-\end{array}$ & $\begin{array}{r}2,759 \\
51 \\
114 \\
45 \\
328 \\
59 \\
- \\
128 \\
754 \\
1,280\end{array}$ & $\begin{array}{r}82,662 \\
1,552 \\
9,022 \\
2,619 \\
9,523 \\
875 \\
15,445 \\
6,918 \\
16,744 \\
19,964\end{array}$ & $\begin{array}{r}90,459 \\
1,693 \\
9,144 \\
2,840 \\
10,649 \\
719 \\
16,014 \\
10,801 \\
17,561 \\
21,038\end{array}$ & $\begin{array}{r}346 \\
- \\
89 \\
- \\
32 \\
16 \\
31 \\
14 \\
76 \\
88\end{array}$ & $\begin{array}{r}358 \\
- \\
88 \\
- \\
28 \\
16 \\
49 \\
8 \\
99 \\
70\end{array}$ & $\begin{array}{l}4 \\
- \\
2 \\
- \\
- \\
- \\
- \\
- \\
- \\
2\end{array}$ & $\begin{array}{l}1 \\
- \\
- \\
- \\
- \\
1 \\
- \\
- \\
- \\
-\end{array}$ \\
\hline $\begin{array}{l}\text { E.S. CENTRAL } \\
\text { Ky. } \\
\text { Tenn. } \\
\text { Ala. } \\
\text { Miss. }\end{array}$ & $\begin{array}{l}8 \\
8 \\
- \\
- \\
-\end{array}$ & $\begin{array}{l}3 \\
3 \\
- \\
- \\
-\end{array}$ & $\begin{array}{r}379 \\
- \\
176 \\
203 \\
-\end{array}$ & $\begin{array}{r}27,104 \\
3,716 \\
9,069 \\
8,459 \\
5,860\end{array}$ & $\begin{array}{r}32,072 \\
3,547 \\
9,883 \\
11,014 \\
7,628\end{array}$ & $\begin{array}{r}66 \\
7 \\
34 \\
16 \\
9\end{array}$ & $\begin{array}{r}76 \\
2 \\
44 \\
28 \\
2\end{array}$ & $\begin{array}{l}1 \\
- \\
- \\
1 \\
-\end{array}$ & $\begin{array}{l}- \\
- \\
- \\
-\end{array}$ \\
\hline $\begin{array}{l}\text { W.S. CENTRAL } \\
\text { Ark. } \\
\text { La. } \\
\text { Okla. } \\
\text { Tex. }\end{array}$ & $\begin{array}{l}4 \\
- \\
- \\
- \\
4\end{array}$ & $\begin{array}{l}- \\
- \\
- \\
- \\
-\end{array}$ & $\begin{array}{r}246 \\
169 \\
5 \\
72 \\
-\end{array}$ & $\begin{array}{r}46,272 \\
4,412 \\
11,176 \\
4,519 \\
26,165\end{array}$ & $\begin{array}{r}51,389 \\
4,604 \\
12,202 \\
4,765 \\
29,818\end{array}$ & $\begin{array}{r}61 \\
1 \\
11 \\
45 \\
4\end{array}$ & $\begin{array}{r}57 \\
2 \\
10 \\
43 \\
2\end{array}$ & $\begin{array}{l}2 \\
- \\
- \\
- \\
2\end{array}$ & $\begin{array}{l}3 \\
- \\
1 \\
- \\
2\end{array}$ \\
\hline $\begin{array}{l}\text { MOUNTAIN } \\
\text { Mont. } \\
\text { Idaho } \\
\text { Wyo. } \\
\text { Colo. } \\
\text { N. Mex. } \\
\text { Ariz. } \\
\text { Utah } \\
\text { Nev. }\end{array}$ & $\begin{array}{l}6 \\
- \\
- \\
- \\
6 \\
- \\
- \\
- \\
-\end{array}$ & $\begin{array}{l}1 \\
- \\
- \\
- \\
1 \\
- \\
- \\
- \\
-\end{array}$ & $\begin{array}{r}1,676 \\
93 \\
132 \\
29 \\
564 \\
136 \\
238 \\
327 \\
157\end{array}$ & $\begin{array}{r}10,427 \\
119 \\
94 \\
63 \\
3,344 \\
1,322 \\
3,566 \\
278 \\
1,641\end{array}$ & $\begin{array}{r}10,238 \\
101 \\
74 \\
77 \\
3,148 \\
1,021 \\
3,863 \\
216 \\
1,738\end{array}$ & $\begin{array}{r}188 \\
- \\
2 \\
1 \\
34 \\
27 \\
94 \\
18 \\
12\end{array}$ & $\begin{array}{r}144 \\
- \\
2 \\
1 \\
38 \\
28 \\
54 \\
9 \\
12\end{array}$ & $\begin{array}{l}6 \\
- \\
- \\
- \\
- \\
- \\
4 \\
1 \\
1\end{array}$ & $\begin{array}{l}8 \\
- \\
- \\
- \\
- \\
1 \\
4 \\
1 \\
2\end{array}$ \\
\hline $\begin{array}{l}\text { PACIFIC } \\
\text { Wash. } \\
\text { Oreg. } \\
\text { Calif. } \\
\text { Alaska } \\
\text { Hawaii }\end{array}$ & $\begin{array}{l}- \\
- \\
- \\
- \\
-\end{array}$ & $\begin{array}{l}- \\
- \\
- \\
- \\
- \\
-\end{array}$ & $\begin{array}{r}1,077 \\
398 \\
441 \\
45 \\
106 \\
87\end{array}$ & $\begin{array}{r}27,072 \\
2,848 \\
893 \\
22,027 \\
593 \\
711\end{array}$ & $\begin{array}{r}27,973 \\
2,937 \\
1,125 \\
22,882 \\
435 \\
594\end{array}$ & $\begin{array}{r}129 \\
4 \\
62 \\
25 \\
2 \\
36\end{array}$ & $\begin{array}{r}129 \\
7 \\
38 \\
55 \\
6 \\
23\end{array}$ & $\begin{array}{l}3 \\
2 \\
- \\
1 \\
- \\
-\end{array}$ & $\begin{array}{l}4 \\
- \\
- \\
4 \\
- \\
-\end{array}$ \\
\hline $\begin{array}{l}\text { Guam } \\
\text { P.R. } \\
\text { V.I. } \\
\text { Amer. Samoa } \\
\text { C.N.M.I. }\end{array}$ & $\begin{array}{l}- \\
- \\
\bar{U} \\
-\end{array}$ & $\begin{array}{l}- \\
- \\
\\
U\end{array}$ & $\begin{array}{r}38 \\
- \\
\\
1\end{array}$ & $\begin{array}{r}- \\
292 \\
31 \\
U \\
14\end{array}$ & $\begin{array}{r}48 \\
586 \\
35 \\
\cup \\
U\end{array}$ & $\begin{array}{l}\overline{1} \\
- \\
\\
-\end{array}$ & $\begin{array}{l}- \\
2 \\
- \\
U \\
U\end{array}$ & $\begin{array}{l}- \\
- \\
\\
-\end{array}$ & $\begin{array}{l}- \\
- \\
\\
U\end{array}$ \\
\hline
\end{tabular}

$\mathrm{N}$ : Not notifiable.

U: Unavailable. $\quad$ - : No reported cases.

* Incidence data for reporting year 2001 and 2002 are provisional and cumulative (year-to-date). 
TABLE II. (Continued) Provisional cases of selected notifiable diseases, United States, weeks ending December 21, 2002, and December 22, 2001 (51st Week)*

\begin{tabular}{|c|c|c|c|c|c|c|c|c|c|c|}
\hline \multirow[b]{4}{*}{ Reporting Area } & \multicolumn{4}{|c|}{ Haemophilus influenzae, Invasive } & \multirow{2}{*}{\multicolumn{6}{|c|}{ Hepatitis (Viral, Acute), By Type }} \\
\hline & \multicolumn{4}{|c|}{ Age $<5$ Years } & & & & & & \\
\hline & Non- & ype B & Unknou & otype & \multicolumn{2}{|c|}{$\bar{A}$} & \multicolumn{2}{|c|}{$B$} & \multicolumn{2}{|c|}{ C; Non-A, Non-B } \\
\hline & $\begin{array}{l}\text { Cum. } \\
2002\end{array}$ & $\begin{array}{l}\text { Cum. } \\
2001 \\
\end{array}$ & $\begin{array}{l}\text { Cum. } \\
2002\end{array}$ & $\begin{array}{l}\text { Cum. } \\
2001 \\
\end{array}$ & $\begin{array}{l}\text { Cum. } \\
2002 \\
\end{array}$ & $\begin{array}{l}\text { Cum. } \\
2001 \\
\end{array}$ & $\begin{array}{l}\text { Cum. } \\
2002 \\
\end{array}$ & $\begin{array}{l}\text { Cum. } \\
2001\end{array}$ & $\begin{array}{l}\text { Cum. } \\
2002\end{array}$ & $\begin{array}{l}\text { Cum } \\
2001 \\
\end{array}$ \\
\hline UNITED STATES & 234 & 237 & 18 & 28 & 7,981 & 10,156 & 6,660 & 7,169 & 3,585 & 3,774 \\
\hline $\begin{array}{l}\text { NEW ENGLAND } \\
\text { Maine } \\
\text { N.H. } \\
\text { Vt. } \\
\text { Mass. } \\
\text { R.I. } \\
\text { Conn. }\end{array}$ & $\begin{array}{r}14 \\
- \\
- \\
- \\
7 \\
7\end{array}$ & $\begin{array}{r}15 \\
- \\
1 \\
- \\
7 \\
7\end{array}$ & $\begin{array}{l}- \\
- \\
- \\
- \\
- \\
-\end{array}$ & $\begin{array}{l}- \\
- \\
- \\
- \\
-\end{array}$ & $\begin{array}{r}282 \\
8 \\
11 \\
3 \\
138 \\
32 \\
90\end{array}$ & $\begin{array}{r}723 \\
11 \\
18 \\
16 \\
372 \\
72 \\
234\end{array}$ & $\begin{array}{r}278 \\
15 \\
22 \\
5 \\
139 \\
30 \\
67\end{array}$ & $\begin{array}{r}140 \\
5 \\
16 \\
5 \\
39 \\
28 \\
47\end{array}$ & $\begin{array}{r}23 \\
- \\
- \\
13 \\
9 \\
1 \\
-\end{array}$ & $\begin{array}{r}33 \\
- \\
- \\
7 \\
26 \\
- \\
-\end{array}$ \\
\hline $\begin{array}{l}\text { MID. ATLANTIC } \\
\text { Upstate N.Y. } \\
\text { N.Y. City } \\
\text { N.J. } \\
\text { Pa. }\end{array}$ & $\begin{array}{r}28 \\
12 \\
8 \\
5 \\
3\end{array}$ & $\begin{array}{r}37 \\
10 \\
13 \\
6 \\
8\end{array}$ & $\begin{array}{l}1 \\
- \\
- \\
- \\
1\end{array}$ & $\begin{array}{l}3 \\
1 \\
- \\
- \\
2\end{array}$ & $\begin{array}{r}1,061 \\
178 \\
517 \\
161 \\
205\end{array}$ & $\begin{array}{r}1,273 \\
273 \\
443 \\
282 \\
275\end{array}$ & $\begin{array}{r}1,588 \\
139 \\
832 \\
385 \\
232\end{array}$ & $\begin{array}{r}1,363 \\
128 \\
645 \\
285 \\
305\end{array}$ & $\begin{array}{r}1,933 \\
69 \\
- \\
1,828 \\
36\end{array}$ & $\begin{array}{r}1,320 \\
30 \\
- \\
1,206 \\
84\end{array}$ \\
\hline $\begin{array}{l}\text { E.N. CENTRAL } \\
\text { Ohio } \\
\text { Ind. } \\
\text { Ill. } \\
\text { Mich. } \\
\text { Wis. }\end{array}$ & $\begin{array}{r}36 \\
9 \\
8 \\
12 \\
5 \\
2\end{array}$ & $\begin{array}{r}40 \\
13 \\
7 \\
14 \\
- \\
6\end{array}$ & $\begin{array}{l}1 \\
1 \\
- \\
- \\
- \\
-\end{array}$ & $\begin{array}{l}2 \\
- \\
1 \\
- \\
1 \\
-\end{array}$ & $\begin{array}{r}1,033 \\
323 \\
47 \\
262 \\
223 \\
178\end{array}$ & $\begin{array}{r}1,185 \\
251 \\
97 \\
430 \\
325 \\
82\end{array}$ & $\begin{array}{r}685 \\
116 \\
59 \\
146 \\
321 \\
43\end{array}$ & $\begin{array}{r}951 \\
92 \\
49 \\
155 \\
609 \\
46\end{array}$ & $\begin{array}{r}107 \\
4 \\
- \\
13 \\
86 \\
4\end{array}$ & $\begin{array}{r}159 \\
9 \\
1 \\
12 \\
137 \\
-\end{array}$ \\
\hline $\begin{array}{l}\text { W.N. CENTRAL } \\
\text { Minn. } \\
\text { lowa } \\
\text { Mo. } \\
\text { N. Dak. } \\
\text { S. Dak. } \\
\text { Nebr. } \\
\text { Kans. }\end{array}$ & $\begin{array}{l}8 \\
6 \\
- \\
- \\
- \\
- \\
1 \\
1\end{array}$ & $\begin{array}{l}6 \\
4 \\
- \\
- \\
1 \\
- \\
1 \\
-\end{array}$ & $\begin{array}{l}3 \\
1 \\
- \\
2 \\
- \\
- \\
- \\
-\end{array}$ & $\begin{array}{l}6 \\
2 \\
- \\
4 \\
- \\
- \\
- \\
-\end{array}$ & $\begin{array}{r}302 \\
47 \\
80 \\
82 \\
3 \\
3 \\
17 \\
70\end{array}$ & $\begin{array}{r}388 \\
42 \\
36 \\
87 \\
3 \\
3 \\
36 \\
181\end{array}$ & $\begin{array}{r}228 \\
36 \\
20 \\
121 \\
5 \\
2 \\
22 \\
22\end{array}$ & $\begin{array}{r}225 \\
31 \\
24 \\
123 \\
2 \\
1 \\
30 \\
14\end{array}$ & $\begin{array}{r}753 \\
1 \\
1 \\
732 \\
- \\
1 \\
13 \\
5\end{array}$ & $\begin{array}{r}1,110 \\
12 \\
- \\
1,082 \\
- \\
- \\
8 \\
8\end{array}$ \\
\hline $\begin{array}{l}\text { S. ATLANTIC } \\
\text { Del. } \\
\text { Md. } \\
\text { D.C. } \\
\text { Va. } \\
\text { W.Va. } \\
\text { N.C. } \\
\text { S.C. } \\
\text { Ga. } \\
\text { Fla. }\end{array}$ & $\begin{array}{r}42 \\
- \\
4 \\
- \\
5 \\
1 \\
3 \\
2 \\
12 \\
15\end{array}$ & $\begin{array}{r}47 \\
- \\
9 \\
- \\
5 \\
1 \\
2 \\
1 \\
20 \\
9\end{array}$ & $\begin{array}{l}2 \\
- \\
- \\
- \\
- \\
1 \\
- \\
- \\
- \\
1\end{array}$ & $\begin{array}{l}7 \\
- \\
2 \\
- \\
- \\
1 \\
4 \\
- \\
-\end{array}$ & $\begin{array}{r}2,274 \\
13 \\
296 \\
80 \\
152 \\
23 \\
203 \\
65 \\
386 \\
1,056\end{array}$ & $\begin{array}{r}2,557 \\
16 \\
288 \\
73 \\
134 \\
28 \\
240 \\
75 \\
921 \\
782\end{array}$ & $\begin{array}{r}1,521 \\
7 \\
122 \\
21 \\
193 \\
18 \\
225 \\
121 \\
288 \\
526\end{array}$ & $\begin{array}{r}1,541 \\
29 \\
138 \\
13 \\
177 \\
25 \\
214 \\
30 \\
425 \\
490\end{array}$ & $\begin{array}{r}205 \\
6 \\
8 \\
- \\
16 \\
3 \\
26 \\
4 \\
45 \\
97\end{array}$ & $\begin{array}{r}108 \\
11 \\
9 \\
- \\
2 \\
9 \\
21 \\
6 \\
- \\
50\end{array}$ \\
\hline $\begin{array}{l}\text { E.S. CENTRAL } \\
\text { Ky. } \\
\text { Tenn. } \\
\text { Ala. } \\
\text { Miss. }\end{array}$ & $\begin{array}{r}15 \\
2 \\
8 \\
3 \\
2\end{array}$ & $\begin{array}{r}13 \\
- \\
7 \\
5 \\
1\end{array}$ & $\begin{array}{l}1 \\
- \\
- \\
1 \\
-\end{array}$ & $\begin{array}{l}4 \\
1 \\
2 \\
1 \\
-\end{array}$ & $\begin{array}{r}256 \\
43 \\
117 \\
39 \\
57\end{array}$ & $\begin{array}{r}418 \\
131 \\
171 \\
79 \\
37\end{array}$ & $\begin{array}{r}369 \\
50 \\
133 \\
106 \\
80\end{array}$ & $\begin{array}{r}484 \\
57 \\
249 \\
88 \\
90\end{array}$ & $\begin{array}{r}193 \\
4 \\
34 \\
11 \\
144\end{array}$ & $\begin{array}{r}191 \\
11 \\
67 \\
5 \\
108\end{array}$ \\
\hline $\begin{array}{l}\text { W.S. CENTRAL } \\
\text { Ark. } \\
\text { La. } \\
\text { Okla. } \\
\text { Tex. }\end{array}$ & $\begin{array}{r}14 \\
- \\
2 \\
10 \\
2\end{array}$ & $\begin{array}{l}9 \\
1 \\
2 \\
6 \\
-\end{array}$ & $\begin{array}{l}1 \\
- \\
1 \\
- \\
-\end{array}$ & $\begin{array}{l}- \\
- \\
- \\
-\end{array}$ & $\begin{array}{r}581 \\
65 \\
71 \\
49 \\
396\end{array}$ & $\begin{array}{r}808 \\
70 \\
86 \\
111 \\
541\end{array}$ & $\begin{array}{r}588 \\
92 \\
100 \\
50 \\
346\end{array}$ & $\begin{array}{r}817 \\
102 \\
120 \\
97 \\
498\end{array}$ & $\begin{array}{r}201 \\
9 \\
70 \\
5 \\
117\end{array}$ & $\begin{array}{r}666 \\
13 \\
150 \\
4 \\
499\end{array}$ \\
\hline $\begin{array}{l}\text { MOUNTAIN } \\
\text { Mont. } \\
\text { Idaho } \\
\text { Wyo. } \\
\text { Colo. } \\
\text { N. Mex. } \\
\text { Ariz. } \\
\text { Utah } \\
\text { Nev. }\end{array}$ & $\begin{array}{r}50 \\
- \\
1 \\
- \\
3 \\
6 \\
31 \\
5 \\
4\end{array}$ & $\begin{array}{r}26 \\
- \\
- \\
- \\
3 \\
12 \\
8 \\
3 \\
-\end{array}$ & $\begin{array}{l}8 \\
- \\
- \\
- \\
- \\
1 \\
6 \\
- \\
1\end{array}$ & $\begin{array}{l}1 \\
- \\
- \\
- \\
1 \\
- \\
- \\
-\end{array}$ & $\begin{array}{r}568 \\
13 \\
30 \\
3 \\
74 \\
29 \\
304 \\
65 \\
50\end{array}$ & $\begin{array}{r}721 \\
13 \\
57 \\
7 \\
88 \\
40 \\
380 \\
66 \\
70\end{array}$ & $\begin{array}{r}623 \\
10 \\
7 \\
17 \\
76 \\
144 \\
239 \\
62 \\
68\end{array}$ & $\begin{array}{r}475 \\
3 \\
11 \\
3 \\
103 \\
135 \\
147 \\
23 \\
50\end{array}$ & $\begin{array}{r}64 \\
1 \\
1 \\
5 \\
15 \\
1 \\
7 \\
4 \\
30\end{array}$ & $\begin{array}{r}57 \\
1 \\
2 \\
8 \\
10 \\
12 \\
9 \\
3 \\
12\end{array}$ \\
\hline $\begin{array}{l}\text { PACIFIC } \\
\text { Wash. } \\
\text { Oreg. } \\
\text { Calif. } \\
\text { Alaska } \\
\text { Hawaii }\end{array}$ & $\begin{array}{r}27 \\
2 \\
5 \\
15 \\
2 \\
3\end{array}$ & $\begin{array}{r}44 \\
4 \\
7 \\
31 \\
1 \\
1 \\
1\end{array}$ & $\begin{array}{l}1 \\
- \\
- \\
1 \\
- \\
-\end{array}$ & $\begin{array}{l}5 \\
2 \\
- \\
1 \\
- \\
2\end{array}$ & $\begin{array}{r}1,624 \\
145 \\
67 \\
1,398 \\
12 \\
2\end{array}$ & $\begin{array}{r}2,083 \\
160 \\
103 \\
1,789 \\
14 \\
17\end{array}$ & $\begin{array}{r}780 \\
68 \\
120 \\
575 \\
6 \\
11\end{array}$ & $\begin{array}{r}1,173 \\
141 \\
167 \\
836 \\
9 \\
20\end{array}$ & $\begin{array}{r}106 \\
25 \\
17 \\
64 \\
- \\
-\end{array}$ & $\begin{array}{r}130 \\
23 \\
15 \\
92 \\
- \\
-\end{array}$ \\
\hline $\begin{array}{l}\text { Guam } \\
\text { P.R. } \\
\text { V.I. } \\
\text { Amer. Samoa } \\
\text { C.N.M.I. }\end{array}$ & $\begin{array}{l}- \\
- \\
\\
\end{array}$ & $\begin{array}{l}- \\
1 \\
\\
U\end{array}$ & $\begin{array}{l}- \\
- \\
\\
\end{array}$ & $\begin{array}{l}- \\
- \\
\\
U\end{array}$ & $\begin{array}{r}96 \\
\dot{U} \\
-\end{array}$ & $\begin{array}{r}2 \\
229 \\
- \\
U \\
U\end{array}$ & $\begin{array}{r}84 \\
\bar{U} \\
37\end{array}$ & $\begin{array}{r}266 \\
\bar{U} \\
U\end{array}$ & $\begin{array}{l}- \\
\end{array}$ & $\begin{array}{l}\overline{1} \\
\\
U\end{array}$ \\
\hline
\end{tabular}


TABLE II. (Continued) Provisional cases of selected notifiable diseases, United States, weeks ending December 21, 2002, and December 22, 2001 (51st Week)*

\begin{tabular}{|c|c|c|c|c|c|c|c|c|c|c|}
\hline \multirow[b]{2}{*}{ Reporting Area } & \multicolumn{2}{|c|}{ Legionellosis } & \multicolumn{2}{|c|}{ Listeriosis } & \multicolumn{2}{|c|}{ Lyme Disease } & \multicolumn{2}{|c|}{ Malaria } & \multicolumn{2}{|c|}{$\begin{array}{c}\text { Measles } \\
\text { Total }\end{array}$} \\
\hline & $\begin{array}{l}\text { Cum. } \\
2002\end{array}$ & $\begin{array}{l}\text { Cum. } \\
2001\end{array}$ & $\begin{array}{l}\text { Cum. } \\
2002\end{array}$ & $\begin{array}{l}\text { Cum. } \\
2001\end{array}$ & $\begin{array}{l}\text { Cum. } \\
2002\end{array}$ & $\begin{array}{l}\text { Cum. } \\
2001\end{array}$ & $\begin{array}{l}\text { Cum. } \\
2002\end{array}$ & $\begin{array}{l}\text { Cum. } \\
2001\end{array}$ & $\begin{array}{l}\text { Cum. } \\
2002\end{array}$ & $\begin{array}{l}\text { Cum. } \\
2001\end{array}$ \\
\hline UNITED STATES & 1,163 & 1,083 & 577 & 588 & 18,008 & 14,985 & 1,224 & 1,431 & $36^{\dagger}$ & $114^{\S}$ \\
\hline $\begin{array}{l}\text { NEW ENGLAND } \\
\text { Maine } \\
\text { N.H. } \\
\text { Vt. } \\
\text { Mass. } \\
\text { R.I. } \\
\text { Conn. }\end{array}$ & $\begin{array}{r}101 \\
5 \\
7 \\
35 \\
30 \\
9 \\
15\end{array}$ & $\begin{array}{r}73 \\
8 \\
12 \\
5 \\
21 \\
13 \\
14\end{array}$ & $\begin{array}{r}58 \\
5 \\
4 \\
3 \\
31 \\
1 \\
14 \\
14\end{array}$ & $\begin{array}{r}56 \\
2 \\
4 \\
3 \\
30 \\
2 \\
15\end{array}$ & $\begin{array}{r}6,274 \\
111 \\
244 \\
36 \\
1,559 \\
346 \\
3,978\end{array}$ & $\begin{array}{r}4,448 \\
- \\
114 \\
18 \\
1,163 \\
493 \\
2,660\end{array}$ & $\begin{array}{r}70 \\
6 \\
7 \\
4 \\
26 \\
11 \\
16\end{array}$ & $\begin{array}{r}102 \\
5 \\
2 \\
1 \\
52 \\
13 \\
29\end{array}$ & $\begin{array}{l}- \\
- \\
- \\
- \\
- \\
- \\
-\end{array}$ & $\begin{array}{l}5 \\
- \\
- \\
1 \\
3 \\
- \\
1\end{array}$ \\
\hline $\begin{array}{l}\text { MID. ATLANTIC } \\
\text { Upstate N.Y. } \\
\text { N.Y. City } \\
\text { N.J. } \\
\text { Pa. }\end{array}$ & $\begin{array}{r}325 \\
109 \\
60 \\
29 \\
127\end{array}$ & $\begin{array}{r}263 \\
69 \\
43 \\
24 \\
127\end{array}$ & $\begin{array}{r}164 \\
56 \\
35 \\
33 \\
40\end{array}$ & $\begin{array}{r}106 \\
28 \\
25 \\
20 \\
33\end{array}$ & $\begin{array}{r}9,640 \\
4,987 \\
169 \\
1,763 \\
2,721\end{array}$ & $\begin{array}{r}8,182 \\
3,552 \\
63 \\
2,014 \\
2,553\end{array}$ & $\begin{array}{r}329 \\
46 \\
213 \\
36 \\
34\end{array}$ & $\begin{array}{r}426 \\
64 \\
250 \\
65 \\
47\end{array}$ & $\begin{array}{l}7 \\
1 \\
6 \\
- \\
-\end{array}$ & $\begin{array}{r}20 \\
4 \\
7 \\
1 \\
8\end{array}$ \\
\hline $\begin{array}{l}\text { E.N. CENTRAL } \\
\text { Ohio } \\
\text { Ind. } \\
\text { III. } \\
\text { Mich. } \\
\text { Wis. }\end{array}$ & $\begin{array}{r}263 \\
119 \\
26 \\
8 \overline{-} \\
34\end{array}$ & $\begin{array}{r}313 \\
142 \\
22 \\
24 \\
81 \\
44\end{array}$ & $\begin{array}{r}79 \\
26 \\
12 \\
12 \\
22 \\
7\end{array}$ & $\begin{array}{r}87 \\
16 \\
8 \\
24 \\
25 \\
14 \\
14\end{array}$ & $\begin{array}{r}108 \\
75 \\
20 \\
- \\
13 \\
U\end{array}$ & $\begin{array}{r}717 \\
43 \\
24 \\
32 \\
21 \\
597\end{array}$ & $\begin{array}{r}130 \\
24 \\
14 \\
30 \\
46 \\
16\end{array}$ & $\begin{array}{r}172 \\
27 \\
16 \\
70 \\
39 \\
20\end{array}$ & $\begin{array}{l}3 \\
1 \\
2 \\
- \\
- \\
-\end{array}$ & $\begin{array}{r}10 \\
3 \\
4 \\
3 \\
- \\
-\end{array}$ \\
\hline $\begin{array}{l}\text { W.N. CENTRAL } \\
\text { Minn. } \\
\text { lowa } \\
\text { Mo. } \\
\text { N. Dak. } \\
\text { S. Dak. } \\
\text { Nebr. } \\
\text { Kans. }\end{array}$ & $\begin{array}{r}62 \\
17 \\
12 \\
18 \\
1 \\
4 \\
10\end{array}$ & $\begin{array}{r}48 \\
9 \\
8 \\
8 \\
22 \\
1 \\
3 \\
4 \\
1\end{array}$ & $\begin{array}{r}21 \\
5 \\
3 \\
9 \\
1 \\
1 \\
1 \\
1\end{array}$ & $\begin{array}{r}21 \\
3 \\
2 \\
10 \\
- \\
- \\
1 \\
5\end{array}$ & $\begin{array}{r}468 \\
369 \\
42 \\
40 \\
1 \\
2 \\
6 \\
8\end{array}$ & $\begin{array}{r}406 \\
331 \\
35 \\
34 \\
- \\
- \\
4 \\
2\end{array}$ & $\begin{array}{r}57 \\
17 \\
4 \\
16 \\
1 \\
1 \\
5 \\
13\end{array}$ & $\begin{array}{r}38 \\
6 \\
9 \\
15 \\
- \\
- \\
2 \\
6\end{array}$ & $\begin{array}{l}3 \\
1 \\
- \\
2 \\
- \\
- \\
- \\
-\end{array}$ & $\begin{array}{l}5 \\
3 \\
- \\
2 \\
- \\
- \\
- \\
-\end{array}$ \\
\hline $\begin{array}{l}\text { S. ATLANTIC } \\
\text { Del. } \\
\text { Md. } \\
\text { D.C. } \\
\text { Va. } \\
\text { W.Va. } \\
\text { N.C. } \\
\text { S.C. } \\
\text { Ga. } \\
\text { Fla. }\end{array}$ & $\begin{array}{r}219 \\
10 \\
54 \\
6 \\
30 \\
\mathrm{~N} \\
13 \\
9 \\
17 \\
80\end{array}$ & $\begin{array}{r}180 \\
12 \\
32 \\
8 \\
28 \\
\mathrm{~N} \\
11 \\
14 \\
12 \\
63\end{array}$ & $\begin{array}{r}81 \\
- \\
20 \\
- \\
7 \\
- \\
8 \\
8 \\
12 \\
26\end{array}$ & $\begin{array}{r}79 \\
2 \\
16 \\
- \\
13 \\
5 \\
6 \\
5 \\
16 \\
16\end{array}$ & $\begin{array}{r}1,265 \\
178 \\
672 \\
22 \\
149 \\
17 \\
127 \\
20 \\
1 \\
79\end{array}$ & $\begin{array}{r}948 \\
152 \\
585 \\
17 \\
118 \\
13 \\
41 \\
5 \\
- \\
17\end{array}$ & $\begin{array}{r}323 \\
4 \\
109 \\
20 \\
32 \\
3 \\
22 \\
7 \\
48 \\
78\end{array}$ & $\begin{array}{r}285 \\
2 \\
111 \\
13 \\
49 \\
1 \\
19 \\
8 \\
45 \\
37\end{array}$ & $\begin{array}{l}4 \\
- \\
- \\
- \\
- \\
- \\
- \\
- \\
2 \\
2\end{array}$ & $\begin{array}{l}5 \\
- \\
3 \\
- \\
1 \\
- \\
- \\
- \\
1 \\
-\end{array}$ \\
\hline $\begin{array}{l}\text { E.S. CENTRAL } \\
\text { Ky. } \\
\text { Tenn. } \\
\text { Ala. } \\
\text { Miss. }\end{array}$ & $\begin{array}{r}48 \\
21 \\
19 \\
8 \\
-\end{array}$ & $\begin{array}{r}60 \\
13 \\
30 \\
13 \\
4\end{array}$ & $\begin{array}{r}20 \\
4 \\
11 \\
4 \\
1\end{array}$ & $\begin{array}{r}23 \\
7 \\
9 \\
7 \\
-\end{array}$ & $\begin{array}{r}52 \\
23 \\
26 \\
3 \\
-\end{array}$ & $\begin{array}{r}72 \\
23 \\
31 \\
10 \\
8\end{array}$ & $\begin{array}{r}20 \\
7 \\
3 \\
5 \\
5\end{array}$ & $\begin{array}{r}36 \\
14 \\
12 \\
6 \\
4\end{array}$ & $\begin{array}{r}12 \\
- \\
- \\
12 \\
-\end{array}$ & $\begin{array}{l}2 \\
2 \\
- \\
- \\
-\end{array}$ \\
\hline $\begin{array}{l}\text { W.S. CENTRAL } \\
\text { Ark. } \\
\text { La. } \\
\text { Okla. } \\
\text { Tex. }\end{array}$ & $\begin{array}{r}24 \\
- \\
4 \\
3 \\
17\end{array}$ & $\begin{array}{r}27 \\
- \\
7 \\
3 \\
17\end{array}$ & $\begin{array}{r}20 \\
- \\
- \\
9 \\
11\end{array}$ & $\begin{array}{r}34 \\
1 \\
- \\
2 \\
31\end{array}$ & $\begin{array}{r}40 \\
3 \\
4 \\
- \\
33\end{array}$ & $\begin{array}{r}84 \\
1 \\
8 \\
- \\
75\end{array}$ & $\begin{array}{r}22 \\
2 \\
4 \\
10 \\
6\end{array}$ & $\begin{array}{r}88 \\
3 \\
6 \\
3 \\
76\end{array}$ & $\begin{array}{l}1 \\
- \\
- \\
1\end{array}$ & $\begin{array}{l}1 \\
- \\
- \\
1\end{array}$ \\
\hline $\begin{array}{l}\text { MOUNTAIN } \\
\text { Mont. } \\
\text { Idaho } \\
\text { Wyo. } \\
\text { Colo. } \\
\text { N. Mex. } \\
\text { Ariz. } \\
\text { Utah } \\
\text { Nev. }\end{array}$ & $\begin{array}{r}52 \\
3 \\
2 \\
1 \\
8 \\
2 \\
14 \\
17 \\
5\end{array}$ & $\begin{array}{r}57 \\
- \\
3 \\
3 \\
17 \\
3 \\
20 \\
7 \\
4\end{array}$ & $\begin{array}{r}30 \\
- \\
2 \\
- \\
7 \\
3 \\
14 \\
3 \\
1\end{array}$ & $\begin{array}{r}38 \\
- \\
1 \\
2 \\
10 \\
7 \\
9 \\
2 \\
7\end{array}$ & $\begin{array}{r}19 \\
- \\
4 \\
2 \\
1 \\
1 \\
3 \\
7 \\
1\end{array}$ & $\begin{array}{r}13 \\
- \\
5 \\
1 \\
- \\
1 \\
2 \\
1 \\
3\end{array}$ & $\begin{array}{r}51 \\
2 \\
- \\
- \\
24 \\
3 \\
13 \\
6 \\
3\end{array}$ & $\begin{array}{r}64 \\
3 \\
4 \\
1 \\
24 \\
3 \\
16 \\
4 \\
9\end{array}$ & $\begin{array}{l}2 \\
- \\
- \\
- \\
- \\
- \\
- \\
1 \\
1\end{array}$ & $\begin{array}{l}2 \\
- \\
1 \\
- \\
- \\
- \\
1 \\
- \\
-\end{array}$ \\
\hline $\begin{array}{l}\text { PACIFIC } \\
\text { Wash. } \\
\text { Oreg. } \\
\text { Calif. } \\
\text { Alaska } \\
\text { Hawaii }\end{array}$ & $\begin{array}{r}69 \\
7 \\
\mathrm{~N} \\
61 \\
- \\
1\end{array}$ & $\begin{array}{r}62 \\
10 \\
N \\
46 \\
1 \\
5\end{array}$ & $\begin{array}{r}104 \\
8 \\
9 \\
79 \\
- \\
8\end{array}$ & $\begin{array}{r}144 \\
10 \\
12 \\
116 \\
- \\
6\end{array}$ & $\begin{array}{r}142 \\
10 \\
15 \\
114 \\
3 \\
\mathrm{~N}\end{array}$ & $\begin{array}{r}115 \\
7 \\
15 \\
91 \\
2 \\
\mathrm{~N}\end{array}$ & $\begin{array}{r}222 \\
23 \\
11 \\
178 \\
2 \\
8\end{array}$ & $\begin{array}{r}220 \\
15 \\
17 \\
174 \\
1 \\
13\end{array}$ & $\begin{array}{l}4 \\
- \\
- \\
3 \\
1\end{array}$ & $\begin{array}{r}64 \\
15 \\
3 \\
39 \\
- \\
7\end{array}$ \\
\hline $\begin{array}{l}\text { Guam } \\
\text { P.R. } \\
\text { V.I. } \\
\text { Amer. Samoa } \\
\text { C.N.M.I. }\end{array}$ & $\begin{array}{l}- \\
- \\
- \\
-\end{array}$ & $\begin{array}{l}- \\
2 \\
\\
U\end{array}$ & $\begin{array}{l}\overline{1} \\
\bar{u} \\
\end{array}$ & $\begin{array}{l}- \\
\bar{U} \\
\end{array}$ & $\begin{array}{l}- \\
\bar{U} \\
-\end{array}$ & $\begin{array}{l}\bar{N} \\
\bar{U} \\
U\end{array}$ & $\begin{array}{l}- \\
\bar{U} \\
-\end{array}$ & $\begin{array}{l}1 \\
5 \\
- \\
U\end{array}$ & $\begin{array}{l}- \\
- \\
-\end{array}$ & $\begin{array}{l}- \\
\bar{U} \\
U\end{array}$ \\
\hline
\end{tabular}

N: Not notifiable.

- No reported cases

* Incidence data for reporting year 2001 and 2002 are provisional and cumulative (year-to-date).

t Of 36 cases reported, 23 were indigenous and 13 were imported from another country.

$\S$ Of 114 cases reported, 60 were indigenous and 54 were imported from another country. 
TABLE II. (Continued) Provisional cases of selected notifiable diseases, United States, weeks ending December 21, 2002, and December 22, 2001 (51st Week)*

\begin{tabular}{|c|c|c|c|c|c|c|c|c|}
\hline \multirow[b]{2}{*}{ Reporting Area } & \multicolumn{2}{|c|}{$\begin{array}{c}\text { Meningococcal } \\
\text { Disease }\end{array}$} & \multicolumn{2}{|c|}{ Mumps } & \multicolumn{2}{|c|}{ Pertussis } & \multicolumn{2}{|c|}{ Rabies, Animal } \\
\hline & $\begin{array}{l}\text { Cum. } \\
2002\end{array}$ & $\begin{array}{l}\text { Cum. } \\
2001\end{array}$ & $\begin{array}{l}\text { Cum. } \\
2002\end{array}$ & $\begin{array}{l}\text { Cum. } \\
2001\end{array}$ & $\begin{array}{l}\text { Cum. } \\
2002\end{array}$ & $\begin{array}{l}\text { Cum. } \\
2001\end{array}$ & $\begin{array}{l}\text { Cum. } \\
2002 \\
\end{array}$ & $\begin{array}{l}\text { Cum } \\
2001 \\
\end{array}$ \\
\hline UNITED STATES & 1,578 & 2,222 & 236 & 248 & 7,845 & 6,051 & 6,080 & 6,902 \\
\hline $\begin{array}{l}\text { NEW ENGLAND } \\
\text { Maine } \\
\text { N.H. } \\
\text { Vt. } \\
\text { Mass. } \\
\text { R.I. } \\
\text { Conn. }\end{array}$ & $\begin{array}{r}89 \\
9 \\
14 \\
4 \\
42 \\
5 \\
15\end{array}$ & $\begin{array}{r}110 \\
7 \\
14 \\
7 \\
56 \\
6 \\
20\end{array}$ & $\begin{array}{l}6 \\
- \\
4 \\
- \\
1 \\
- \\
1\end{array}$ & $\begin{array}{l}2 \\
- \\
- \\
- \\
2 \\
- \\
-\end{array}$ & $\begin{array}{r}788 \\
17 \\
57 \\
160 \\
511 \\
16 \\
27\end{array}$ & $\begin{array}{r}690 \\
22 \\
28 \\
92 \\
521 \\
6 \\
21\end{array}$ & $\begin{array}{r}893 \\
61 \\
48 \\
89 \\
297 \\
75 \\
323\end{array}$ & $\begin{array}{r}734 \\
69 \\
21 \\
61 \\
278 \\
71 \\
234\end{array}$ \\
\hline $\begin{array}{l}\text { MID. ATLANTIC } \\
\text { Upstate N.Y. } \\
\text { N.Y. City } \\
\text { N.J. } \\
\text { Pa. }\end{array}$ & $\begin{array}{r}155 \\
48 \\
23 \\
27 \\
57\end{array}$ & $\begin{array}{r}246 \\
70 \\
42 \\
43 \\
91\end{array}$ & $\begin{array}{r}25 \\
6 \\
2 \\
- \\
17\end{array}$ & $\begin{array}{r}29 \\
4 \\
13 \\
4 \\
8\end{array}$ & $\begin{array}{r}494 \\
364 \\
13 \\
1 \\
116\end{array}$ & $\begin{array}{r}379 \\
149 \\
58 \\
23 \\
149\end{array}$ & $\begin{array}{r}1,146 \\
693 \\
24 \\
186 \\
243\end{array}$ & $\begin{array}{r}1,299 \\
777 \\
38 \\
196 \\
288\end{array}$ \\
\hline $\begin{array}{l}\text { E.N. CENTRAL } \\
\text { Ohio } \\
\text { Ind. } \\
\text { Ill. } \\
\text { Mich. } \\
\text { Wis. }\end{array}$ & $\begin{array}{r}202 \\
74 \\
32 \\
36 \\
44 \\
16\end{array}$ & $\begin{array}{r}351 \\
91 \\
42 \\
85 \\
82 \\
51\end{array}$ & $\begin{array}{r}38 \\
14 \\
2 \\
14 \\
7 \\
1\end{array}$ & $\begin{array}{r}29 \\
1 \\
3 \\
18 \\
5 \\
2\end{array}$ & $\begin{array}{r}910 \\
420 \\
152 \\
154 \\
59 \\
125\end{array}$ & $\begin{array}{r}867 \\
323 \\
95 \\
106 \\
147 \\
196\end{array}$ & $\begin{array}{r}148 \\
39 \\
32 \\
31 \\
46 \\
-\end{array}$ & $\begin{array}{r}158 \\
52 \\
15 \\
24 \\
47 \\
20\end{array}$ \\
\hline $\begin{array}{l}\text { W.N. CENTRAL } \\
\text { Minn. } \\
\text { lowa } \\
\text { Mo. } \\
\text { N. Dak. } \\
\text { S. Dak. } \\
\text { Nebr. } \\
\text { Kans. }\end{array}$ & $\begin{array}{r}151 \\
35 \\
27 \\
50 \\
3 \\
2 \\
26 \\
8\end{array}$ & $\begin{array}{r}167 \\
26 \\
31 \\
58 \\
6 \\
5 \\
26 \\
15\end{array}$ & $\begin{array}{r}17 \\
4 \\
1 \\
5 \\
1 \\
- \\
- \\
6\end{array}$ & $\begin{array}{r}16 \\
5 \\
1 \\
4 \\
- \\
- \\
1 \\
5\end{array}$ & $\begin{array}{r}734 \\
367 \\
143 \\
144 \\
3 \\
6 \\
8 \\
8 \\
63\end{array}$ & $\begin{array}{r}460 \\
207 \\
101 \\
104 \\
5 \\
5 \\
7 \\
7 \\
31\end{array}$ & $\begin{array}{r}437 \\
35 \\
79 \\
50 \\
36 \\
79 \\
- \\
158\end{array}$ & $\begin{array}{r}367 \\
46 \\
84 \\
40 \\
41 \\
57 \\
4 \\
95\end{array}$ \\
\hline $\begin{array}{l}\text { S. ATLANTIC } \\
\text { Del. } \\
\text { Md. } \\
\text { D.C. } \\
\text { Va. } \\
\text { W.Va. } \\
\text { N.C. } \\
\text { S.C. } \\
\text { Ga. } \\
\text { Fla. }\end{array}$ & $\begin{array}{r}278 \\
7 \\
9 \\
- \\
41 \\
4 \\
32 \\
32 \\
30 \\
123\end{array}$ & $\begin{array}{r}338 \\
6 \\
41 \\
- \\
40 \\
14 \\
63 \\
33 \\
55 \\
86\end{array}$ & $\begin{array}{r}23 \\
- \\
5 \\
- \\
4 \\
- \\
2 \\
3 \\
2 \\
7\end{array}$ & $\begin{array}{r}43 \\
- \\
8 \\
- \\
8 \\
- \\
5 \\
7 \\
9 \\
6\end{array}$ & $\begin{array}{r}394 \\
4 \\
63 \\
2 \\
2 \\
140 \\
32 \\
45 \\
43 \\
14 \\
51\end{array}$ & $\begin{array}{r}351 \\
- \\
52 \\
1 \\
140 \\
4 \\
74 \\
33 \\
23 \\
24\end{array}$ & $\begin{array}{r}2,491 \\
53 \\
352 \\
- \\
505 \\
169 \\
705 \\
142 \\
375 \\
190\end{array}$ & $\begin{array}{r}2,421 \\
30 \\
496 \\
- \\
485 \\
140 \\
563 \\
111 \\
398 \\
198\end{array}$ \\
\hline $\begin{array}{l}\text { E.S. CENTRAL } \\
\text { Ky. } \\
\text { Tenn. } \\
\text { Ala. } \\
\text { Miss. }\end{array}$ & $\begin{array}{l}90 \\
15 \\
38 \\
23 \\
14\end{array}$ & $\begin{array}{r}141 \\
27 \\
61 \\
34 \\
19\end{array}$ & $\begin{array}{r}13 \\
3 \\
2 \\
3 \\
5\end{array}$ & $\begin{array}{l}9 \\
3 \\
1 \\
- \\
5\end{array}$ & $\begin{array}{r}253 \\
93 \\
114 \\
37 \\
9\end{array}$ & $\begin{array}{r}199 \\
92 \\
65 \\
37 \\
5\end{array}$ & $\begin{array}{r}172 \\
27 \\
108 \\
33 \\
4\end{array}$ & $\begin{array}{r}203 \\
29 \\
106 \\
64 \\
4\end{array}$ \\
\hline $\begin{array}{l}\text { W.S. CENTRAL } \\
\text { Ark. } \\
\text { La. } \\
\text { Okla. } \\
\text { Tex. }\end{array}$ & $\begin{array}{r}189 \\
24 \\
39 \\
22 \\
104\end{array}$ & $\begin{array}{r}327 \\
24 \\
77 \\
32 \\
194\end{array}$ & $\begin{array}{r}12 \\
- \\
1 \\
- \\
11\end{array}$ & $\begin{array}{r}14 \\
- \\
2 \\
- \\
12\end{array}$ & $\begin{array}{r}1,567 \\
489 \\
7 \\
66 \\
1,005\end{array}$ & $\begin{array}{r}774 \\
251 \\
12 \\
34 \\
477\end{array}$ & $\begin{array}{r}229 \\
8 \\
- \\
119 \\
102\end{array}$ & $\begin{array}{r}1,101 \\
- \\
9 \\
60 \\
1,032\end{array}$ \\
\hline $\begin{array}{l}\text { MOUNTAIN } \\
\text { Mont. } \\
\text { Idaho } \\
\text { Wyo. } \\
\text { Colo. } \\
\text { N. Mex. } \\
\text { Ariz. } \\
\text { Utah } \\
\text { Nev. }\end{array}$ & $\begin{array}{r}93 \\
3 \\
5 \\
- \\
24 \\
4 \\
31 \\
6 \\
20\end{array}$ & $\begin{array}{r}98 \\
4 \\
8 \\
5 \\
38 \\
11 \\
16 \\
8 \\
8\end{array}$ & $\begin{array}{r}21 \\
- \\
2 \\
- \\
3 \\
1 \\
1 \\
8 \\
6\end{array}$ & $\begin{array}{r}16 \\
1 \\
2 \\
2 \\
3 \\
2 \\
1 \\
1 \\
4\end{array}$ & $\begin{array}{r}1,354 \\
9 \\
152 \\
11 \\
427 \\
188 \\
412 \\
107 \\
48\end{array}$ & $\begin{array}{r}1,449 \\
53 \\
170 \\
1 \\
381 \\
136 \\
592 \\
76 \\
40\end{array}$ & $\begin{array}{r}292 \\
19 \\
38 \\
18 \\
59 \\
7 \\
127 \\
13 \\
11\end{array}$ & $\begin{array}{r}253 \\
38 \\
28 \\
28 \\
- \\
15 \\
128 \\
15 \\
1\end{array}$ \\
\hline $\begin{array}{l}\text { PACIFIC } \\
\text { Wash. } \\
\text { Oreg. } \\
\text { Calif. } \\
\text { Alaska } \\
\text { Hawaii }\end{array}$ & $\begin{array}{r}331 \\
63 \\
45 \\
210 \\
4 \\
9\end{array}$ & $\begin{array}{r}444 \\
64 \\
60 \\
304 \\
3 \\
13\end{array}$ & $\begin{array}{r}81 \\
- \\
N \\
65 \\
- \\
16\end{array}$ & $\begin{array}{r}90 \\
2 \\
\mathrm{~N} \\
47 \\
1 \\
40\end{array}$ & $\begin{array}{r}1,351 \\
439 \\
188 \\
702 \\
5 \\
17\end{array}$ & $\begin{array}{r}882 \\
168 \\
53 \\
605 \\
15 \\
41\end{array}$ & $\begin{array}{r}272 \\
- \\
13 \\
235 \\
24 \\
-\end{array}$ & $\begin{array}{r}366 \\
- \\
4 \\
318 \\
44 \\
-\end{array}$ \\
\hline $\begin{array}{l}\text { Guam } \\
\text { P.R. } \\
\text { V.I. } \\
\text { Amer. Samoa } \\
\text { C.N.M.I. }\end{array}$ & $\begin{array}{c}- \\
5 \\
- \\
\\
-\end{array}$ & $\begin{array}{l}- \\
\\
\\
U\end{array}$ & $\begin{array}{l}- \\
- \\
\text { U }\end{array}$ & $\begin{array}{l}- \\
1 \\
\\
U\end{array}$ & $\begin{array}{c}- \\
3 \\
- \\
\end{array}$ & $\begin{array}{l}- \\
- \\
U \\
U\end{array}$ & $\begin{array}{r}- \\
49 \\
\\
\end{array}$ & $\begin{array}{r}- \\
\\
U\end{array}$ \\
\hline
\end{tabular}

N: Not notifiable. U: Unavailable. $\quad-:$ No reported cases.

* Incidence data for reporting year 2001 and 2002 are provisional and cumulative (year-to-date). 
TABLE II. (Continued) Provisional cases of selected notifiable diseases, United States, weeks ending December 21, 2002, and December 22, 2001 (51st Week)*

\begin{tabular}{|c|c|c|c|c|c|c|c|c|}
\hline \multirow[b]{3}{*}{ Reporting Area } & \multirow{2}{*}{\multicolumn{2}{|c|}{$\begin{array}{l}\text { Rocky Mountain } \\
\text { Spotted Fever }\end{array}$}} & \multicolumn{4}{|c|}{ Rubella } & \multirow{2}{*}{\multicolumn{2}{|c|}{ Salmonellosis }} \\
\hline & & & \multicolumn{2}{|c|}{ Rubella } & \multicolumn{2}{|c|}{$\begin{array}{c}\text { Congenital } \\
\text { Rubella }\end{array}$} & & \\
\hline & $\begin{array}{l}\text { Cum. } \\
2002 \\
\end{array}$ & $\begin{array}{l}\text { Cum. } \\
2001\end{array}$ & $\begin{array}{l}\text { Cum. } \\
2002 \\
\end{array}$ & $\begin{array}{l}\text { Cum. } \\
2001 \\
\end{array}$ & $\begin{array}{l}\text { Cum. } \\
2002 \\
\end{array}$ & $\begin{array}{l}\text { Cum. } \\
2001 \\
\end{array}$ & $\begin{array}{l}\text { Cum. } \\
2002 \\
\end{array}$ & $\begin{array}{l}\text { Cum. } \\
2001 \\
\end{array}$ \\
\hline UNITED STATES & 961 & 597 & 13 & 21 & 3 & 3 & 40,516 & 39,175 \\
\hline $\begin{array}{l}\text { NEW ENGLAND } \\
\text { Maine } \\
\text { N.H. } \\
\text { Vt. } \\
\text { Mass. } \\
\text { R.I. } \\
\text { Conn. }\end{array}$ & $\begin{array}{r}10 \\
- \\
- \\
- \\
6 \\
4 \\
-\end{array}$ & $\begin{array}{l}3 \\
- \\
1 \\
- \\
2 \\
- \\
-\end{array}$ & $\begin{array}{l}- \\
- \\
- \\
- \\
- \\
-\end{array}$ & $\begin{array}{l}- \\
- \\
- \\
- \\
-\end{array}$ & $\begin{array}{l}- \\
- \\
- \\
- \\
- \\
-\end{array}$ & $\begin{array}{l}- \\
- \\
- \\
- \\
- \\
-\end{array}$ & $\begin{array}{r}2,135 \\
146 \\
137 \\
75 \\
1,168 \\
171 \\
438\end{array}$ & $\begin{array}{r}2,291 \\
165 \\
163 \\
81 \\
1,314 \\
139 \\
429\end{array}$ \\
\hline $\begin{array}{l}\text { MID. ATLANTIC } \\
\text { Upstate N.Y. } \\
\text { N.Y. City } \\
\text { N.J. } \\
\text { Pa. }\end{array}$ & $\begin{array}{r}40 \\
9 \\
9 \\
2 \\
20\end{array}$ & $\begin{array}{r}32 \\
2 \\
2 \\
9 \\
19\end{array}$ & $\begin{array}{l}1 \\
1 \\
- \\
- \\
-\end{array}$ & $\begin{array}{l}8 \\
1 \\
6 \\
1 \\
-\end{array}$ & $\begin{array}{l}- \\
- \\
- \\
-\end{array}$ & $\begin{array}{l}- \\
- \\
- \\
-\end{array}$ & $\begin{array}{r}5,122 \\
1,539 \\
1,439 \\
757 \\
1,387\end{array}$ & $\begin{array}{l}5,146 \\
1,230 \\
1,303 \\
1,163 \\
1,450\end{array}$ \\
\hline $\begin{array}{l}\text { E.N. CENTRAL } \\
\text { Ohio } \\
\text { Ind. } \\
\text { IIl. } \\
\text { Mich. } \\
\text { Wis. }\end{array}$ & $\begin{array}{r}19 \\
13 \\
3 \\
- \\
3 \\
-\end{array}$ & $\begin{array}{r}16 \\
2 \\
1 \\
12 \\
1 \\
-\end{array}$ & $\begin{array}{l}1 \\
- \\
- \\
- \\
1 \\
-\end{array}$ & $\begin{array}{l}2 \\
- \\
5 \\
2 \\
- \\
-\end{array}$ & $\begin{array}{l}- \\
- \\
- \\
- \\
-\end{array}$ & $\begin{array}{l}1 \\
1 \\
- \\
- \\
- \\
-\end{array}$ & $\begin{array}{r}5,158 \\
1,371 \\
508 \\
1,556 \\
866 \\
857\end{array}$ & \begin{tabular}{r|}
4,927 \\
1,343 \\
520 \\
1,366 \\
876 \\
822
\end{tabular} \\
\hline $\begin{array}{l}\text { W.N. CENTRAL } \\
\text { Minn. } \\
\text { lowa } \\
\text { Mo. } \\
\text { N. Dak. } \\
\text { S. Dak. } \\
\text { Nebr. } \\
\text { Kans. }\end{array}$ & $\begin{array}{r}100 \\
- \\
3 \\
92 \\
- \\
1 \\
4 \\
-\end{array}$ & $\begin{array}{r}68 \\
- \\
2 \\
62 \\
1 \\
2 \\
1 \\
-\end{array}$ & $\begin{array}{l}- \\
- \\
- \\
- \\
- \\
-\end{array}$ & $\begin{array}{l}3 \\
- \\
1 \\
1 \\
- \\
- \\
- \\
1\end{array}$ & $\begin{array}{l}- \\
- \\
- \\
- \\
- \\
- \\
-\end{array}$ & $\begin{array}{l}- \\
- \\
- \\
- \\
- \\
- \\
-\end{array}$ & $\begin{array}{r}2,617 \\
599 \\
516 \\
865 \\
43 \\
108 \\
150 \\
336\end{array}$ & $\begin{array}{r}2,290 \\
637 \\
334 \\
634 \\
62 \\
147 \\
164 \\
312\end{array}$ \\
\hline $\begin{array}{l}\text { S. ATLANTIC } \\
\text { Del. } \\
\text { Md. } \\
\text { D.C. } \\
\text { Va. } \\
\text { W. Va. } \\
\text { N.C. } \\
\text { S.C. } \\
\text { Ga. } \\
\text { Fla. }\end{array}$ & $\begin{array}{r}494 \\
4 \\
56 \\
2 \\
42 \\
2 \\
285 \\
69 \\
19 \\
15\end{array}$ & $\begin{array}{r}305 \\
12 \\
39 \\
1 \\
31 \\
1 \\
177 \\
31 \\
9 \\
4\end{array}$ & $\begin{array}{l}6 \\
1 \\
- \\
- \\
- \\
- \\
- \\
- \\
- \\
5\end{array}$ & $\begin{array}{l}5 \\
- \\
1 \\
- \\
- \\
- \\
- \\
2 \\
- \\
2\end{array}$ & $\begin{array}{l}- \\
- \\
- \\
- \\
- \\
- \\
-\end{array}$ & $\begin{array}{l}1 \\
- \\
- \\
1 \\
- \\
- \\
- \\
-\end{array}$ & $\begin{array}{r}11,111 \\
95 \\
939 \\
76 \\
1,228 \\
152 \\
1,574 \\
809 \\
1,694 \\
4,544\end{array}$ & \begin{tabular}{r|r}
9,402 \\
94 \\
793 \\
81 \\
1,301 \\
141 \\
1,368 \\
876 \\
1,696 \\
3,052
\end{tabular} \\
\hline $\begin{array}{l}\text { E.S. CENTRAL } \\
\text { Ky. } \\
\text { Tenn. } \\
\text { Ala. } \\
\text { Miss. }\end{array}$ & $\begin{array}{r}113 \\
5 \\
84 \\
20 \\
4\end{array}$ & $\begin{array}{r}119 \\
2 \\
83 \\
18 \\
16\end{array}$ & $\begin{array}{l}- \\
- \\
- \\
-\end{array}$ & $\begin{array}{l}- \\
- \\
- \\
-\end{array}$ & $\begin{array}{l}1 \\
- \\
1 \\
-\end{array}$ & $\begin{array}{l}- \\
- \\
- \\
-\end{array}$ & $\begin{array}{r}3,247 \\
396 \\
839 \\
872 \\
1,140\end{array}$ & $\begin{array}{r}2,690 \\
372 \\
661 \\
746 \\
911\end{array}$ \\
\hline $\begin{array}{l}\text { W.S. CENTRAL } \\
\text { Ark. } \\
\text { La. } \\
\text { Okla. } \\
\text { Tex. }\end{array}$ & $\begin{array}{r}163 \\
97 \\
- \\
61 \\
5\end{array}$ & $\begin{array}{r}42 \\
9 \\
2 \\
31 \\
-\end{array}$ & $\begin{array}{l}1 \\
- \\
- \\
- \\
1\end{array}$ & $\begin{array}{l}1 \\
- \\
- \\
- \\
1\end{array}$ & $\begin{array}{l}1 \\
- \\
1 \\
- \\
-\end{array}$ & $\begin{array}{l}- \\
- \\
- \\
-\end{array}$ & $\begin{array}{r}3,554 \\
1,047 \\
805 \\
505 \\
1,197\end{array}$ & $\begin{array}{r}4,972 \\
908 \\
823 \\
475 \\
2,766\end{array}$ \\
\hline $\begin{array}{l}\text { MOUNTAIN } \\
\text { Mont. } \\
\text { Idaho } \\
\text { Wyo. } \\
\text { Colo. } \\
\text { N. Mex. } \\
\text { Ariz. } \\
\text { Utah } \\
\text { Nev. }\end{array}$ & $\begin{array}{r}14 \\
1 \\
- \\
5 \\
2 \\
1 \\
- \\
- \\
5\end{array}$ & $\begin{array}{r}11 \\
1 \\
1 \\
2 \\
2 \\
1 \\
- \\
3 \\
1\end{array}$ & $\begin{array}{l}1 \\
- \\
- \\
- \\
- \\
- \\
- \\
1 \\
-\end{array}$ & $\begin{array}{l}- \\
- \\
- \\
- \\
- \\
- \\
-\end{array}$ & $\begin{array}{l}- \\
- \\
- \\
- \\
- \\
- \\
-\end{array}$ & $\begin{array}{l}- \\
- \\
- \\
- \\
- \\
- \\
-\end{array}$ & $\begin{array}{r}2,344 \\
89 \\
169 \\
105 \\
598 \\
320 \\
681 \\
199 \\
183\end{array}$ & $\begin{array}{r}2,198 \\
78 \\
143 \\
61 \\
586 \\
279 \\
637 \\
218 \\
196\end{array}$ \\
\hline $\begin{array}{l}\text { PACIFIC } \\
\text { Wash. } \\
\text { Oreg. } \\
\text { Calif. } \\
\text { Alaska } \\
\text { Hawaii }\end{array}$ & $\begin{array}{l}8 \\
- \\
3 \\
5 \\
- \\
-\end{array}$ & $\begin{array}{l}1 \\
- \\
1 \\
- \\
- \\
-\end{array}$ & $\begin{array}{l}3 \\
- \\
5 \\
- \\
-\end{array}$ & $\begin{array}{l}2 \\
- \\
- \\
1 \\
- \\
1\end{array}$ & $\begin{array}{l}1 \\
- \\
- \\
- \\
1\end{array}$ & $\begin{array}{l}1 \\
- \\
- \\
- \\
1\end{array}$ & $\begin{array}{r}5,228 \\
493 \\
344 \\
4,041 \\
79 \\
271\end{array}$ & $\begin{array}{r}5,259 \\
545 \\
274 \\
4,039 \\
49 \\
352\end{array}$ \\
\hline $\begin{array}{l}\text { Guam } \\
\text { P.R. } \\
\text { V.I. } \\
\text { Amer. Samoa } \\
\text { C.N.M.I. }\end{array}$ & $\begin{array}{l}- \\
- \\
\\
-\end{array}$ & $\begin{array}{l}- \\
- \\
\\
U\end{array}$ & $\begin{array}{l}- \\
- \\
\\
-\end{array}$ & $\begin{array}{l}- \\
\\
\\
\\
U\end{array}$ & $\begin{array}{l}- \\
- \\
\\
\end{array}$ & $\begin{array}{l}- \\
- \\
\\
U\end{array}$ & $\begin{array}{r}201 \\
\\
25\end{array}$ & $\begin{array}{r}24 \\
914 \\
\\
U\end{array}$ \\
\hline
\end{tabular}

\footnotetext{
N: Not notifiable. U: Unavailable. $\quad$ - : No reported cases.
}

* Incidence data for reporting year 2001 and 2002 are provisional and cumulative (year-to-date). 
TABLE II. (Continued) Provisional cases of selected notifiable diseases, United States, weeks ending December 21, 2002, and December 22, 2001 (51st Week)*

\begin{tabular}{|c|c|c|c|c|c|c|c|c|}
\hline \multirow[b]{2}{*}{ Reporting Area } & \multicolumn{2}{|c|}{ Shigellosis } & \multicolumn{2}{|c|}{$\begin{array}{c}\text { Streptococcal Disease, } \\
\text { Invasive, Group A }\end{array}$} & \multicolumn{2}{|c|}{$\begin{array}{l}\text { Streptococcus pneumoniae, } \\
\text { Drug Resistant, Invasive }\end{array}$} & \multicolumn{2}{|c|}{$\begin{array}{c}\begin{array}{c}\text { Streptococcus pneumoniae, } \\
\text { Invasive (<5 Years) }\end{array} \\
\end{array}$} \\
\hline & $\begin{array}{l}\text { Cum. } \\
2002\end{array}$ & $\begin{array}{l}\text { Cum. } \\
2001\end{array}$ & $\begin{array}{l}\text { Cum. } \\
2002\end{array}$ & $\begin{array}{l}\text { Cum. } \\
2001\end{array}$ & $\begin{array}{l}\text { Cum. } \\
2002\end{array}$ & $\begin{array}{l}\text { Cum. } \\
2001\end{array}$ & $\begin{array}{l}\text { Cum. } \\
2002\end{array}$ & $\begin{array}{l}\text { Cum. } \\
2001\end{array}$ \\
\hline UNITED STATES & 19,049 & 19,411 & 3,891 & 3,518 & 2,190 & 2,559 & 283 & 424 \\
\hline $\begin{array}{l}\text { NEW ENGLAND } \\
\text { Maine } \\
\text { N.H. } \\
\text { Vt. } \\
\text { Mass. } \\
\text { R.I. } \\
\text { Conn. }\end{array}$ & $\begin{array}{r}329 \\
12 \\
13 \\
1 \\
187 \\
17 \\
99\end{array}$ & $\begin{array}{r}303 \\
6 \\
7 \\
7 \\
206 \\
23 \\
54\end{array}$ & $\begin{array}{r}173 \\
20 \\
35 \\
10 \\
93 \\
15 \\
-\end{array}$ & $\begin{array}{r}220 \\
12 \\
\mathrm{~N} \\
16 \\
67 \\
13 \\
112\end{array}$ & $\begin{array}{r}21 \\
- \\
- \\
5 \\
N \\
16 \\
-\end{array}$ & $\begin{array}{r}136 \\
- \\
- \\
9 \\
\mathrm{~N} \\
13 \\
114\end{array}$ & $\begin{array}{c}3 \\
- \\
\mathrm{N} \\
2 \\
\mathrm{~N} \\
1 \\
-\end{array}$ & $\begin{array}{r}48 \\
- \\
N \\
1 \\
N \\
4 \\
43\end{array}$ \\
\hline $\begin{array}{l}\text { MID. ATLANTIC } \\
\text { Upstate N.Y. } \\
\text { N.Y. City } \\
\text { N.J. } \\
\text { Pa. }\end{array}$ & $\begin{array}{r}1,463 \\
358 \\
450 \\
403 \\
252\end{array}$ & $\begin{array}{r}1,463 \\
468 \\
409 \\
268 \\
318\end{array}$ & $\begin{array}{r}637 \\
288 \\
148 \\
136 \\
65\end{array}$ & $\begin{array}{r}652 \\
259 \\
164 \\
143 \\
86\end{array}$ & $\begin{array}{r}119 \\
93 \\
U \\
N \\
26\end{array}$ & $\begin{array}{r}171 \\
162 \\
U \\
N \\
9\end{array}$ & $\begin{array}{r}74 \\
72 \\
\text { U } \\
\mathrm{N} \\
2\end{array}$ & $\begin{array}{r}114 \\
114 \\
\mathrm{U} \\
\mathrm{N} \\
-\end{array}$ \\
\hline $\begin{array}{l}\text { E.N. CENTRAL } \\
\text { Ohio } \\
\text { Ind. } \\
\text { III. } \\
\text { Mich. } \\
\text { Wis. }\end{array}$ & $\begin{array}{r}1,808 \\
661 \\
107 \\
672 \\
196 \\
172\end{array}$ & $\begin{array}{r}4,395 \\
2,949 \\
223 \\
621 \\
301 \\
301\end{array}$ & $\begin{array}{r}744 \\
202 \\
48 \\
196 \\
297 \\
1\end{array}$ & $\begin{array}{r}768 \\
196 \\
61 \\
250 \\
210 \\
51\end{array}$ & $\begin{array}{r}248 \\
78 \\
165 \\
2 \\
3 \\
\mathrm{~N}\end{array}$ & $\begin{array}{r}173 \\
3 \\
170 \\
- \\
- \\
\end{array}$ & $\begin{array}{r}121 \\
29 \\
66 \\
- \\
N \\
26\end{array}$ & $\begin{array}{r}129 \\
- \\
59 \\
70 \\
\mathrm{~N} \\
-\end{array}$ \\
\hline $\begin{array}{l}\text { W.N. CENTRAL } \\
\text { Minn. } \\
\text { lowa } \\
\text { Mo. } \\
\text { N. Dak. } \\
\text { S. Dak. } \\
\text { Nebr. } \\
\text { Kans. }\end{array}$ & $\begin{array}{r}996 \\
222 \\
123 \\
209 \\
16 \\
156 \\
179 \\
91\end{array}$ & $\begin{array}{r}1,952 \\
432 \\
359 \\
316 \\
22 \\
642 \\
105 \\
76\end{array}$ & $\begin{array}{r}247 \\
129 \\
- \\
46 \\
3 \\
13 \\
18 \\
38\end{array}$ & $\begin{array}{r}370 \\
176 \\
- \\
74 \\
17 \\
12 \\
40 \\
51\end{array}$ & $\begin{array}{r}430 \\
292 \\
\mathrm{~N} \\
5 \\
1 \\
1 \\
29 \\
102\end{array}$ & $\begin{array}{r}164 \\
74 \\
\mathrm{~N} \\
11 \\
6 \\
5 \\
5 \\
25 \\
43\end{array}$ & $\begin{array}{r}60 \\
59 \\
\mathrm{~N} \\
1 \\
- \\
- \\
\mathrm{N} \\
\mathrm{N}\end{array}$ & $\begin{array}{r}63 \\
54 \\
\mathrm{~N} \\
- \\
9 \\
- \\
\mathrm{N} \\
\mathrm{N}\end{array}$ \\
\hline $\begin{array}{l}\text { S. ATLANTIC } \\
\text { Del. } \\
\text { Md. } \\
\text { D.C. } \\
\text { Va. } \\
\text { W.Va. } \\
\text { N.C. } \\
\text { S.C. } \\
\text { Ga. } \\
\text { Fla. }\end{array}$ & $\begin{array}{r}7,136 \\
397 \\
1,232 \\
61 \\
1,000 \\
12 \\
550 \\
127 \\
1,339 \\
2,418\end{array}$ & $\begin{array}{r}3,158 \\
17 \\
157 \\
54 \\
594 \\
8 \\
354 \\
247 \\
705 \\
1,022\end{array}$ & $\begin{array}{r}732 \\
2 \\
145 \\
9 \\
71 \\
19 \\
113 \\
35 \\
124 \\
214\end{array}$ & $\begin{array}{r}569 \\
4 \\
\mathrm{~N} \\
22 \\
79 \\
20 \\
144 \\
13 \\
180 \\
107\end{array}$ & $\begin{array}{r}1,111 \\
3 \\
\mathrm{~N} \\
57 \\
\mathrm{~N} \\
46 \\
\mathrm{~N} \\
186 \\
195 \\
624\end{array}$ & $\begin{array}{r}1,342 \\
6 \\
N \\
11 \\
N \\
41 \\
N \\
278 \\
419 \\
587\end{array}$ & $\begin{array}{l}8 \\
N \\
N \\
1 \\
N \\
7 \\
U \\
N \\
N \\
N\end{array}$ & $\begin{array}{l}9 \\
N \\
N \\
4 \\
N \\
5 \\
U \\
N \\
N \\
N\end{array}$ \\
\hline $\begin{array}{l}\text { E.S. CENTRAL } \\
\text { Ky. } \\
\text { Tenn. } \\
\text { Ala. } \\
\text { Miss. }\end{array}$ & $\begin{array}{r}1,501 \\
198 \\
140 \\
825 \\
338\end{array}$ & $\begin{array}{r}1,727 \\
817 \\
119 \\
210 \\
581\end{array}$ & $\begin{array}{r}112 \\
21 \\
91 \\
- \\
-\end{array}$ & $\begin{array}{r}117 \\
38 \\
79 \\
- \\
-\end{array}$ & $\begin{array}{r}130 \\
18 \\
112 \\
- \\
-\end{array}$ & $\begin{array}{r}239 \\
26 \\
212 \\
1 \\
-\end{array}$ & $\begin{array}{r}- \\
N \\
N \\
-\end{array}$ & $\begin{array}{l}- \\
\mathrm{N} \\
\mathrm{N} \\
\mathrm{N} \\
-\end{array}$ \\
\hline $\begin{array}{l}\text { W.S. CENTRAL } \\
\text { Ark. } \\
\text { La. } \\
\text { Okla. } \\
\text { Tex. }\end{array}$ & $\begin{array}{r}1,765 \\
196 \\
441 \\
586 \\
542\end{array}$ & $\begin{array}{r}2,929 \\
565 \\
252 \\
108 \\
2,004\end{array}$ & $\begin{array}{r}117 \\
8 \\
- \\
48 \\
61\end{array}$ & $\begin{array}{r}315 \\
- \\
1 \\
46 \\
268\end{array}$ & $\begin{array}{r}88 \\
12 \\
75 \\
N \\
N\end{array}$ & $\begin{array}{r}284 \\
22 \\
262 \\
N \\
N\end{array}$ & $\begin{array}{r}12 \\
- \\
4 \\
8 \\
-\end{array}$ & $\begin{array}{r}61 \\
- \\
61 \\
- \\
-\end{array}$ \\
\hline $\begin{array}{l}\text { MOUNTAIN } \\
\text { Mont. } \\
\text { Idaho } \\
\text { Wyo. } \\
\text { Colo. } \\
\text { N. Mex. } \\
\text { Ariz. } \\
\text { Utah } \\
\text { Nev. }\end{array}$ & $\begin{array}{r}1,076 \\
4 \\
19 \\
9 \\
211 \\
231 \\
513 \\
42 \\
47\end{array}$ & $\begin{array}{r}976 \\
9 \\
40 \\
7 \\
244 \\
120 \\
424 \\
62 \\
70\end{array}$ & $\begin{array}{r}586 \\
- \\
11 \\
7 \\
145 \\
109 \\
283 \\
31 \\
-\end{array}$ & $\begin{array}{r}421 \\
- \\
7 \\
12 \\
159 \\
90 \\
150 \\
3 \\
-\end{array}$ & $\begin{array}{r}43 \\
- \\
\mathrm{N} \\
11 \\
- \\
31 \\
- \\
- \\
1\end{array}$ & $\begin{array}{r}46 \\
- \\
N \\
10 \\
- \\
34 \\
- \\
- \\
2\end{array}$ & $\begin{array}{r}5 \\
- \\
N \\
- \\
- \\
- \\
N \\
5 \\
-\end{array}$ & $\begin{array}{l}- \\
- \\
\text { N } \\
- \\
- \\
- \\
\text { N } \\
- \\
-\end{array}$ \\
\hline $\begin{array}{l}\text { PACIFIC } \\
\text { Wash. } \\
\text { Oreg. } \\
\text { Calif. } \\
\text { Alaska } \\
\text { Hawaii }\end{array}$ & $\begin{array}{r}2,975 \\
174 \\
117 \\
2,614 \\
6 \\
64\end{array}$ & $\begin{array}{r}2,508 \\
213 \\
114 \\
2,115 \\
7 \\
59\end{array}$ & $\begin{array}{r}543 \\
65 \\
\mathrm{~N} \\
381 \\
- \\
97\end{array}$ & $\begin{array}{r}86 \\
- \\
\mathrm{N} \\
- \\
- \\
86\end{array}$ & $\begin{array}{l}- \\
- \\
N \\
N \\
- \\
-\end{array}$ & $\begin{array}{c}4 \\
- \\
\mathrm{N} \\
\mathrm{N} \\
- \\
4\end{array}$ & $\begin{array}{l}- \\
N \\
N \\
N \\
N\end{array}$ & $\begin{array}{l}- \\
N \\
N \\
N \\
N\end{array}$ \\
\hline $\begin{array}{l}\text { Guam } \\
\text { P.R. } \\
\text { V.I. } \\
\text { Amer. Samoa } \\
\text { C.N.M.I. }\end{array}$ & $\begin{array}{r}- \\
8 \\
- \\
\\
18\end{array}$ & $\begin{array}{r}50 \\
20 \\
- \\
\cup \\
U\end{array}$ & $\begin{array}{l}\bar{N} \\
- \\
\bar{U} \\
-\end{array}$ & $\begin{array}{c}1 \\
N \\
- \\
U\end{array}$ & $\begin{array}{l}- \\
- \\
- \\
-\end{array}$ & $\begin{array}{l}- \\
- \\
- \\
-\end{array}$ & $\begin{array}{l}\bar{N} \\
- \\
\bar{U} \\
-\end{array}$ & $\begin{array}{c}\bar{N} \\
\bar{U} \\
U\end{array}$ \\
\hline
\end{tabular}

$\mathrm{N}$ : Not notifiable. U: Unavailable. $\quad-:$ No reported cases.

* Incidence data for reporting year 2001 and 2002 are provisional and cumulative (year-to-date). 
TABLE II. (Continued) Provisional cases of selected notifiable diseases, United States, weeks ending December 21, 2002, and December 22, 2001 (51st Week)*

\begin{tabular}{|c|c|c|c|c|c|c|c|c|}
\hline \multirow[b]{3}{*}{ Reporting Area } & \multicolumn{4}{|c|}{ Syphilis } & \multirow{2}{*}{\multicolumn{2}{|c|}{ Tuberculosis }} & \multirow{2}{*}{\multicolumn{2}{|c|}{$\begin{array}{c}\text { Typhoid } \\
\text { Fever }\end{array}$}} \\
\hline & \multicolumn{2}{|c|}{ Primary \& Secondary } & \multicolumn{2}{|c|}{ Congenital } & & & & \\
\hline & $\begin{array}{l}\text { Cum. } \\
2002 \\
\end{array}$ & $\begin{array}{l}\text { Cum. } \\
2001 \\
\end{array}$ & $\begin{array}{l}\text { Cum. } \\
2002 \\
\end{array}$ & $\begin{array}{l}\text { Cum. } \\
2001 \\
\end{array}$ & $\begin{array}{l}\text { Cum. } \\
2002 \\
\end{array}$ & $\begin{array}{l}\text { Cum. } \\
2001 \\
\end{array}$ & $\begin{array}{l}\text { Cum. } \\
2002 \\
\end{array}$ & $\begin{array}{l}\text { Cum } \\
2001 \\
\end{array}$ \\
\hline UNITED STATES & 6,240 & 5,946 & 349 & 487 & 11,878 & 13,923 & 262 & 350 \\
\hline $\begin{array}{l}\text { NEW ENGLAND } \\
\text { Maine } \\
\text { N.H. } \\
\text { Vt. } \\
\text { Mass. } \\
\text { R.I. } \\
\text { Conn. }\end{array}$ & $\begin{array}{r}137 \\
2 \\
8 \\
2 \\
93 \\
6 \\
26\end{array}$ & $\begin{array}{r}67 \\
1 \\
1 \\
3 \\
41 \\
9 \\
12\end{array}$ & $\begin{array}{l}1 \\
- \\
- \\
- \\
1 \\
-\end{array}$ & $\begin{array}{l}8 \\
3 \\
- \\
5 \\
3 \\
5 \\
2\end{array}$ & $\begin{array}{r}402 \\
20 \\
17 \\
6 \\
235 \\
37 \\
87\end{array}$ & $\begin{array}{r}454 \\
20 \\
17 \\
5 \\
239 \\
60 \\
113\end{array}$ & $\begin{array}{r}14 \\
- \\
- \\
8 \\
- \\
6\end{array}$ & $\begin{array}{r}18 \\
1 \\
2 \\
- \\
12 \\
- \\
3\end{array}$ \\
\hline $\begin{array}{l}\text { MID. ATLANTIC } \\
\text { Upstate N.Y. } \\
\text { N.Y. City } \\
\text { N.J. } \\
\text { Pa. }\end{array}$ & $\begin{array}{r}674 \\
35 \\
413 \\
151 \\
75\end{array}$ & $\begin{array}{r}525 \\
20 \\
275 \\
136 \\
94\end{array}$ & $\begin{array}{r}69 \\
11 \\
23 \\
34 \\
1\end{array}$ & $\begin{array}{r}72 \\
5 \\
32 \\
35 \\
-\end{array}$ & $\begin{array}{r}2,068 \\
286 \\
1,047 \\
484 \\
251\end{array}$ & $\begin{array}{r}2,249 \\
349 \\
1,120 \\
496 \\
284\end{array}$ & $\begin{array}{r}63 \\
9 \\
34 \\
16 \\
4\end{array}$ & $\begin{array}{r}111 \\
15 \\
48 \\
38 \\
10\end{array}$ \\
\hline $\begin{array}{l}\text { E.N. CENTRAL } \\
\text { Ohio } \\
\text { Ind. } \\
\text { Ill. } \\
\text { Mich. } \\
\text { Wis. }\end{array}$ & $\begin{array}{r}1,075 \\
164 \\
71 \\
330 \\
482 \\
28\end{array}$ & $\begin{array}{r}1,050 \\
80 \\
151 \\
399 \\
397 \\
23\end{array}$ & $\begin{array}{r}64 \\
4 \\
1 \\
32 \\
27 \\
-\end{array}$ & $\begin{array}{r}69 \\
2 \\
13 \\
44 \\
6 \\
4\end{array}$ & $\begin{array}{r}1,191 \\
156 \\
120 \\
594 \\
256 \\
65\end{array}$ & $\begin{array}{r}1,431 \\
280 \\
109 \\
669 \\
293 \\
80\end{array}$ & $\begin{array}{r}19 \\
7 \\
2 \\
1 \\
4 \\
5\end{array}$ & $\begin{array}{r}34 \\
5 \\
2 \\
18 \\
5 \\
4\end{array}$ \\
\hline $\begin{array}{l}\text { W.N. CENTRAL } \\
\text { Minn. } \\
\text { lowa } \\
\text { Mo. } \\
\text { N. Dak. } \\
\text { S. Dak. } \\
\text { Nebr. } \\
\text { Kans. }\end{array}$ & $\begin{array}{r}105 \\
53 \\
2 \\
29 \\
- \\
- \\
3 \\
18\end{array}$ & $\begin{array}{r}100 \\
33 \\
5 \\
26 \\
- \\
1 \\
10 \\
25\end{array}$ & $\begin{array}{l}- \\
- \\
- \\
- \\
- \\
-\end{array}$ & $\begin{array}{l}9 \\
2 \\
- \\
5 \\
- \\
- \\
- \\
2\end{array}$ & $\begin{array}{r}521 \\
223 \\
30 \\
126 \\
4 \\
12 \\
23 \\
103\end{array}$ & $\begin{array}{r}533 \\
225 \\
35 \\
138 \\
4 \\
13 \\
38 \\
80\end{array}$ & $\begin{array}{l}9 \\
3 \\
- \\
2 \\
- \\
- \\
4 \\
-\end{array}$ & $\begin{array}{r}16 \\
7 \\
- \\
9 \\
- \\
- \\
-\end{array}$ \\
\hline $\begin{array}{l}\text { S. ATLANTIC } \\
\text { Del. } \\
\text { Md. } \\
\text { D.C. } \\
\text { Va. } \\
\text { W.Va. } \\
\text { N.C. } \\
\text { S.C. } \\
\text { Ga. } \\
\text { Fla. }\end{array}$ & $\begin{array}{r}1,709 \\
11 \\
210 \\
64 \\
68 \\
2 \\
279 \\
126 \\
358 \\
591\end{array}$ & $\begin{array}{r}1,953 \\
14 \\
261 \\
43 \\
102 \\
5 \\
436 \\
235 \\
385 \\
472\end{array}$ & $\begin{array}{r}79 \\
- \\
14 \\
1 \\
1 \\
- \\
20 \\
11 \\
10 \\
22\end{array}$ & $\begin{array}{r}112 \\
- \\
4 \\
2 \\
5 \\
- \\
15 \\
21 \\
23 \\
42\end{array}$ & $\begin{array}{r}2,457 \\
15 \\
270 \\
- \\
283 \\
28 \\
417 \\
147 \\
387 \\
910\end{array}$ & $\begin{array}{r}2,639 \\
15 \\
232 \\
51 \\
279 \\
28 \\
394 \\
206 \\
482 \\
952\end{array}$ & $\begin{array}{r}42 \\
- \\
10 \\
- \\
7 \\
5 \\
2 \\
- \\
4 \\
19\end{array}$ & $\begin{array}{r}47 \\
1 \\
10 \\
- \\
11 \\
- \\
3 \\
- \\
12 \\
10\end{array}$ \\
\hline $\begin{array}{l}\text { E.S. CENTRAL } \\
\text { Ky. } \\
\text { Tenn. } \\
\text { Ala. } \\
\text { Miss. }\end{array}$ & $\begin{array}{r}445 \\
88 \\
163 \\
151 \\
43\end{array}$ & $\begin{array}{r}653 \\
48 \\
324 \\
142 \\
139\end{array}$ & $\begin{array}{r}22 \\
3 \\
11 \\
4 \\
4\end{array}$ & $\begin{array}{r}39 \\
1 \\
24 \\
5 \\
9\end{array}$ & $\begin{array}{l}733 \\
131 \\
286 \\
207 \\
109\end{array}$ & $\begin{array}{l}818 \\
125 \\
292 \\
265 \\
136\end{array}$ & $\begin{array}{l}4 \\
4 \\
- \\
- \\
-\end{array}$ & $\begin{array}{l}1 \\
- \\
1 \\
- \\
-\end{array}$ \\
\hline $\begin{array}{l}\text { W.S. CENTRAL } \\
\text { Ark. } \\
\text { La. } \\
\text { Okla. } \\
\text { Tex. }\end{array}$ & $\begin{array}{r}814 \\
34 \\
147 \\
71 \\
562\end{array}$ & $\begin{array}{r}753 \\
48 \\
174 \\
60 \\
471\end{array}$ & $\begin{array}{r}69 \\
3 \\
- \\
3 \\
63\end{array}$ & $\begin{array}{r}84 \\
9 \\
- \\
6 \\
69\end{array}$ & $\begin{array}{r}1,569 \\
119 \\
- \\
142 \\
1,308\end{array}$ & $\begin{array}{r}2,101 \\
153 \\
194 \\
151 \\
1,603\end{array}$ & $\begin{array}{l}6 \\
- \\
- \\
2 \\
4\end{array}$ & $\begin{array}{r}18 \\
- \\
- \\
18\end{array}$ \\
\hline $\begin{array}{l}\text { MOUNTAIN } \\
\text { Mont. } \\
\text { Idaho } \\
\text { Wyo. } \\
\text { Colo. } \\
\text { N. Mex. } \\
\text { Ariz. } \\
\text { Utah } \\
\text { Nev. }\end{array}$ & $\begin{array}{r}300 \\
- \\
9 \\
- \\
46 \\
38 \\
186 \\
8 \\
13\end{array}$ & $\begin{array}{r}233 \\
- \\
1 \\
1 \\
23 \\
19 \\
171 \\
10 \\
8\end{array}$ & $\begin{array}{r}15 \\
- \\
- \\
- \\
1 \\
- \\
14 \\
- \\
-\end{array}$ & $\begin{array}{r}35 \\
- \\
- \\
- \\
1 \\
2 \\
32 \\
- \\
-\end{array}$ & $\begin{array}{r}364 \\
12 \\
9 \\
3 \\
56 \\
28 \\
211 \\
31 \\
14\end{array}$ & $\begin{array}{r}567 \\
14 \\
7 \\
3 \\
131 \\
54 \\
239 \\
34 \\
85\end{array}$ & $\begin{array}{r}10 \\
- \\
- \\
- \\
5 \\
1 \\
- \\
2 \\
2\end{array}$ & $\begin{array}{r}10 \\
2 \\
- \\
- \\
1 \\
- \\
2 \\
1 \\
4\end{array}$ \\
\hline $\begin{array}{l}\text { PACIFIC } \\
\text { Wash. } \\
\text { Oreg. } \\
\text { Calif. } \\
\text { Alaska } \\
\text { Hawaii }\end{array}$ & $\begin{array}{r}981 \\
66 \\
26 \\
881 \\
- \\
8\end{array}$ & $\begin{array}{r}612 \\
54 \\
13 \\
533 \\
- \\
12\end{array}$ & $\begin{array}{r}30 \\
2 \\
1 \\
26 \\
-\end{array}$ & $\begin{array}{r}59 \\
- \\
59 \\
- \\
-\end{array}$ & $\begin{array}{r}2,573 \\
228 \\
107 \\
2,054 \\
48 \\
136\end{array}$ & $\begin{array}{r}3,131 \\
242 \\
119 \\
2,574 \\
50 \\
146\end{array}$ & $\begin{array}{r}95 \\
6 \\
2 \\
82 \\
- \\
5\end{array}$ & $\begin{array}{r}95 \\
6 \\
8 \\
77 \\
1 \\
3\end{array}$ \\
\hline $\begin{array}{l}\text { Guam } \\
\text { P.R. } \\
\text { V.I. } \\
\text { Amer. Samoa } \\
\text { C.N.M.I. }\end{array}$ & $\begin{array}{r}- \\
227 \\
1 \\
U \\
15\end{array}$ & $\begin{array}{r}11 \\
266 \\
\dot{U} \\
U\end{array}$ & $\begin{array}{r}15 \\
\bar{U} \\
-\end{array}$ & $\begin{array}{r}1 \\
13 \\
\\
U\end{array}$ & $\begin{array}{r}- \\
75 \\
- \\
32\end{array}$ & $\begin{array}{r}63 \\
95 \\
- \\
U \\
U\end{array}$ & $\begin{array}{l}- \\
- \\
U \\
-\end{array}$ & $\begin{array}{c}3 \\
- \\
- \\
U \\
U\end{array}$ \\
\hline
\end{tabular}

N: Not notifiable. U: Unavailable.

$-:$ No reported cases.

* Incidence data for reporting year 2001 and 2002 are provisional and cumulative (year-to-date). 
TABLE III. Deaths in 122 U.S. cities, ${ }^{*}$ week ending December 21, 2002 (51st Week)

\begin{tabular}{|c|c|c|c|c|c|c|c|c|c|c|c|c|c|c|c|}
\hline \multirow[b]{2}{*}{ Reporting Area } & \multicolumn{6}{|c|}{ All Causes, By Age (Years) } & \multirow[b]{2}{*}{$\begin{array}{l}\text { P\& }\left.\right|^{\dagger} \\
\text { Total }\end{array}$} & \multirow[b]{2}{*}{ Reporting Area } & \multicolumn{6}{|c|}{ All Causes, By Age (Years) } & \multirow[b]{2}{*}{$\begin{array}{l}\text { P\&l' } \\
\text { Tota }\end{array}$} \\
\hline & $\begin{array}{c}\text { All } \\
\text { Ages }\end{array}$ & $\geq 65$ & $45-64$ & $25-44$ & $1-24$ & $<1$ & & & $\begin{array}{c}\text { All } \\
\text { Ages }\end{array}$ & $\geq 65$ & $45-64$ & $25-44$ & $1-24$ & $<1$ & \\
\hline NEW ENGLAND & 364 & 270 & 63 & 22 & 4 & 5 & 49 & S. ATLANTIC & 1,515 & 976 & 329 & 145 & 36 & 28 & 96 \\
\hline Boston, Mass. & U & $U$ & $U$ & $U$ & $U$ & $U$ & $\mathrm{U}$ & Atlanta, Ga. & 400 & 244 & 85 & 52 & 14 & 5 & 19 \\
\hline Bridgeport, Conn. & 53 & 44 & 8 & - & 1 & - & 9 & Baltimore, Md. & 195 & 105 & 65 & 22 & 2 & 1 & 13 \\
\hline Cambridge, Mass. & 16 & 13 & 2 & 1 & - & - & 1 & Charlotte, N.C. & 140 & 100 & 27 & 11 & 2 & - & 18 \\
\hline Fall River, Mass. & 26 & 19 & 5 & 2 & - & - & 6 & Jacksonville, Fla. & 111 & 78 & 16 & 16 & 1 & - & 12 \\
\hline Hartford, Conn. & 72 & 48 & 17 & 5 & 2 & - & 8 & Miami, Fla. & $U$ & $\mathrm{U}$ & $U$ & $U$ & $\mathrm{U}$ & $\mathrm{U}$ & $\bar{U}$ \\
\hline Lowell, Mass. & 25 & 20 & 2 & 3 & - & - & 3 & Norfolk, Va. & 68 & 42 & 14 & 2 & 4 & 6 & 3 \\
\hline Lynn, Mass. & 10 & 8 & 1 & 1 & - & - & 1 & Richmond, Va. & 58 & 32 & 14 & 8 & 1 & 3 & 5 \\
\hline New Bedford, Mass. & 26 & 23 & 2 & 1 & - & - & 3 & Savannah, Ga. & 36 & 27 & 6 & 2 & 1 & - & 3 \\
\hline New Haven, Conn. & 49 & 31 & 11 & 4 & 1 & 2 & 6 & St. Petersburg, Fla. & 74 & 49 & 16 & 3 & 2 & 4 & 2 \\
\hline Providence, R.I. & U & U & U & $\mathrm{U}$ & U & $\mathrm{U}$ & $U$ & Tampa, Fla. & 208 & 147 & 43 & 13 & 2 & 3 & 10 \\
\hline Somerville, Mass. & $U$ & U & $U$ & $U$ & $U$ & $\mathrm{U}$ & $U$ & Washington, D.C. & 207 & 137 & 40 & 16 & 7 & 6 & 8 \\
\hline Springfield, Mass. & $U$ & $U$ & $U$ & $U$ & $U$ & $U$ & $U$ & Wilmington, Del. & 18 & 15 & 3 & - & - & - & 3 \\
\hline Waterbury, Conn. & 29 & 23 & 4 & 2 & - & - & 2 & E.S. CENTRAL & 879 & 608 & 187 & 51 & 20 & 11 & 88 \\
\hline Worcester, Mass. & 58 & 41 & 11 & 3 & - & 3 & 10 & Birmingham, Ala. & $\begin{array}{l}8 / 9 \\
195\end{array}$ & $\begin{array}{l}008 \\
130\end{array}$ & $\begin{array}{r}181 \\
50\end{array}$ & $\begin{array}{r}51 \\
6\end{array}$ & 4 & 3 & 24 \\
\hline MID. ATLANTIC & 2,368 & 1,676 & 423 & 169 & 51 & 47 & 125 & Chattanooga, Tenn. & 108 & 80 & 19 & 8 & 1 & - & 9 \\
\hline Albany, N.Y. & 56 & 36 & 13 & 5 & - & 2 & 4 & Knoxville, Tenn. & 94 & 70 & 19 & 2 & 2 & 1 & 6 \\
\hline Allentown, $\mathrm{Pa}$. & 25 & 21 & - & 2 & - & 2 & 1 & Lexington, Ky. & 61 & 40 & 17 & 2 & 1 & 1 & 6 \\
\hline Buffalo, N.Y. & $U$ & $\mathrm{U}$ & U & $\mathrm{U}$ & $\mathrm{U}$ & $U$ & $U$ & Memphis, Tenn. & 161 & 101 & 34 & 16 & 6 & 4 & 18 \\
\hline Camden, N.J. & $U$ & $\mathrm{U}$ & $\mathrm{U}$ & U & U & $U$ & $U$ & Mobile, Ala. & 89 & 64 & 18 & 4 & 1 & 2 & 5 \\
\hline Elizabeth, N.J. & 22 & 15 & 3 & 2 & 2 & - & - & Montgomery, Ala. & 44 & 35 & 8 & - & 1 & - & 9 \\
\hline Erie, $\mathrm{Pa}$. & 52 & 35 & 12 & 2 & 1 & 2 & 1 & Nashville, Tenn. & 127 & 88 & 22 & 13 & 4 & - & 11 \\
\hline Jersey City, N.J. & U & U & U & U & $U$ & U & U & WS CENTRAL & 1.042 & 625 & 218 & 80 & 84 & 35 & 67 \\
\hline New York City, N.Y. & 1,301 & 937 & 231 & 96 & 24 & 13 & 58 & $\begin{array}{l}\text { Austin, Tex. } \\
\text { A.S. }\end{array}$ & $\begin{array}{r}1,042 \\
U\end{array}$ & ${ }^{0} \mathrm{U}$ & $\mathrm{U}$ & U & $\stackrel{04}{U}$ & U & U \\
\hline Newark, N.J. & 52 & 27 & 13 & 8 & - & 3 & 2 & $\begin{array}{l}\text { Austin, lex. } \\
\text { Baton Rouge, La. }\end{array}$ & 43 & 36 & 4 & 2 & 1 & - & - \\
\hline Paterson, N.J. & 37 & 24 & 6 & 5 & 2 & - & 3 & $\begin{array}{l}\text { Baton Rouge, La. } \\
\text { Corpus Christi, Tex. }\end{array}$ & $\begin{array}{l}40 \\
51\end{array}$ & 36 & $\begin{array}{r}4 \\
11\end{array}$ & 2 & 1 & 1 & 3 \\
\hline Philadelphia, $\mathrm{Pa}$. & 397 & 239 & 93 & 39 & 16 & 10 & 26 & $\begin{array}{l}\text { Corpus Christi, Iex. } \\
\text { Dallas, Tex. }\end{array}$ & 228 & $\begin{array}{r}30 \\
139\end{array}$ & 58 & $\begin{array}{r}2 \\
14\end{array}$ & 13 & 4 & $\begin{array}{r}3 \\
16\end{array}$ \\
\hline Pittsburgh, $\mathrm{Pa} .^{\S}$ & 43 & 34 & 6 & 1 & - & 2 & 1 & $\begin{array}{l}\text { Dallas, lex. } \\
\text { EIPaso. Tex }\end{array}$ & $\begin{array}{l}228 \\
102\end{array}$ & $\begin{array}{r}139 \\
68\end{array}$ & $\begin{array}{l}58 \\
26\end{array}$ & $\begin{array}{r}14 \\
4\end{array}$ & $\begin{array}{r}13 \\
2\end{array}$ & $\begin{array}{l}4 \\
2\end{array}$ & $\begin{array}{r}16 \\
8\end{array}$ \\
\hline Reading, $\mathrm{Pa}$. & 27 & 22 & 5 & - & - & - & 4 & Et Worth Tex. & $\begin{array}{l}102 \\
138\end{array}$ & $\begin{array}{l}08 \\
92\end{array}$ & $\begin{array}{l}20 \\
31\end{array}$ & $\begin{array}{r}4 \\
10\end{array}$ & $\frac{2}{3}$ & 2 & $\begin{array}{r}8 \\
11\end{array}$ \\
\hline Rochester, N.Y. & 148 & 120 & 19 & 4 & 3 & 2 & 12 & $\begin{array}{l}\text { Ft.Worth, Iex. } \\
\text { Houston Tex }\end{array}$ & $\begin{array}{l}138 \\
270\end{array}$ & $\begin{array}{r}92 \\
123\end{array}$ & 40 & 39 & 50 & $\begin{array}{r}2 \\
18\end{array}$ & $\begin{array}{r}11 \\
9\end{array}$ \\
\hline Schenectady, N.Y. & 28 & 25 & 1 & - & 1 & - & 1 & Houston, lex. & 270 & 120 & 4 & 39 & 50 & 18 & U \\
\hline Scranton, Pa. & 46 & 41 & 3 & 2 & - & - & 3 & Little Rock, Ark. & U & U & U & $U$ & U & U & U \\
\hline Syracuse, N.Y. & 77 & 57 & 10 & 1 & 1 & 8 & 5 & $\begin{array}{l}\text { New Urleans, La. } \\
\text { San Antonio Tex }\end{array}$ & U & U & U & U & U & U & U \\
\hline Trenton, N.J. & 28 & 21 & 3 & 2 & - & 2 & - & San Antonio, lex. & 78 & $\begin{array}{r}0 \\
48\end{array}$ & 19 & 4 & 5 & $\begin{array}{l}0 \\
5\end{array}$ & 12 \\
\hline Utica, N.Y. & $U$ & $\mathrm{U}$ & $U$ & $\mathrm{U}$ & $U$ & $\mathrm{U}$ & $U$ & Shreveport, La. & $\begin{array}{r}78 \\
132\end{array}$ & $\begin{array}{l}48 \\
83\end{array}$ & 19 & $\begin{array}{l}4 \\
5\end{array}$ & $\begin{array}{l}5 \\
9\end{array}$ & 2 & $\begin{array}{r}12 \\
8\end{array}$ \\
\hline Yonkers, N.Y. & 29 & 22 & 5 & - & 1 & 1 & 4 & Tulsa, Okla. & 132 & & 29 & 5 & 9 & 6 & 8 \\
\hline E.N. CENTRAL & 1,722 & 1,182 & 367 & 112 & 27 & 34 & 121 & MOUNTAIN & 786 & 526 & 167 & 54 & 19 & 20 & 52 \\
\hline Akron, Ohio & 57 & 41 & 9 & 5 & - & 2 & 9 & Albuquerque, N.M. & 137 & 92 & 27 & 11 & 4 & 3 & 5 \\
\hline Canton, Ohio & 50 & 35 & 13 & 2 & - & - & 8 & Boise, Idaho & 43 & 28 & 11 & 4 & - & - & 5 \\
\hline Chicago, III. & U & $U$ & U & U & $\mathrm{U}$ & $u$ & U & Colo. Springs, Colo. & 66 & 44 & 17 & 4 & 1 & - & 2 \\
\hline Cincinnati, Ohio & 108 & 73 & 25 & 8 & - & 2 & 12 & Denver, Colo. & 103 & 74 & 18 & 6 & 2 & 3 & 7 \\
\hline Cleveland, Ohio & 143 & 93 & $\begin{array}{l}20 \\
35\end{array}$ & 10 & 3 & 2 & 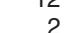 & Las Vegas, Nev. & 264 & 165 & 63 & 21 & $\overline{7}$ & 8 & 19 \\
\hline Columbus, Ohio & 232 & 156 & 49 & 21 & 4 & 2 & 15 & Ogden, Utah & 30 & 23 & 5 & 2 & - & - & 2 \\
\hline Dayton, Ohio & 127 & 96 & 21 & 5 & $\begin{array}{l}4 \\
1\end{array}$ & $\frac{2}{4}$ & $\begin{array}{r}10 \\
6\end{array}$ & Phoenix, Ariz. & U & $U$ & $U$ & $\bar{U}$ & $\mathrm{U}$ & $U$ & $\mathrm{U}$ \\
\hline Detroit, Mich. & 186 & 97 & 66 & 14 & 5 & 4 & $\begin{array}{r}0 \\
16\end{array}$ & Pueblo, Colo. & 34 & 27 & 6 & 1 & - & - & 2 \\
\hline Evansville, Ind. & 53 & 40 & 12 & 1 & - & - & 3 & Salt Lake City, Utah & 109 & 73 & 20 & 5 & 5 & 6 & 10 \\
\hline Fort Wayne, Ind. & 84 & 66 & 10 & 6 & - & 2 & 5 & Tucson, Ariz. & U & $U$ & $U$ & U & U & U & $U$ \\
\hline Gary, Ind. & 21 & 13 & 6 & 1 & 1 & - & 1 & PACIFIC & 1,587 & 1,109 & 312 & 113 & 26 & 26 & 104 \\
\hline Grand Rapids, Mich. & 49 & 31 & 10 & 3 & 1 & 4 & 4 & Berkeley, Calif. & 14 & 12 & 1 & 1 & - & - & 1 \\
\hline Indianapolis, Ind. & 192 & 146 & 30 & 7 & 3 & 6 & 15 & Fresno, Calif. & 132 & 102 & 23 & 5 & 2 & - & 16 \\
\hline Lansing, Mich. & 45 & 28 & 12 & 3 & 1 & 1 & 4 & Glendale, Calif. & 10 & 8 & 2 & - & - & - & 1 \\
\hline Milwaukee, Wis. & 124 & 91 & 20 & 9 & 2 & 2 & 11 & Honolulu, Hawaii & 62 & 50 & 6 & 6 & - & - & 3 \\
\hline Peoria, III. & $U$ & $\mathrm{U}$ & U & $U$ & $\mathrm{U}$ & $U$ & $U$ & Long Beach, Calif. & 78 & 57 & 16 & 2 & 1 & 2 & 8 \\
\hline Rockford, III. & 61 & 42 & 13 & 5 & - & 1 & 2 & Los Angeles, Calif. & 316 & 215 & 67 & 29 & 4 & 1 & 10 \\
\hline South Bend, Ind. & 69 & 53 & 9 & 4 & 3 & - & 3 & Pasadena, Calif. & 33 & 23 & 5 & 4 & - & 1 & 3 \\
\hline Toledo, Ohio & 121 & 81 & 27 & 8 & 3 & 2 & 5 & Portland, Oreg. & 86 & 53 & 23 & 4 & 2 & 4 & 7 \\
\hline Youngstown, Ohio & $U$ & U & $U$ & $U$ & $U$ & $\bar{U}$ & $U$ & Sacramento, Calif. & 192 & 135 & 35 & 12 & 4 & 6 & 10 \\
\hline W.N. CENTRAL & 512 & 366 & & 33 & 12 & 10 & 46 & San Diego, Calif. & 184 & 119 & 32 & 19 & 6 & 7 & 16 \\
\hline Des Moines, lowa & 100 & $\begin{array}{r}500 \\
68\end{array}$ & 25 & 4 & 3 & 10 & 12 & San Francisco, Calif. & U & $U$ & $\bar{U}$ & $U$ & $\mathrm{U}$ & $\mathrm{U}$ & $U$ \\
\hline Duluth, Minn. & 33 & 26 & 7 & $\begin{array}{l}4 \\
-\end{array}$ & - & - & 5 & San Jose, Calif. & 171 & 118 & 33 & 14 & 4 & 2 & 12 \\
\hline Kansas City, Kans. & 30 & 21 & 3 & 5 & 1 & - & $\begin{array}{l}5 \\
2\end{array}$ & Santa Cruz, Calif. & 27 & 22 & 5 & - & - & - & - \\
\hline Kansas City, Mo. & 94 & 69 & 16 & 6 & 2 & 1 & 6 & Seattle, Wash. & 133 & 92 & 30 & 8 & 2 & 1 & 6 \\
\hline Lincoln, Nebr. & 35 & 28 & 4 & 2 & - & 1 & - & Spokane, Wash. & 56 & 39 & 14 & 3 & - & - & 5 \\
\hline Minneapolis, Minn. & 81 & 58 & 11 & 2 & 4 & 6 & 5 & Tacoma, Wash. & 93 & 64 & 20 & 6 & 1 & 2 & 6 \\
\hline Omaha, Nebr. & $U$ & $U$ & $\mathrm{U}$ & $\bar{U}$ & U & $\mathrm{U}$ & $\mathrm{U}$ & TOTAL & $10,775^{\Uparrow}$ & 7,338 & 2,157 & 779 & 279 & 216 & 748 \\
\hline St. Louis, Mo. & $U$ & $U$ & $U$ & U & U & $U$ & $U$ & & & & & & & & \\
\hline St. Paul, Minn. & 61 & 45 & 10 & 5 & 1 & - & 6 & & & & & & & & \\
\hline Wichita, Kans. & 78 & 51 & 15 & 9 & 1 & 2 & 10 & & & & & & & & \\
\hline
\end{tabular}

\section{U: Unavailable. -:No reported cases.}

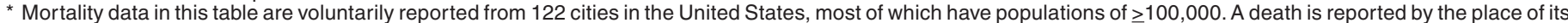
occurrence and by the week that the death certificate was filed. Fetal deaths are not included.

t Pneumonia and influenza.

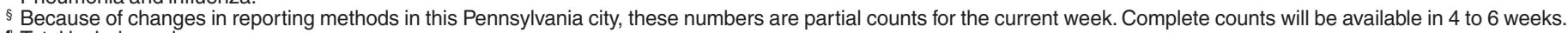

ๆ Total includes unknown ages. 
FIGURE I. Selected notifiable disease reports, United States, comparison of provisional 4-week totals ending December 28, 2002, with historical data

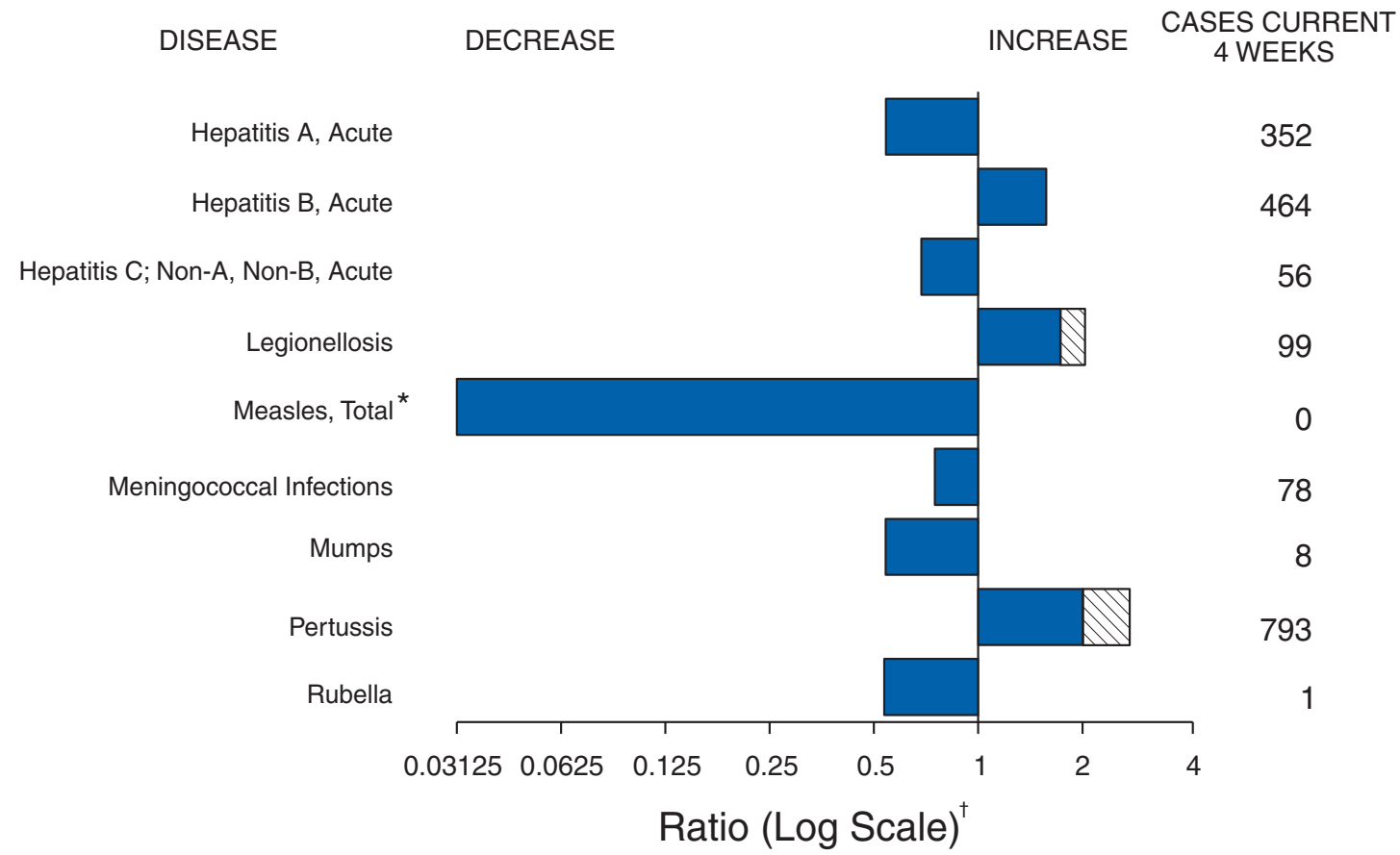

* No measles cases were reported for the current 4-week period yielding a ratio for week 52 of zero (0).

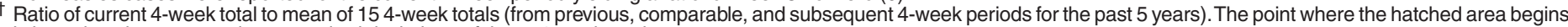
is based on the mean and two standard deviations of these 4-week totals.

TABLE I. Summary of provisional cases of selected notifiable diseases, United States, cumulative, week ending December 28,2002 (52nd Week)

Anthrax

Botulism:

foodborne

infant

other (wound \& unspecified)

Brucellosis ${ }^{\dagger}$

Chancroid

Cholera

Cyclosporiasis $^{\dagger}$

Diphtheria

Ehrlichiosis: human granulocytic (HGE) ${ }^{\dagger}$ human monocytic (HME) ${ }^{\dagger}$

other and unspecified

Encephalitis: California serogroup viral ${ }^{\dagger}$ eastern equine ${ }^{\dagger}$

Powassan ${ }^{\dagger}$

St. Louis ${ }^{\dagger}$ western equine ${ }^{\dagger}$

\begin{tabular}{|c|c|}
\hline Cum. & Cum. \\
$\mathbf{2 0 0 2}$ & $\mathbf{2 0 0 1}$ \\
\hline 2 & 22 \\
14 & 39 \\
55 & 97 \\
28 & 20 \\
84 & 136 \\
67 & 38 \\
5 & 6 \\
158 & 147 \\
1 & 2 \\
381 & 278 \\
167 & 142 \\
14 & 6 \\
136 & 128 \\
7 & 9 \\
1 & 2 \\
13 & 79 \\
3 & - \\
\hline
\end{tabular}

Encephalitis: $\quad$ West Nile ${ }^{\dagger}$

Hansen disease (leprosy) ${ }^{\dagger}$

Hantavirus pulmonary syndrome ${ }^{\dagger}$

Hemolytic uremic syndrome, postdiarrheal ${ }^{\dagger}$

HIV infection, pediatric ${ }^{\dagger \S}$

Plague

Poliomyelitis, paralytic

Psittacosis ${ }^{\dagger}$

Q fever ${ }^{\dagger}$

Rabies, human

Streptococcal toxic-shock syndrome

Tetanus

Toxic-shock syndrome

Trichinosis

Tularemia ${ }^{\dagger}$

Yellow fever

\begin{tabular}{|c|r|}
\hline Cum. & Cum. \\
$\mathbf{2 0 0 2}$ & $\mathbf{2 0 0 1}$ \\
\hline 1,860 & 63 \\
77 & 79 \\
15 & 8 \\
186 & 206 \\
163 & 212 \\
1 & 2 \\
- & - \\
18 & 25 \\
49 & 27 \\
2 & 1 \\
88 & 78 \\
22 & 37 \\
111 & 128 \\
13 & 22 \\
59 & 131 \\
1 & - \\
& \\
\hline
\end{tabular}

-:No reported cases.

* Incidence data for reporting year 2001 and 2002 are provisional and cumulative (year-to-date).

${ }^{\dagger}$ Not notifiable in all states.

$\S$ Updated monthly from reports to the Division of HIV/AIDS Prevention — Surveillance and Epidemiology, National Center for HIV, STD, and TB Prevention (NCHSTP). Last update November 24, 2002. 
TABLE II. Provisional cases of selected notifiable diseases, United States, weeks ending December 28, 2002, and December 29, 2001 (52nd Week)*

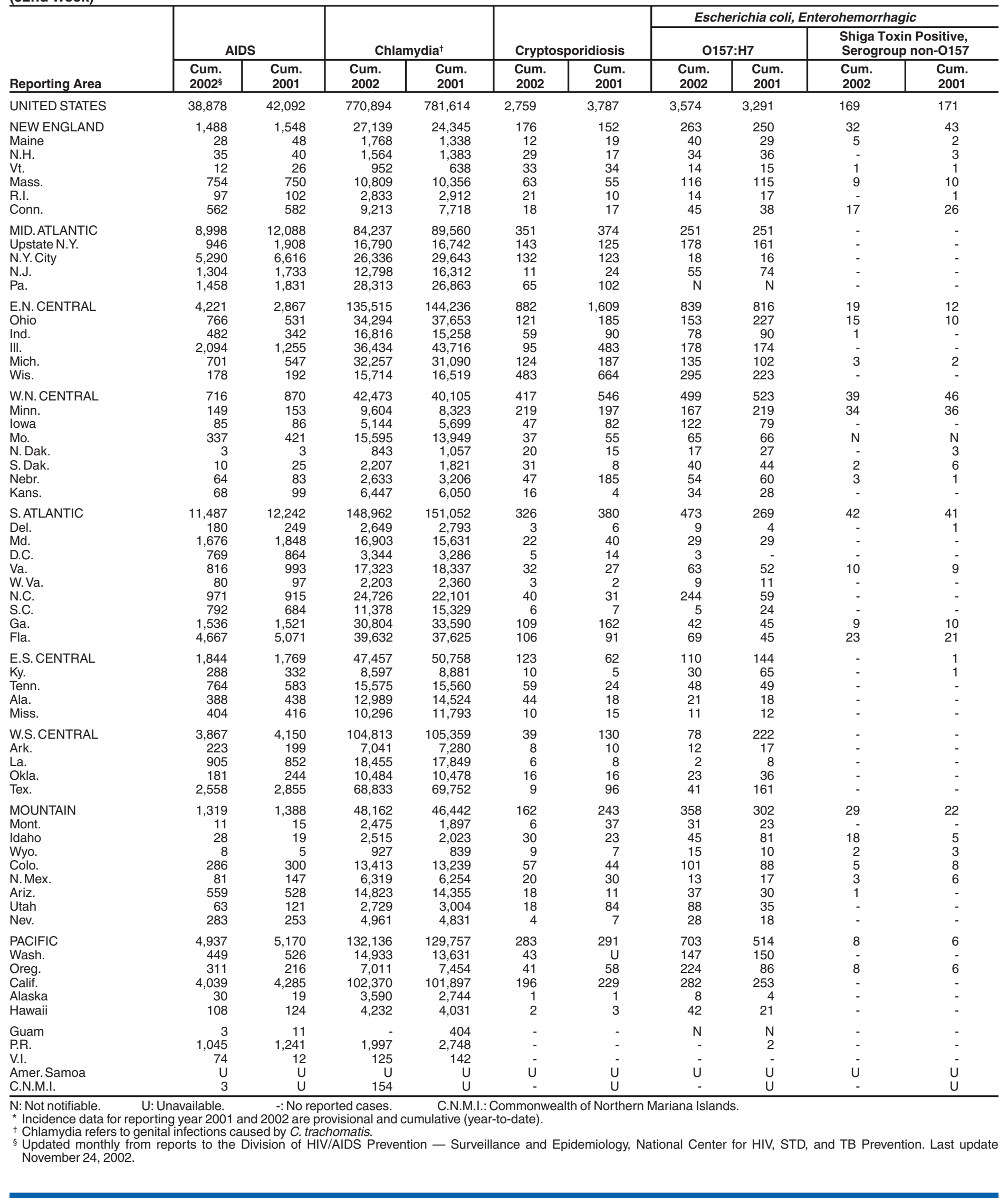


TABLE II. (Continued) Provisional cases of selected notifiable diseases, United States, weeks ending December 28, 2002, and December 29, 2001 (52nd Week)*

\begin{tabular}{|c|c|c|c|c|c|c|c|c|c|}
\hline \multirow[b]{4}{*}{ Reporting Area } & \multirow{2}{*}{\multicolumn{2}{|c|}{$\begin{array}{c}\text { Escherichia coli } \\
\text { Enterohemorrhagic }\end{array}$}} & \multirow[b]{3}{*}{ Giardiasis } & \multirow{3}{*}{\multicolumn{2}{|c|}{ Gonorrhea }} & \multicolumn{4}{|c|}{$\begin{array}{c}\text { Haemophilus influenzae, } \\
\text { Invasive }\end{array}$} \\
\hline & & & & & & \multirow{2}{*}{\multicolumn{2}{|c|}{$\begin{array}{l}\text { All Ages, } \\
\text { All Serotypes }\end{array}$}} & \multirow{2}{*}{\multicolumn{2}{|c|}{$\begin{array}{c}\text { Age }<5 \text { Years } \\
\text { Serotype } \\
\text { B }\end{array}$}} \\
\hline & \multicolumn{2}{|c|}{$\begin{array}{c}\text { Shiga Toxin Positive, } \\
\text { Not Serogrouped }\end{array}$} & & & & & & & \\
\hline & $\begin{array}{l}\text { Cum. } \\
2002\end{array}$ & $\begin{array}{l}\text { Cum. } \\
2001\end{array}$ & $\begin{array}{l}\text { Cum. } \\
2002\end{array}$ & $\begin{array}{l}\text { Cum. } \\
2002\end{array}$ & $\begin{array}{l}\text { Cum. } \\
2001\end{array}$ & $\begin{array}{l}\text { Cum. } \\
2002 \\
\end{array}$ & $\begin{array}{l}\text { Cum. } \\
2001\end{array}$ & $\begin{array}{l}\text { Cum. } \\
2002\end{array}$ & $\begin{array}{l}\text { Cum. } \\
2001\end{array}$ \\
\hline UNITED STATES & 41 & 20 & 16,986 & 326,017 & 360,906 & 1,479 & 1,597 & 27 & 27 \\
\hline $\begin{array}{l}\text { NEW ENGLAND } \\
\text { Maine } \\
\text { N.H. } \\
\text { Vt. } \\
\text { Mass. } \\
\text { R.I. } \\
\text { Conn. }\end{array}$ & $\begin{array}{l}1 \\
- \\
- \\
1 \\
- \\
- \\
-\end{array}$ & $\begin{array}{l}1 \\
- \\
- \\
1 \\
- \\
- \\
-\end{array}$ & $\begin{array}{r}1,650 \\
216 \\
43 \\
145 \\
830 \\
156 \\
260\end{array}$ & $\begin{array}{r}7,540 \\
141 \\
122 \\
98 \\
3,217 \\
926 \\
3,036\end{array}$ & $\begin{array}{r}6,976 \\
141 \\
176 \\
76 \\
3,207 \\
830 \\
2,546\end{array}$ & $\begin{array}{r}126 \\
2 \\
11 \\
7 \\
50 \\
10 \\
46\end{array}$ & $\begin{array}{r}121 \\
2 \\
7 \\
5 \\
43 \\
10 \\
54\end{array}$ & $\begin{array}{l}- \\
- \\
- \\
- \\
- \\
- \\
-\end{array}$ & $\begin{array}{l}1 \\
- \\
- \\
- \\
1 \\
- \\
-\end{array}$ \\
\hline $\begin{array}{l}\text { MID. ATLANTIC } \\
\text { Upstate N.Y. } \\
\text { N.Y. City } \\
\text { N.J. } \\
\text { Pa. }\end{array}$ & $\begin{array}{l}1 \\
- \\
- \\
- \\
1\end{array}$ & $\begin{array}{l}3 \\
- \\
- \\
- \\
3\end{array}$ & $\begin{array}{r}3,715 \\
1,244 \\
1,329 \\
385 \\
757\end{array}$ & $\begin{array}{r}39,276 \\
8,613 \\
10,944 \\
7,814 \\
11,905\end{array}$ & $\begin{array}{r}44,754 \\
9,685 \\
12,613 \\
8,921 \\
13,535\end{array}$ & $\begin{array}{r}261 \\
120 \\
63 \\
48 \\
30\end{array}$ & $\begin{array}{r}248 \\
98 \\
59 \\
48 \\
43\end{array}$ & $\begin{array}{l}6 \\
2 \\
- \\
- \\
4\end{array}$ & $\begin{array}{l}3 \\
- \\
- \\
- \\
3\end{array}$ \\
\hline $\begin{array}{l}\text { E.N. CENTRAL } \\
\text { Ohio } \\
\text { Ind. } \\
\text { III. } \\
\text { Mich. } \\
\text { Wis. }\end{array}$ & $\begin{array}{r}13 \\
12 \\
- \\
- \\
1 \\
-\end{array}$ & $\begin{array}{l}7 \\
7 \\
- \\
- \\
- \\
-\end{array}$ & $\begin{array}{r}3,263 \\
975 \\
- \\
766 \\
910 \\
612\end{array}$ & $\begin{array}{r}66,503 \\
19,363 \\
7,268 \\
19,285 \\
14,730 \\
5,857\end{array}$ & $\begin{array}{r}75,374 \\
21,163 \\
6,972 \\
24,025 \\
17,120 \\
6,094\end{array}$ & $\begin{array}{r}211 \\
85 \\
42 \\
58 \\
18 \\
8\end{array}$ & $\begin{array}{r}285 \\
74 \\
59 \\
103 \\
14 \\
35\end{array}$ & $\begin{array}{l}4 \\
- \\
2 \\
- \\
2 \\
-\end{array}$ & $\begin{array}{l}2 \\
1 \\
- \\
- \\
- \\
1\end{array}$ \\
\hline $\begin{array}{l}\text { W.N. CENTRAL } \\
\text { Minn. } \\
\text { lowa } \\
\text { Mo. } \\
\text { N. Dak. } \\
\text { S. Dak. } \\
\text { Nebr. } \\
\text { Kans. }\end{array}$ & $\begin{array}{l}7 \\
- \\
- \\
N \\
2 \\
- \\
- \\
5\end{array}$ & $\begin{array}{l}4 \\
- \\
- \\
N \\
4 \\
- \\
- \\
-\end{array}$ & $\begin{array}{r}2,042 \\
826 \\
310 \\
491 \\
28 \\
73 \\
133 \\
181\end{array}$ & $\begin{array}{r}16,517 \\
2,926 \\
1,229 \\
8,721 \\
52 \\
264 \\
723 \\
2,602\end{array}$ & $\begin{array}{r}17,045 \\
2,701 \\
1,418 \\
8,723 \\
56 \\
289 \\
1,189 \\
2,669\end{array}$ & $\begin{array}{r}70 \\
48 \\
1 \\
12 \\
- \\
- \\
1 \\
8\end{array}$ & $\begin{array}{r}89 \\
56 \\
- \\
20 \\
8 \\
- \\
3 \\
2\end{array}$ & $\begin{array}{l}1 \\
1 \\
- \\
- \\
- \\
- \\
- \\
-\end{array}$ & $\begin{array}{l}1 \\
- \\
- \\
- \\
- \\
- \\
1 \\
-\end{array}$ \\
\hline $\begin{array}{l}\text { S. ATLANTIC } \\
\text { Del. } \\
\text { Md. } \\
\text { D.C. } \\
\text { Va. } \\
\text { W.Va. } \\
\text { N.C. } \\
\text { S.C. } \\
\text { Ga. } \\
\text { Fla. }\end{array}$ & $\begin{array}{l}1 \\
- \\
- \\
- \\
- \\
1 \\
- \\
- \\
- \\
-\end{array}$ & $\begin{array}{l}- \\
- \\
- \\
- \\
- \\
- \\
- \\
- \\
- \\
-\end{array}$ & $\begin{array}{r}2,832 \\
51 \\
117 \\
45 \\
344 \\
59 \\
- \\
129 \\
768 \\
1,319\end{array}$ & $\begin{array}{r}83,749 \\
1,576 \\
9,234 \\
2,720 \\
9,774 \\
875 \\
15,531 \\
6,918 \\
16,880 \\
20,241\end{array}$ & $\begin{array}{r}93,530 \\
1,733 \\
9,399 \\
2,883 \\
11,095 \\
729 \\
16,583 \\
10,805 \\
18,772 \\
21,531\end{array}$ & $\begin{array}{r}359 \\
- \\
93 \\
- \\
32 \\
16 \\
33 \\
14 \\
76 \\
95\end{array}$ & $\begin{array}{r}394 \\
- \\
92 \\
- \\
34 \\
16 \\
50 \\
8 \\
109 \\
85\end{array}$ & $\begin{array}{l}4 \\
- \\
2 \\
- \\
- \\
- \\
- \\
- \\
- \\
2\end{array}$ & $\begin{array}{l}1 \\
- \\
- \\
- \\
- \\
1 \\
- \\
- \\
- \\
-\end{array}$ \\
\hline $\begin{array}{l}\text { E.S. CENTRAL } \\
\text { Ky. } \\
\text { Tenn. } \\
\text { Ala. } \\
\text { Miss. }\end{array}$ & $\begin{array}{l}8 \\
8 \\
- \\
- \\
-\end{array}$ & $\begin{array}{l}3 \\
3 \\
- \\
- \\
-\end{array}$ & $\begin{array}{r}379 \\
- \\
176 \\
203 \\
-\end{array}$ & $\begin{array}{r}27,295 \\
3,716 \\
9,069 \\
8,496 \\
6,014\end{array}$ & $\begin{array}{r}32,674 \\
3,588 \\
10,145 \\
11,182 \\
7,759\end{array}$ & $\begin{array}{r}66 \\
7 \\
34 \\
16 \\
9\end{array}$ & $\begin{array}{r}84 \\
2 \\
51 \\
29 \\
2\end{array}$ & $\begin{array}{l}1 \\
- \\
- \\
1 \\
-\end{array}$ & $\begin{array}{l}1 \\
- \\
1 \\
- \\
-\end{array}$ \\
\hline $\begin{array}{l}\text { W.S. CENTRAL } \\
\text { Ark. } \\
\text { La. } \\
\text { Okla. } \\
\text { Tex. }\end{array}$ & $\begin{array}{l}4 \\
- \\
- \\
- \\
4\end{array}$ & $\begin{array}{l}- \\
- \\
- \\
- \\
-\end{array}$ & $\begin{array}{r}246 \\
169 \\
5 \\
72 \\
-\end{array}$ & $\begin{array}{r}46,918 \\
4,412 \\
11,399 \\
4,519 \\
26,588\end{array}$ & $\begin{array}{r}51,689 \\
4,604 \\
12,277 \\
4,784 \\
30,024\end{array}$ & $\begin{array}{r}61 \\
1 \\
11 \\
45 \\
4\end{array}$ & $\begin{array}{r}64 \\
3 \\
10 \\
48 \\
3\end{array}$ & $\begin{array}{l}2 \\
- \\
- \\
- \\
2\end{array}$ & $\begin{array}{l}3 \\
- \\
1 \\
- \\
2\end{array}$ \\
\hline $\begin{array}{l}\text { MOUNTAIN } \\
\text { Mont. } \\
\text { Idaho } \\
\text { Wyo. } \\
\text { Colo. } \\
\text { N. Mex. } \\
\text { Ariz. } \\
\text { Utah } \\
\text { Nev. }\end{array}$ & $\begin{array}{l}6 \\
- \\
- \\
- \\
6 \\
- \\
- \\
- \\
-\end{array}$ & $\begin{array}{l}2 \\
- \\
- \\
- \\
2 \\
- \\
- \\
- \\
-\end{array}$ & $\begin{array}{r}1,714 \\
94 \\
137 \\
29 \\
572 \\
136 \\
256 \\
333 \\
157\end{array}$ & $\begin{array}{r}10,637 \\
124 \\
95 \\
63 \\
3,344 \\
1,322 \\
3,761 \\
287 \\
1,641\end{array}$ & $\begin{array}{r}10,385 \\
104 \\
76 \\
77 \\
3,190 \\
1,040 \\
3,923 \\
219 \\
1,756\end{array}$ & $\begin{array}{r}194 \\
- \\
2 \\
1 \\
34 \\
27 \\
99 \\
19 \\
12\end{array}$ & $\begin{array}{r}175 \\
1 \\
2 \\
1 \\
38 \\
29 \\
82 \\
10 \\
12\end{array}$ & $\begin{array}{l}6 \\
- \\
- \\
- \\
- \\
- \\
4 \\
1 \\
1\end{array}$ & $\begin{array}{r}10 \\
- \\
- \\
- \\
- \\
2 \\
5 \\
1 \\
2\end{array}$ \\
\hline $\begin{array}{l}\text { PACIFIC } \\
\text { Wash. } \\
\text { Oreg. } \\
\text { Calif. } \\
\text { Alaska } \\
\text { Hawaii }\end{array}$ & $\begin{array}{l}- \\
- \\
- \\
- \\
-\end{array}$ & $\begin{array}{l}- \\
- \\
- \\
- \\
- \\
-\end{array}$ & $\begin{array}{r}1,145 \\
419 \\
451 \\
81 \\
106 \\
88\end{array}$ & $\begin{array}{r}27,582 \\
2,921 \\
908 \\
22,449 \\
593 \\
711\end{array}$ & $\begin{array}{r}28,479 \\
2,991 \\
1,144 \\
23,283 \\
457 \\
604\end{array}$ & $\begin{array}{r}131 \\
4 \\
64 \\
25 \\
2 \\
36\end{array}$ & $\begin{array}{r}137 \\
9 \\
39 \\
60 \\
6 \\
23\end{array}$ & $\begin{array}{l}3 \\
2 \\
- \\
1 \\
- \\
-\end{array}$ & $\begin{array}{l}5 \\
1 \\
- \\
4 \\
- \\
-\end{array}$ \\
\hline $\begin{array}{l}\text { Guam } \\
\text { P.R. } \\
\text { V.I. } \\
\text { Amer. Samoa } \\
\text { C.N.M.I. }\end{array}$ & $\begin{array}{l}- \\
- \\
\bar{U} \\
-\end{array}$ & $\begin{array}{l}- \\
- \\
\\
U\end{array}$ & $\begin{array}{r}38 \\
- \\
\\
1\end{array}$ & $\begin{array}{r}292 \\
31 \\
U \\
14\end{array}$ & $\begin{array}{r}48 \\
588 \\
35 \\
U \\
U\end{array}$ & $\begin{array}{l}\overline{1} \\
- \\
\\
-\end{array}$ & $\begin{array}{l}- \\
2 \\
- \\
U \\
U\end{array}$ & $\begin{array}{l}- \\
- \\
\\
-\end{array}$ & $\begin{array}{l}- \\
- \\
\\
U\end{array}$ \\
\hline
\end{tabular}

$\mathrm{N}$ : Not notifiable.

* Incidence data for reporting year 2001 and 2002 are provisional and cumulative (year-to-date). 
TABLE II. (Continued) Provisional cases of selected notifiable diseases, United States, weeks ending December 28, 2002, and December 29, 2001 (52nd Week)*

\begin{tabular}{|c|c|c|c|c|c|c|c|c|c|c|}
\hline \multirow[b]{4}{*}{ Reporting Area } & \multicolumn{4}{|c|}{ Haemophilus influenzae, Invasive } & \multirow{2}{*}{\multicolumn{6}{|c|}{ Hepatitis (Viral, Acute), By Type }} \\
\hline & \multicolumn{4}{|c|}{ Age $<5$ Years } & & & & & & \\
\hline & Non & pe B & Unknol & otype & \multicolumn{2}{|c|}{$\mathbf{A}$} & \multicolumn{2}{|c|}{ B } & \multicolumn{2}{|c|}{ C; Non-A, Non-B } \\
\hline & $\begin{array}{l}\text { Cum. } \\
2002\end{array}$ & $\begin{array}{l}\text { Cum. } \\
2001\end{array}$ & $\begin{array}{l}\text { Cum. } \\
2002\end{array}$ & $\begin{array}{l}\text { Cum. } \\
2001\end{array}$ & $\begin{array}{l}\text { Cum. } \\
2002\end{array}$ & $\begin{array}{l}\text { Cum. } \\
2001\end{array}$ & $\begin{array}{l}\text { Cum. } \\
2002\end{array}$ & $\begin{array}{l}\text { Cum. } \\
2001\end{array}$ & $\begin{array}{l}\text { Cum. } \\
2002\end{array}$ & $\begin{array}{l}\text { Cum. } \\
2001\end{array}$ \\
\hline UNITED STATES & 237 & 267 & 18 & 31 & 8,085 & 10,614 & 6,785 & 7,844 & 3,585 & 3,977 \\
\hline $\begin{array}{l}\text { NEW ENGLAND } \\
\text { Maine } \\
\text { N.H. } \\
\text { Vt. } \\
\text { Mass. } \\
\text { R.I. } \\
\text { Conn. }\end{array}$ & $\begin{array}{r}14 \\
- \\
- \\
- \\
7 \\
- \\
7\end{array}$ & $\begin{array}{r}18 \\
- \\
1 \\
- \\
7 \\
1 \\
9\end{array}$ & $\begin{array}{l}- \\
- \\
- \\
- \\
- \\
- \\
-\end{array}$ & $\begin{array}{l}- \\
- \\
- \\
- \\
-\end{array}$ & $\begin{array}{r}284 \\
8 \\
11 \\
3 \\
138 \\
32 \\
92\end{array}$ & $\begin{array}{r}736 \\
11 \\
18 \\
16 \\
376 \\
75 \\
240\end{array}$ & $\begin{array}{r}278 \\
15 \\
22 \\
5 \\
139 \\
30 \\
67\end{array}$ & $\begin{array}{r}149 \\
7 \\
16 \\
5 \\
41 \\
33 \\
47\end{array}$ & $\begin{array}{r}23 \\
- \\
- \\
13 \\
9 \\
1 \\
-\end{array}$ & $\begin{array}{r}34 \\
1 \\
- \\
7 \\
26 \\
- \\
-\end{array}$ \\
\hline $\begin{array}{l}\text { MID. ATLANTIC } \\
\text { Upstate N.Y. } \\
\text { N.Y. City } \\
\text { N.J. } \\
\text { Pa. }\end{array}$ & $\begin{array}{r}29 \\
13 \\
8 \\
5 \\
3\end{array}$ & $\begin{array}{r}39 \\
11 \\
13 \\
6 \\
9\end{array}$ & $\begin{array}{l}1 \\
- \\
- \\
- \\
1\end{array}$ & $\begin{array}{l}4 \\
2 \\
- \\
- \\
2\end{array}$ & $\begin{array}{r}1,071 \\
180 \\
524 \\
161 \\
206\end{array}$ & $\begin{array}{r}1,370 \\
333 \\
447 \\
283 \\
307\end{array}$ & $\begin{array}{r}1,609 \\
141 \\
839 \\
394 \\
235\end{array}$ & $\begin{array}{r}1,426 \\
153 \\
660 \\
286 \\
327\end{array}$ & $\begin{array}{r}1,970 \\
69 \\
- \\
1,865 \\
36\end{array}$ & $\begin{array}{r}1,397 \\
36 \\
- \\
1,218 \\
143\end{array}$ \\
\hline $\begin{array}{l}\text { E.N. CENTRAL } \\
\text { Ohio } \\
\text { Ind. } \\
\text { Ill. } \\
\text { Mich. } \\
\text { Wis. }\end{array}$ & $\begin{array}{r}37 \\
10 \\
8 \\
12 \\
5 \\
2\end{array}$ & $\begin{array}{r}40 \\
13 \\
7 \\
14 \\
- \\
6\end{array}$ & $\begin{array}{l}1 \\
1 \\
- \\
- \\
- \\
-\end{array}$ & $\begin{array}{l}2 \\
- \\
1 \\
- \\
1 \\
-\end{array}$ & $\begin{array}{r}1,050 \\
327 \\
47 \\
274 \\
224 \\
178\end{array}$ & $\begin{array}{r}1,217 \\
261 \\
102 \\
441 \\
326 \\
87\end{array}$ & $\begin{array}{r}717 \\
123 \\
59 \\
167 \\
325 \\
43\end{array}$ & $\begin{array}{r}1,049 \\
92 \\
75 \\
218 \\
618 \\
46\end{array}$ & $\begin{array}{r}108 \\
4 \\
- \\
14 \\
86 \\
4\end{array}$ & $\begin{array}{r}162 \\
9 \\
1 \\
12 \\
140\end{array}$ \\
\hline $\begin{array}{l}\text { W.N. CENTRAL } \\
\text { Minn. } \\
\text { lowa } \\
\text { Mo. } \\
\text { N. Dak. } \\
\text { S. Dak. } \\
\text { Nebr. } \\
\text { Kans. }\end{array}$ & $\begin{array}{l}7 \\
6 \\
- \\
- \\
- \\
- \\
1 \\
-\end{array}$ & $\begin{array}{l}6 \\
4 \\
- \\
- \\
1 \\
- \\
1 \\
-\end{array}$ & $\begin{array}{l}3 \\
1 \\
- \\
2 \\
- \\
- \\
- \\
-\end{array}$ & $\begin{array}{l}7 \\
3 \\
- \\
4 \\
- \\
- \\
- \\
-\end{array}$ & $\begin{array}{r}302 \\
47 \\
80 \\
82 \\
3 \\
3 \\
17 \\
70\end{array}$ & $\begin{array}{r}395 \\
47 \\
36 \\
88 \\
3 \\
3 \\
37 \\
181\end{array}$ & $\begin{array}{r}223 \\
39 \\
20 \\
113 \\
5 \\
2 \\
22 \\
22\end{array}$ & $\begin{array}{r}250 \\
44 \\
24 \\
130 \\
2 \\
1 \\
35 \\
14\end{array}$ & $\begin{array}{r}677 \\
1 \\
1 \\
656 \\
- \\
1 \\
13 \\
5\end{array}$ & $\begin{array}{r}1,170 \\
33 \\
- \\
1,119 \\
- \\
- \\
10 \\
8\end{array}$ \\
\hline $\begin{array}{l}\text { S. ATLANTIC } \\
\text { Del. } \\
\text { Md. } \\
\text { D.C. } \\
\text { Va. } \\
\text { W.Va. } \\
\text { N.C. } \\
\text { S.C. } \\
\text { Ga. } \\
\text { Fla. }\end{array}$ & $\begin{array}{r}44 \\
- \\
4 \\
- \\
5 \\
1 \\
3 \\
2 \\
13 \\
16\end{array}$ & $\begin{array}{r}57 \\
- \\
9 \\
- \\
8 \\
1 \\
2 \\
1 \\
24 \\
12\end{array}$ & $\begin{array}{l}2 \\
- \\
- \\
- \\
- \\
1 \\
- \\
- \\
- \\
1\end{array}$ & $\begin{array}{l}7 \\
- \\
2 \\
- \\
- \\
1 \\
4 \\
- \\
- \\
-\end{array}$ & $\begin{array}{r}2,331 \\
13 \\
298 \\
80 \\
152 \\
23 \\
209 \\
65 \\
420 \\
1,071\end{array}$ & $\begin{array}{r}2,693 \\
16 \\
296 \\
80 \\
167 \\
29 \\
242 \\
85 \\
930 \\
848\end{array}$ & $\begin{array}{r}1,553 \\
7 \\
123 \\
21 \\
193 \\
18 \\
228 \\
121 \\
297 \\
545\end{array}$ & $\begin{array}{r}1,667 \\
29 \\
141 \\
13 \\
213 \\
35 \\
221 \\
72 \\
435 \\
508\end{array}$ & $\begin{array}{r}234 \\
6 \\
8 \\
- \\
16 \\
3 \\
29 \\
4 \\
70 \\
98\end{array}$ & $\begin{array}{r}144 \\
11 \\
9 \\
- \\
3 \\
26 \\
22 \\
13 \\
- \\
60\end{array}$ \\
\hline $\begin{array}{l}\text { E.S. CENTRAL } \\
\text { Ky. } \\
\text { Tenn. } \\
\text { Ala. } \\
\text { Miss. }\end{array}$ & $\begin{array}{r}15 \\
2 \\
8 \\
3 \\
2\end{array}$ & $\begin{array}{r}14 \\
- \\
8 \\
5 \\
1\end{array}$ & $\begin{array}{l}1 \\
- \\
- \\
1 \\
-\end{array}$ & $\begin{array}{l}4 \\
1 \\
2 \\
1 \\
-\end{array}$ & $\begin{array}{r}256 \\
43 \\
117 \\
39 \\
57\end{array}$ & $\begin{array}{r}454 \\
145 \\
190 \\
81 \\
38\end{array}$ & $\begin{array}{r}370 \\
51 \\
133 \\
106 \\
80\end{array}$ & $\begin{array}{r}520 \\
64 \\
275 \\
88 \\
93\end{array}$ & $\begin{array}{r}193 \\
4 \\
34 \\
11 \\
144\end{array}$ & $\begin{array}{r}198 \\
13 \\
70 \\
5 \\
110\end{array}$ \\
\hline $\begin{array}{l}\text { W.S. CENTRAL } \\
\text { Ark. } \\
\text { La. } \\
\text { Okla. } \\
\text { Tex. }\end{array}$ & $\begin{array}{r}14 \\
- \\
2 \\
10 \\
2\end{array}$ & $\begin{array}{r}10 \\
1 \\
2 \\
7 \\
-\end{array}$ & $\begin{array}{l}1 \\
- \\
1 \\
- \\
-\end{array}$ & $\begin{array}{l}- \\
- \\
- \\
-\end{array}$ & $\begin{array}{r}570 \\
65 \\
71 \\
49 \\
385\end{array}$ & $\begin{array}{r}825 \\
74 \\
87 \\
116 \\
548\end{array}$ & $\begin{array}{r}594 \\
92 \\
102 \\
50 \\
350\end{array}$ & $\begin{array}{r}1,061 \\
107 \\
124 \\
116 \\
714\end{array}$ & $\begin{array}{r}210 \\
9 \\
71 \\
5 \\
125\end{array}$ & $\begin{array}{r}671 \\
15 \\
151 \\
6 \\
499\end{array}$ \\
\hline $\begin{array}{l}\text { MOUNTAIN } \\
\text { Mont. } \\
\text { Idaho } \\
\text { Wyo. } \\
\text { Colo. } \\
\text { N. Mex. } \\
\text { Ariz. } \\
\text { Utah } \\
\text { Nev. }\end{array}$ & $\begin{array}{r}50 \\
- \\
1 \\
- \\
3 \\
6 \\
31 \\
5 \\
4\end{array}$ & $\begin{array}{r}36 \\
- \\
- \\
- \\
3 \\
12 \\
18 \\
3 \\
-\end{array}$ & $\begin{array}{l}8 \\
- \\
- \\
- \\
- \\
1 \\
6 \\
- \\
1\end{array}$ & $\begin{array}{l}1 \\
- \\
- \\
- \\
- \\
1 \\
- \\
-\end{array}$ & $\begin{array}{r}581 \\
13 \\
31 \\
3 \\
75 \\
29 \\
315 \\
65 \\
50\end{array}$ & $\begin{array}{r}754 \\
16 \\
57 \\
7 \\
89 \\
40 \\
409 \\
66 \\
70\end{array}$ & $\begin{array}{r}649 \\
10 \\
7 \\
17 \\
77 \\
144 \\
262 \\
64 \\
68\end{array}$ & $\begin{array}{r}497 \\
3 \\
11 \\
3 \\
103 \\
136 \\
164 \\
25 \\
52\end{array}$ & $\begin{array}{r}64 \\
1 \\
1 \\
5 \\
15 \\
1 \\
7 \\
4 \\
30\end{array}$ & $\begin{array}{r}58 \\
1 \\
2 \\
8 \\
11 \\
12 \\
9 \\
3 \\
12\end{array}$ \\
\hline $\begin{array}{l}\text { PACIFIC } \\
\text { Wash. } \\
\text { Oreg. } \\
\text { Calif. } \\
\text { Alaska } \\
\text { Hawaii }\end{array}$ & $\begin{array}{r}27 \\
2 \\
5 \\
15 \\
2 \\
3\end{array}$ & $\begin{array}{r}47 \\
4 \\
7 \\
34 \\
1 \\
1\end{array}$ & $\begin{array}{l}1 \\
- \\
- \\
1 \\
- \\
-\end{array}$ & $\begin{array}{l}6 \\
2 \\
- \\
2 \\
- \\
2\end{array}$ & $\begin{array}{r}1,640 \\
145 \\
70 \\
1,411 \\
12 \\
2\end{array}$ & $\begin{array}{r}2,170 \\
184 \\
105 \\
1,848 \\
16 \\
17\end{array}$ & $\begin{array}{r}792 \\
69 \\
122 \\
584 \\
6 \\
11\end{array}$ & $\begin{array}{r}1,225 \\
171 \\
168 \\
854 \\
10 \\
22\end{array}$ & $\begin{array}{r}106 \\
25 \\
17 \\
64 \\
- \\
-\end{array}$ & $\begin{array}{r}143 \\
31 \\
15 \\
97 \\
- \\
-\end{array}$ \\
\hline $\begin{array}{l}\text { Guam } \\
\text { P.R. } \\
\text { V.I. } \\
\text { Amer.Samoa } \\
\text { C.N.M.I. }\end{array}$ & $\begin{array}{l}- \\
- \\
\\
-\end{array}$ & $\begin{array}{l}\overline{1} \\
\bar{U} \\
\end{array}$ & $\begin{array}{l}- \\
- \\
\end{array}$ & $\begin{array}{l}- \\
- \\
\\
U\end{array}$ & $\begin{array}{r}96 \\
\bar{U}\end{array}$ & $\begin{array}{r}2 \\
258 \\
- \\
U \\
U\end{array}$ & $\begin{array}{r}84 \\
\bar{U} \\
37\end{array}$ & $\begin{array}{r}- \\
297 \\
\dot{U} \\
U\end{array}$ & $\begin{array}{l}- \\
- \\
\end{array}$ & $\begin{array}{l}- \\
1 \\
\dot{U} \\
U\end{array}$ \\
\hline
\end{tabular}


TABLE II. (Continued) Provisional cases of selected notifiable diseases, United States, weeks ending December 28, 2002, and December 29, 2001 (52nd Week)*

\begin{tabular}{|c|c|c|c|c|c|c|c|c|c|c|}
\hline \multirow[b]{2}{*}{ Reporting Area } & \multicolumn{2}{|c|}{ Legionellosis } & \multicolumn{2}{|c|}{ Listeriosis } & \multicolumn{2}{|c|}{ Lyme Disease } & \multicolumn{2}{|c|}{ Malaria } & \multicolumn{2}{|c|}{$\begin{array}{c}\text { Measles } \\
\text { Total }\end{array}$} \\
\hline & $\begin{array}{l}\text { Cum. } \\
2002 \\
\end{array}$ & $\begin{array}{l}\text { Cum. } \\
2001\end{array}$ & $\begin{array}{l}\text { Cum. } \\
2002\end{array}$ & $\begin{array}{l}\text { Cum. } \\
2001\end{array}$ & $\begin{array}{l}\text { Cum. } \\
2002\end{array}$ & $\begin{array}{l}\text { Cum. } \\
2001\end{array}$ & $\begin{array}{l}\text { Cum. } \\
2002\end{array}$ & $\begin{array}{l}\text { Cum. } \\
2001\end{array}$ & $\begin{array}{l}\text { Cum. } \\
2002\end{array}$ & $\begin{array}{l}\text { Cum. } \\
2001\end{array}$ \\
\hline UNITED STATES & 1,183 & 1,171 & 591 & 621 & 18,181 & 17,029 & 1,245 & 1,544 & $37^{\dagger}$ & $116^{\S}$ \\
\hline $\begin{array}{l}\text { NEW ENGLAND } \\
\text { Maine } \\
\text { N.H. } \\
\text { Vt. } \\
\text { Mass. } \\
\text { R.I. } \\
\text { Conn. }\end{array}$ & $\begin{array}{r}105 \\
6 \\
7 \\
35 \\
30 \\
9 \\
18\end{array}$ & $\begin{array}{r}74 \\
8 \\
12 \\
5 \\
21 \\
13 \\
15\end{array}$ & $\begin{array}{r}59 \\
5 \\
4 \\
3 \\
31 \\
1 \\
15\end{array}$ & $\begin{array}{r}57 \\
2 \\
4 \\
3 \\
30 \\
3 \\
15\end{array}$ & $\begin{array}{r}6,277 \\
111 \\
246 \\
37 \\
1,559 \\
346 \\
3,978\end{array}$ & $\begin{array}{r}5,526 \\
108 \\
129 \\
18 \\
1,164 \\
510 \\
3,597\end{array}$ & $\begin{array}{r}70 \\
6 \\
7 \\
4 \\
26 \\
11 \\
16\end{array}$ & $\begin{array}{r}107 \\
5 \\
2 \\
1 \\
53 \\
16 \\
30\end{array}$ & $\begin{array}{l}- \\
- \\
- \\
- \\
- \\
-\end{array}$ & $\begin{array}{l}5 \\
- \\
- \\
1 \\
3 \\
- \\
1\end{array}$ \\
\hline $\begin{array}{l}\text { MID. ATLANTIC } \\
\text { Upstate N.Y. } \\
\text { N.Y. City } \\
\text { N.J. } \\
\text { Pa. }\end{array}$ & $\begin{array}{r}328 \\
111 \\
61 \\
29 \\
127\end{array}$ & $\begin{array}{r}286 \\
82 \\
43 \\
24 \\
137\end{array}$ & $\begin{array}{r}166 \\
57 \\
35 \\
33 \\
41\end{array}$ & $\begin{array}{r}119 \\
36 \\
26 \\
20 \\
37\end{array}$ & $\begin{array}{r}9,718 \\
5,017 \\
174 \\
1,767 \\
2,760\end{array}$ & $\begin{array}{r}8,909 \\
4,020 \\
63 \\
2,020 \\
2,806\end{array}$ & $\begin{array}{r}334 \\
49 \\
214 \\
37 \\
34\end{array}$ & $\begin{array}{r}440 \\
76 \\
250 \\
65 \\
49\end{array}$ & $\begin{array}{l}7 \\
1 \\
6 \\
- \\
-\end{array}$ & $\begin{array}{r}20 \\
4 \\
7 \\
1 \\
8\end{array}$ \\
\hline $\begin{array}{l}\text { E.N. CENTRAL } \\
\text { Ohio } \\
\text { Ind. } \\
\text { III. } \\
\text { Mich. } \\
\text { Wis. }\end{array}$ & $\begin{array}{r}267 \\
123 \\
26 \\
- \\
84 \\
34\end{array}$ & $\begin{array}{r}316 \\
143 \\
23 \\
24 \\
82 \\
44\end{array}$ & $\begin{array}{r}81 \\
28 \\
12 \\
12 \\
22 \\
7\end{array}$ & $\begin{array}{r}88 \\
17 \\
8 \\
24 \\
25 \\
14\end{array}$ & $\begin{array}{r}115 \\
82 \\
20 \\
- \\
13 \\
U\end{array}$ & $\begin{array}{r}720 \\
44 \\
26 \\
32 \\
21 \\
597\end{array}$ & $\begin{array}{r}138 \\
25 \\
14 \\
37 \\
46 \\
16\end{array}$ & $\begin{array}{r}177 \\
27 \\
19 \\
71 \\
40 \\
20\end{array}$ & $\begin{array}{l}3 \\
1 \\
2 \\
- \\
- \\
-\end{array}$ & $\begin{array}{r}10 \\
3 \\
4 \\
3 \\
- \\
-\end{array}$ \\
\hline $\begin{array}{l}\text { W.N. CENTRAL } \\
\text { Minn. } \\
\text { lowa } \\
\text { Mo. } \\
\text { N. Dak. } \\
\text { S. Dak. } \\
\text { Nebr. } \\
\text { Kans. }\end{array}$ & $\begin{array}{r}61 \\
17 \\
12 \\
17 \\
1 \\
4 \\
10 \\
-\end{array}$ & $\begin{array}{r}55 \\
15 \\
8 \\
22 \\
1 \\
1 \\
3 \\
5 \\
1\end{array}$ & $\begin{array}{r}22 \\
6 \\
3 \\
9 \\
1 \\
1 \\
1 \\
1\end{array}$ & $\begin{array}{r}22 \\
4 \\
2 \\
10 \\
- \\
- \\
1 \\
5\end{array}$ & $\begin{array}{r}503 \\
404 \\
42 \\
40 \\
1 \\
2 \\
6 \\
8\end{array}$ & $\begin{array}{r}540 \\
461 \\
36 \\
37 \\
- \\
- \\
4 \\
2\end{array}$ & $\begin{array}{r}57 \\
17 \\
4 \\
16 \\
1 \\
1 \\
5 \\
13\end{array}$ & $\begin{array}{r}77 \\
45 \\
9 \\
15 \\
- \\
- \\
2 \\
6\end{array}$ & $\begin{array}{l}3 \\
1 \\
- \\
2 \\
- \\
- \\
- \\
-\end{array}$ & $\begin{array}{l}6 \\
4 \\
- \\
2 \\
- \\
- \\
- \\
-\end{array}$ \\
\hline $\begin{array}{l}\text { S. ATLANTIC } \\
\text { Del. } \\
\text { Md. } \\
\text { D.C. } \\
\text { Va. } \\
\text { W. Va. } \\
\text { N.C. } \\
\text { S.C. } \\
\text { Ga. } \\
\text { Fla. }\end{array}$ & $\begin{array}{r}225 \\
10 \\
54 \\
6 \\
30 \\
\mathrm{~N} \\
13 \\
9 \\
17 \\
86\end{array}$ & $\begin{array}{r}224 \\
12 \\
32 \\
8 \\
39 \\
\mathrm{~N} \\
11 \\
15 \\
12 \\
95\end{array}$ & $\begin{array}{r}84 \\
- \\
21 \\
- \\
7 \\
- \\
8 \\
8 \\
12 \\
28\end{array}$ & $\begin{array}{r}85 \\
2 \\
16 \\
- \\
15 \\
6 \\
6 \\
5 \\
16 \\
19\end{array}$ & $\begin{array}{r}1,286 \\
178 \\
681 \\
22 \\
149 \\
17 \\
137 \\
20 \\
1 \\
81\end{array}$ & $\begin{array}{r}1,039 \\
152 \\
608 \\
17 \\
156 \\
16 \\
41 \\
6 \\
- \\
43\end{array}$ & $\begin{array}{r}324 \\
4 \\
111 \\
20 \\
32 \\
3 \\
22 \\
7 \\
49 \\
76\end{array}$ & $\begin{array}{r}317 \\
2 \\
112 \\
13 \\
55 \\
1 \\
19 \\
9 \\
45 \\
61\end{array}$ & $\begin{array}{l}5 \\
- \\
- \\
- \\
- \\
- \\
- \\
- \\
3 \\
2\end{array}$ & $\begin{array}{l}5 \\
- \\
3 \\
- \\
1 \\
- \\
- \\
- \\
1\end{array}$ \\
\hline $\begin{array}{l}\text { E.S. CENTRAL } \\
\text { Ky. } \\
\text { Tenn. } \\
\text { Ala. } \\
\text { Miss. }\end{array}$ & $\begin{array}{r}48 \\
21 \\
19 \\
8 \\
-\end{array}$ & $\begin{array}{r}63 \\
14 \\
32 \\
13 \\
4\end{array}$ & $\begin{array}{r}20 \\
4 \\
11 \\
4 \\
1\end{array}$ & $\begin{array}{r}23 \\
7 \\
9 \\
7 \\
-\end{array}$ & $\begin{array}{r}52 \\
23 \\
26 \\
3 \\
-\end{array}$ & $\begin{array}{r}72 \\
23 \\
31 \\
10 \\
8\end{array}$ & $\begin{array}{r}21 \\
7 \\
3 \\
6 \\
5\end{array}$ & $\begin{array}{r}38 \\
14 \\
14 \\
6 \\
4\end{array}$ & $\begin{array}{r}12 \\
- \\
- \\
12 \\
-\end{array}$ & $\begin{array}{l}2 \\
2 \\
- \\
- \\
-\end{array}$ \\
\hline $\begin{array}{l}\text { W.S. CENTRAL } \\
\text { Ark. } \\
\text { La. } \\
\text { Okla. } \\
\text { Tex. }\end{array}$ & $\begin{array}{r}24 \\
- \\
4 \\
3 \\
17\end{array}$ & $\begin{array}{r}31 \\
- \\
7 \\
7 \\
17\end{array}$ & $\begin{array}{r}21 \\
- \\
9 \\
12\end{array}$ & $\begin{array}{r}34 \\
1 \\
- \\
2 \\
31\end{array}$ & $\begin{array}{r}68 \\
3 \\
4 \\
- \\
61\end{array}$ & $\begin{array}{r}87 \\
4 \\
8 \\
- \\
75\end{array}$ & $\begin{array}{r}22 \\
2 \\
4 \\
10 \\
6\end{array}$ & $\begin{array}{r}91 \\
3 \\
6 \\
5 \\
77\end{array}$ & $\begin{array}{l}1 \\
- \\
- \\
1\end{array}$ & $\begin{array}{l}1 \\
- \\
- \\
1\end{array}$ \\
\hline $\begin{array}{l}\text { MOUNTAIN } \\
\text { Mont. } \\
\text { Idaho } \\
\text { Wyo. } \\
\text { Colo. } \\
\text { N. Mex. } \\
\text { Ariz. } \\
\text { Utah } \\
\text { Nev. }\end{array}$ & $\begin{array}{r}54 \\
3 \\
3 \\
1 \\
8 \\
2 \\
15 \\
17 \\
5\end{array}$ & $\begin{array}{r}58 \\
- \\
3 \\
3 \\
17 \\
3 \\
21 \\
7 \\
4\end{array}$ & $\begin{array}{r}32 \\
- \\
2 \\
- \\
7 \\
3 \\
16 \\
3 \\
1\end{array}$ & $\begin{array}{r}39 \\
- \\
1 \\
2 \\
10 \\
7 \\
10 \\
2 \\
7\end{array}$ & $\begin{array}{r}19 \\
- \\
4 \\
2 \\
1 \\
1 \\
3 \\
7 \\
1\end{array}$ & $\begin{array}{r}15 \\
- \\
5 \\
1 \\
- \\
1 \\
3 \\
1 \\
4\end{array}$ & $\begin{array}{r}51 \\
2 \\
- \\
- \\
24 \\
3 \\
13 \\
6 \\
3\end{array}$ & $\begin{array}{r}68 \\
3 \\
4 \\
1 \\
25 \\
3 \\
19 \\
4 \\
9\end{array}$ & $\begin{array}{l}2 \\
- \\
- \\
- \\
- \\
- \\
1 \\
1\end{array}$ & $\begin{array}{l}2 \\
- \\
1 \\
- \\
- \\
- \\
- \\
-\end{array}$ \\
\hline $\begin{array}{l}\text { PACIFIC } \\
\text { Wash. } \\
\text { Oreg. } \\
\text { Calif. } \\
\text { Alaska } \\
\text { Hawaii }\end{array}$ & $\begin{array}{r}71 \\
7 \\
N \\
63 \\
- \\
1\end{array}$ & $\begin{array}{r}64 \\
10 \\
\mathrm{~N} \\
48 \\
1 \\
5\end{array}$ & $\begin{array}{r}106 \\
8 \\
9 \\
81 \\
- \\
8\end{array}$ & $\begin{array}{r}154 \\
14 \\
12 \\
122 \\
- \\
6\end{array}$ & $\begin{array}{r}143 \\
11 \\
15 \\
114 \\
3 \\
\mathrm{~N}\end{array}$ & $\begin{array}{r}121 \\
9 \\
15 \\
95 \\
2 \\
\mathrm{~N}\end{array}$ & $\begin{array}{r}228 \\
23 \\
12 \\
183 \\
2 \\
8\end{array}$ & $\begin{array}{r}229 \\
19 \\
17 \\
179 \\
1 \\
13\end{array}$ & $\begin{array}{l}4 \\
- \\
- \\
3 \\
1\end{array}$ & $\begin{array}{r}65 \\
15 \\
3 \\
40 \\
- \\
7\end{array}$ \\
\hline $\begin{array}{l}\text { Guam } \\
\text { P.R. } \\
\text { V.I. } \\
\text { Amer.Samoa } \\
\text { C.N.M.I. }\end{array}$ & $\begin{array}{l}- \\
- \\
\\
-\end{array}$ & $\begin{array}{l}\overline{2} \\
\bar{U} \\
\end{array}$ & $\begin{array}{l}\overline{1} \\
\end{array}$ & $\begin{array}{l}- \\
\bar{U} \\
U\end{array}$ & $\begin{array}{l}\bar{N} \\
\bar{U} \\
-\end{array}$ & $\begin{array}{l}\bar{N} \\
\bar{U} \\
\end{array}$ & $\begin{array}{l}- \\
\end{array}$ & $\begin{array}{l}1 \\
6 \\
\vdots \\
U\end{array}$ & $\begin{array}{l}- \\
\bar{U} \\
-\end{array}$ & $\begin{array}{l}- \\
\bar{U} \\
\end{array}$ \\
\hline
\end{tabular}

N: Not notifiable.

$\therefore$ No reported cases.

* Incidence data for reporting year 2001 and 2002 are provisional and cumulative (year-to-date).

† Of 37 cases reported, 24 were indigenous and 13 were imported from another country.

$\S$ Of 116 cases reported, 62 were indigenous and 54 were imported from another country. 
TABLE II. (Continued) Provisional cases of selected notifiable diseases, United States, weeks ending December 28, 2002, and December 29, 2001 (52nd Week)*

\begin{tabular}{|c|c|c|c|c|c|c|c|c|}
\hline \multirow[b]{2}{*}{ Reporting Area } & \multicolumn{2}{|c|}{$\begin{array}{c}\text { Meningococcal } \\
\text { Disease }\end{array}$} & \multicolumn{2}{|c|}{ Mumps } & \multicolumn{2}{|c|}{ Pertussis } & \multicolumn{2}{|c|}{ Rabies, Animal } \\
\hline & $\begin{array}{l}\text { Cum. } \\
2002\end{array}$ & $\begin{array}{l}\text { Cum. } \\
2001\end{array}$ & $\begin{array}{l}\text { Cum. } \\
2002\end{array}$ & $\begin{array}{l}\text { Cum. } \\
2001\end{array}$ & $\begin{array}{l}\text { Cum. } \\
2002\end{array}$ & $\begin{array}{l}\text { Cum. } \\
2001\end{array}$ & $\begin{array}{l}\text { Cum. } \\
2002\end{array}$ & $\begin{array}{l}\text { Cum. } \\
2001\end{array}$ \\
\hline UNITED STATES & 1,595 & 2,333 & 238 & 266 & 8,296 & 7,580 & 6,875 & 7,150 \\
\hline $\begin{array}{l}\text { NEW ENGLAND } \\
\text { Maine } \\
\text { N.H. } \\
\text { Vt. } \\
\text { Mass. } \\
\text { R.I. } \\
\text { Conn. }\end{array}$ & $\begin{array}{r}89 \\
9 \\
14 \\
4 \\
42 \\
5 \\
15\end{array}$ & $\begin{array}{r}113 \\
8 \\
14 \\
7 \\
57 \\
7 \\
20\end{array}$ & $\begin{array}{l}6 \\
- \\
4 \\
- \\
1 \\
- \\
1\end{array}$ & $\begin{array}{l}2 \\
- \\
- \\
- \\
2 \\
- \\
-\end{array}$ & $\begin{array}{r}798 \\
17 \\
61 \\
166 \\
511 \\
16 \\
27\end{array}$ & $\begin{array}{r}736 \\
22 \\
31 \\
113 \\
537 \\
9 \\
24\end{array}$ & $\begin{array}{r}899 \\
61 \\
48 \\
89 \\
297 \\
75 \\
329\end{array}$ & $\begin{array}{r}760 \\
82 \\
21 \\
62 \\
279 \\
72 \\
244\end{array}$ \\
\hline $\begin{array}{l}\text { MID. ATLANTIC } \\
\text { Upstate N.Y. } \\
\text { N.Y. City } \\
\text { N.J. } \\
\text { Pa. }\end{array}$ & $\begin{array}{r}157 \\
49 \\
23 \\
27 \\
58\end{array}$ & $\begin{array}{r}257 \\
72 \\
42 \\
43 \\
100\end{array}$ & $\begin{array}{r}25 \\
6 \\
2 \\
- \\
17\end{array}$ & $\begin{array}{r}35 \\
4 \\
13 \\
4 \\
14\end{array}$ & $\begin{array}{r}506 \\
376 \\
13 \\
1 \\
116\end{array}$ & $\begin{array}{r}455 \\
175 \\
59 \\
23 \\
198\end{array}$ & $\begin{array}{r}1,158 \\
701 \\
24 \\
188 \\
245\end{array}$ & $\begin{array}{r}1,371 \\
781 \\
38 \\
200 \\
352\end{array}$ \\
\hline $\begin{array}{l}\text { E.N. CENTRAL } \\
\text { Ohio } \\
\text { Ind. } \\
\text { Ill. } \\
\text { Mich. } \\
\text { Wis. }\end{array}$ & $\begin{array}{r}202 \\
74 \\
32 \\
36 \\
44 \\
16\end{array}$ & $\begin{array}{r}361 \\
91 \\
47 \\
88 \\
83 \\
52\end{array}$ & $\begin{array}{r}39 \\
14 \\
2 \\
2 \\
15 \\
7 \\
1\end{array}$ & $\begin{array}{r}32 \\
1 \\
3 \\
21 \\
5 \\
2\end{array}$ & $\begin{array}{r}946 \\
443 \\
152 \\
166 \\
60 \\
125\end{array}$ & $\begin{array}{l}985 \\
327 \\
116 \\
194 \\
149 \\
199\end{array}$ & $\begin{array}{r}148 \\
39 \\
32 \\
31 \\
46 \\
-\end{array}$ & $\begin{array}{r}158 \\
52 \\
15 \\
24 \\
47 \\
20\end{array}$ \\
\hline $\begin{array}{l}\text { W.N. CENTRAL } \\
\text { Minn. } \\
\text { lowa } \\
\text { Mo. } \\
\text { N. Dak. } \\
\text { S. Dak. } \\
\text { Nebr. } \\
\text { Kans. }\end{array}$ & $\begin{array}{r}153 \\
35 \\
28 \\
51 \\
3 \\
2 \\
26 \\
8\end{array}$ & $\begin{array}{r}174 \\
29 \\
31 \\
58 \\
8 \\
5 \\
28 \\
15\end{array}$ & $\begin{array}{r}16 \\
4 \\
1 \\
4 \\
1 \\
- \\
- \\
6\end{array}$ & $\begin{array}{r}17 \\
6 \\
1 \\
4 \\
- \\
- \\
1 \\
5\end{array}$ & $\begin{array}{r}747 \\
379 \\
143 \\
144 \\
3 \\
6 \\
8 \\
8 \\
64\end{array}$ & $\begin{array}{r}609 \\
308 \\
139 \\
107 \\
11 \\
5 \\
8 \\
31\end{array}$ & $\begin{array}{r}440 \\
36 \\
79 \\
50 \\
36 \\
79 \\
- \\
160\end{array}$ & $\begin{array}{r}375 \\
47 \\
84 \\
40 \\
42 \\
58 \\
4 \\
100\end{array}$ \\
\hline $\begin{array}{l}\text { S. ATLANTIC } \\
\text { Del. } \\
\text { Md. } \\
\text { D.C. } \\
\text { Va. } \\
\text { W.Va. } \\
\text { N.C. } \\
\text { S.C. } \\
\text { Ga. } \\
\text { Fla. }\end{array}$ & $\begin{array}{r}284 \\
7 \\
9 \\
- \\
41 \\
4 \\
33 \\
32 \\
30 \\
128\end{array}$ & $\begin{array}{r}383 \\
6 \\
42 \\
- \\
46 \\
15 \\
63 \\
33 \\
57 \\
121\end{array}$ & $\begin{array}{r}23 \\
- \\
5 \\
- \\
4 \\
- \\
2 \\
3 \\
2 \\
7\end{array}$ & $\begin{array}{r}45 \\
- \\
8 \\
- \\
8 \\
- \\
5 \\
7 \\
9 \\
8\end{array}$ & $\begin{array}{r}418 \\
4 \\
65 \\
2 \\
2 \\
159 \\
32 \\
45 \\
43 \\
15 \\
53\end{array}$ & $\begin{array}{r}493 \\
- \\
53 \\
1 \\
272 \\
6 \\
75 \\
34 \\
23 \\
29\end{array}$ & $\begin{array}{r}2,503 \\
53 \\
359 \\
- \\
505 \\
169 \\
710 \\
142 \\
375 \\
190\end{array}$ & $\begin{array}{r}2,512 \\
39 \\
504 \\
- \\
502 \\
141 \\
571 \\
144 \\
402 \\
209\end{array}$ \\
\hline $\begin{array}{l}\text { E.S. CENTRAL } \\
\text { Ky. } \\
\text { Tenn. } \\
\text { Ala. } \\
\text { Miss. }\end{array}$ & $\begin{array}{l}90 \\
15 \\
38 \\
23 \\
14\end{array}$ & $\begin{array}{r}146 \\
27 \\
64 \\
35 \\
20\end{array}$ & $\begin{array}{r}13 \\
3 \\
2 \\
3 \\
5\end{array}$ & $\begin{array}{l}9 \\
3 \\
1 \\
- \\
5\end{array}$ & $\begin{array}{r}253 \\
93 \\
114 \\
37 \\
9\end{array}$ & $\begin{array}{r}208 \\
96 \\
70 \\
37 \\
5\end{array}$ & $\begin{array}{r}173 \\
27 \\
108 \\
34 \\
4\end{array}$ & $\begin{array}{r}204 \\
30 \\
106 \\
64 \\
4\end{array}$ \\
\hline $\begin{array}{l}\text { W.S. CENTRAL } \\
\text { Ark. } \\
\text { La. } \\
\text { Okla. } \\
\text { Tex. }\end{array}$ & $\begin{array}{r}191 \\
24 \\
40 \\
22 \\
105\end{array}$ & $\begin{array}{r}336 \\
25 \\
78 \\
32 \\
201\end{array}$ & $\begin{array}{r}12 \\
- \\
1 \\
- \\
11\end{array}$ & $\begin{array}{r}16 \\
- \\
2 \\
- \\
14\end{array}$ & $\begin{array}{r}1,587 \\
489 \\
7 \\
66 \\
1,025\end{array}$ & $\begin{array}{r}1,528 \\
858 \\
12 \\
43 \\
615\end{array}$ & $\begin{array}{r}990 \\
8 \\
- \\
119 \\
863\end{array}$ & $\begin{array}{r}1,144 \\
32 \\
9 \\
60 \\
1,043\end{array}$ \\
\hline $\begin{array}{l}\text { MOUNTAIN } \\
\text { Mont. } \\
\text { Idaho } \\
\text { Wyo. } \\
\text { Colo. } \\
\text { N. Mex. } \\
\text { Ariz. } \\
\text { Utah } \\
\text { Nev. }\end{array}$ & $\begin{array}{r}94 \\
3 \\
5 \\
- \\
24 \\
4 \\
32 \\
6 \\
20\end{array}$ & $\begin{array}{r}103 \\
4 \\
8 \\
5 \\
38 \\
11 \\
21 \\
8 \\
8\end{array}$ & $\begin{array}{r}21 \\
- \\
2 \\
- \\
3 \\
1 \\
1 \\
8 \\
6\end{array}$ & $\begin{array}{r}17 \\
1 \\
2 \\
2 \\
3 \\
2 \\
2 \\
1 \\
4\end{array}$ & $\begin{array}{r}1,653 \\
9 \\
152 \\
11 \\
432 \\
188 \\
706 \\
107 \\
48\end{array}$ & $\begin{array}{r}1,561 \\
54 \\
171 \\
1 \\
389 \\
137 \\
690 \\
78 \\
41\end{array}$ & $\begin{array}{r}292 \\
19 \\
38 \\
18 \\
59 \\
7 \\
127 \\
13 \\
11\end{array}$ & $\begin{array}{r}254 \\
38 \\
28 \\
28 \\
- \\
15 \\
129 \\
15 \\
1\end{array}$ \\
\hline $\begin{array}{l}\text { PACIFIC } \\
\text { Wash. } \\
\text { Oreg. } \\
\text { Calif. } \\
\text { Alaska } \\
\text { Hawaii }\end{array}$ & $\begin{array}{r}335 \\
63 \\
45 \\
213 \\
4 \\
10\end{array}$ & $\begin{array}{r}460 \\
71 \\
63 \\
310 \\
3 \\
13\end{array}$ & $\begin{array}{r}83 \\
- \\
N \\
67 \\
- \\
16\end{array}$ & $\begin{array}{r}93 \\
2 \\
\mathrm{~N} \\
48 \\
1 \\
42\end{array}$ & $\begin{array}{r}1,388 \\
472 \\
192 \\
702 \\
5 \\
17\end{array}$ & $\begin{array}{r}1,005 \\
184 \\
57 \\
706 \\
16 \\
42\end{array}$ & $\begin{array}{r}272 \\
- \\
13 \\
235 \\
24 \\
-\end{array}$ & $\begin{array}{r}372 \\
- \\
4 \\
319 \\
49 \\
-\end{array}$ \\
\hline $\begin{array}{l}\text { Guam } \\
\text { P.R. } \\
\text { V.I. } \\
\text { Amer. Samoa } \\
\text { C.N.M.I. }\end{array}$ & $\begin{array}{c}- \\
5 \\
- \\
\\
-\end{array}$ & $\begin{array}{l}- \\
\overline{9} \\
\dot{U} \\
\text { U }\end{array}$ & $\begin{array}{l}- \\
- \\
\\
-\end{array}$ & $\begin{array}{l}- \\
\bar{U} \\
\dot{U}\end{array}$ & $\begin{array}{c}- \\
3 \\
- \\
\end{array}$ & $\begin{array}{l}- \\
- \\
U \\
U\end{array}$ & $\begin{array}{r}\overline{-} \\
\bar{U} \\
\overline{-}\end{array}$ & $\begin{array}{r}99 \\
\bar{U} \\
\mathrm{U}\end{array}$ \\
\hline
\end{tabular}

N: Not notifiable. U: Unavailable. $\quad-:$ No reported cases.

* Incidence data for reporting year 2001 and 2002 are provisional and cumulative (year-to-date). 
TABLE II. (Continued) Provisional cases of selected notifiable diseases, United States, weeks ending December 28, 2002, and December 29, 2001 (52nd Week)*

\begin{tabular}{|c|c|c|c|c|c|c|c|c|}
\hline \multirow[b]{3}{*}{ Reporting Area } & \multirow{2}{*}{\multicolumn{2}{|c|}{$\begin{array}{l}\text { Rocky Mountain } \\
\text { Spotted Fever }\end{array}$}} & \multicolumn{4}{|c|}{ Rubella } & \multirow{2}{*}{\multicolumn{2}{|c|}{ Salmonellosis }} \\
\hline & & & \multicolumn{2}{|c|}{ Rubella } & \multicolumn{2}{|c|}{$\begin{array}{c}\text { Congenital } \\
\text { Rubella }\end{array}$} & & \\
\hline & $\begin{array}{l}\text { Cum. } \\
2002 \\
\end{array}$ & $\begin{array}{l}\text { Cum. } \\
2001\end{array}$ & $\begin{array}{l}\text { Cum. } \\
2002 \\
\end{array}$ & $\begin{array}{l}\text { Cum. } \\
2001 \\
\end{array}$ & $\begin{array}{l}\text { Cum. } \\
2002 \\
\end{array}$ & $\begin{array}{l}\text { Cum. } \\
2001 \\
\end{array}$ & $\begin{array}{l}\text { Cum. } \\
2002 \\
\end{array}$ & $\begin{array}{l}\text { Cum. } \\
2001 \\
\end{array}$ \\
\hline UNITED STATES & 975 & 697 & 14 & 23 & 3 & 3 & 41,257 & 40,518 \\
\hline $\begin{array}{l}\text { NEW ENGLAND } \\
\text { Maine } \\
\text { N.H. } \\
\text { Vt. } \\
\text { Mass. } \\
\text { R.I. } \\
\text { Conn. }\end{array}$ & $\begin{array}{r}10 \\
- \\
- \\
- \\
6 \\
4 \\
-\end{array}$ & $\begin{array}{l}3 \\
- \\
1 \\
- \\
2 \\
- \\
-\end{array}$ & $\begin{array}{l}- \\
- \\
- \\
- \\
- \\
-\end{array}$ & $\begin{array}{l}- \\
- \\
- \\
- \\
-\end{array}$ & $\begin{array}{l}- \\
- \\
- \\
- \\
- \\
-\end{array}$ & $\begin{array}{l}- \\
- \\
- \\
- \\
- \\
-\end{array}$ & $\begin{array}{r}2,145 \\
146 \\
138 \\
77 \\
1,168 \\
171 \\
445\end{array}$ & $\begin{array}{r}2,344 \\
168 \\
166 \\
82 \\
1,328 \\
151 \\
449\end{array}$ \\
\hline $\begin{array}{l}\text { MID. ATLANTIC } \\
\text { Upstate N.Y. } \\
\text { N.Y. City } \\
\text { N.J. } \\
\text { Pa. }\end{array}$ & $\begin{array}{r}40 \\
9 \\
9 \\
2 \\
20\end{array}$ & $\begin{array}{r}34 \\
2 \\
2 \\
9 \\
21\end{array}$ & $\begin{array}{l}1 \\
1 \\
- \\
- \\
-\end{array}$ & $\begin{array}{l}9 \\
1 \\
6 \\
1 \\
1\end{array}$ & $\begin{array}{l}- \\
- \\
- \\
-\end{array}$ & $\begin{array}{l}- \\
- \\
- \\
-\end{array}$ & $\begin{array}{r}5,172 \\
1,565 \\
1,447 \\
761 \\
1,399\end{array}$ & $\begin{array}{l}5,428 \\
1,398 \\
1,313 \\
1,174 \\
1,543\end{array}$ \\
\hline $\begin{array}{l}\text { E.N. CENTRAL } \\
\text { Ohio } \\
\text { Ind. } \\
\text { IIl. } \\
\text { Mich. } \\
\text { Wis. }\end{array}$ & $\begin{array}{r}19 \\
13 \\
3 \\
- \\
3 \\
-\end{array}$ & $\begin{array}{r}16 \\
2 \\
1 \\
12 \\
1 \\
-\end{array}$ & $\begin{array}{l}2 \\
- \\
- \\
1 \\
1 \\
-\end{array}$ & $\begin{array}{l}2 \\
- \\
5 \\
2 \\
- \\
-\end{array}$ & $\begin{array}{l}- \\
- \\
- \\
- \\
-\end{array}$ & $\begin{array}{l}1 \\
1 \\
- \\
- \\
- \\
-\end{array}$ & $\begin{array}{r}5,345 \\
1,447 \\
508 \\
1,658 \\
875 \\
857\end{array}$ & $\begin{array}{r}4,999 \\
1,352 \\
549 \\
1,383 \\
885 \\
830\end{array}$ \\
\hline $\begin{array}{l}\text { W.N. CENTRAL } \\
\text { Minn. } \\
\text { lowa } \\
\text { Mo. } \\
\text { N. Dak. } \\
\text { S. Dak. } \\
\text { Nebr. } \\
\text { Kans. }\end{array}$ & $\begin{array}{r}102 \\
- \\
3 \\
94 \\
- \\
1 \\
4 \\
-\end{array}$ & $\begin{array}{r}69 \\
1 \\
2 \\
62 \\
1 \\
2 \\
1 \\
-\end{array}$ & $\begin{array}{l}- \\
- \\
- \\
- \\
- \\
-\end{array}$ & $\begin{array}{l}3 \\
- \\
1 \\
1 \\
- \\
- \\
- \\
1\end{array}$ & $\begin{array}{l}- \\
- \\
- \\
- \\
- \\
- \\
-\end{array}$ & $\begin{array}{l}- \\
- \\
- \\
- \\
- \\
- \\
-\end{array}$ & $\begin{array}{r}2,585 \\
610 \\
518 \\
820 \\
43 \\
108 \\
150 \\
336\end{array}$ & $\begin{array}{r}2,380 \\
689 \\
335 \\
648 \\
73 \\
151 \\
170 \\
314\end{array}$ \\
\hline $\begin{array}{l}\text { S. ATLANTIC } \\
\text { Del. } \\
\text { Md. } \\
\text { D.C. } \\
\text { Va. } \\
\text { W. Va. } \\
\text { N.C. } \\
\text { S.C. } \\
\text { Ga. } \\
\text { Fla. }\end{array}$ & $\begin{array}{r}505 \\
4 \\
55 \\
2 \\
42 \\
2 \\
294 \\
69 \\
19 \\
18\end{array}$ & $\begin{array}{r}328 \\
13 \\
39 \\
1 \\
40 \\
1 \\
185 \\
31 \\
9 \\
9\end{array}$ & $\begin{array}{l}6 \\
1 \\
- \\
- \\
- \\
- \\
- \\
- \\
- \\
5\end{array}$ & $\begin{array}{l}5 \\
- \\
1 \\
- \\
- \\
- \\
- \\
2 \\
- \\
2\end{array}$ & $\begin{array}{l}- \\
- \\
- \\
- \\
- \\
- \\
-\end{array}$ & $\begin{array}{l}1 \\
- \\
- \\
1 \\
- \\
- \\
- \\
-\end{array}$ & $\begin{array}{r}11,300 \\
95 \\
954 \\
76 \\
1,244 \\
152 \\
1,595 \\
813 \\
1,712 \\
4,659\end{array}$ & $\begin{array}{r}9,681 \\
96 \\
809 \\
81 \\
1,368 \\
183 \\
1,386 \\
915 \\
1,721 \\
3,122\end{array}$ \\
\hline $\begin{array}{l}\text { E.S. CENTRAL } \\
\text { Ky. } \\
\text { Tenn. } \\
\text { Ala. } \\
\text { Miss. }\end{array}$ & $\begin{array}{r}113 \\
5 \\
84 \\
20 \\
4\end{array}$ & $\begin{array}{r}122 \\
2 \\
86 \\
18 \\
16\end{array}$ & $\begin{array}{l}- \\
- \\
- \\
-\end{array}$ & $\begin{array}{l}- \\
- \\
- \\
-\end{array}$ & $\begin{array}{l}1 \\
- \\
1 \\
-\end{array}$ & $\begin{array}{l}- \\
- \\
- \\
-\end{array}$ & $\begin{array}{r}3,254 \\
398 \\
839 \\
877 \\
1,140\end{array}$ & $\begin{array}{r}2,775 \\
406 \\
706 \\
748 \\
915\end{array}$ \\
\hline $\begin{array}{l}\text { W.S. CENTRAL } \\
\text { Ark. } \\
\text { La. } \\
\text { Okla. } \\
\text { Tex. }\end{array}$ & $\begin{array}{r}163 \\
97 \\
- \\
61 \\
5\end{array}$ & $\begin{array}{r}113 \\
54 \\
2 \\
57 \\
-\end{array}$ & $\begin{array}{l}1 \\
- \\
- \\
- \\
1\end{array}$ & $\begin{array}{l}2 \\
- \\
- \\
- \\
2\end{array}$ & $\begin{array}{l}1 \\
- \\
1 \\
- \\
-\end{array}$ & $\begin{array}{l}- \\
- \\
- \\
-\end{array}$ & $\begin{array}{r}3,653 \\
1,047 \\
813 \\
505 \\
1,288\end{array}$ & $\begin{array}{r}5,052 \\
928 \\
832 \\
500 \\
2,792\end{array}$ \\
\hline $\begin{array}{l}\text { MOUNTAIN } \\
\text { Mont. } \\
\text { Idaho } \\
\text { Wyo. } \\
\text { Colo. } \\
\text { N. Mex. } \\
\text { Ariz. } \\
\text { Utah } \\
\text { Nev. }\end{array}$ & $\begin{array}{r}14 \\
1 \\
- \\
5 \\
2 \\
1 \\
- \\
- \\
5\end{array}$ & $\begin{array}{r}11 \\
1 \\
1 \\
2 \\
2 \\
1 \\
- \\
3 \\
1\end{array}$ & $\begin{array}{l}1 \\
- \\
- \\
- \\
- \\
- \\
- \\
1 \\
-\end{array}$ & $\begin{array}{l}- \\
- \\
- \\
- \\
- \\
- \\
-\end{array}$ & $\begin{array}{l}- \\
- \\
- \\
- \\
- \\
- \\
-\end{array}$ & $\begin{array}{l}- \\
- \\
- \\
- \\
- \\
- \\
- \\
-\end{array}$ & $\begin{array}{r}2,477 \\
91 \\
184 \\
107 \\
602 \\
320 \\
788 \\
202 \\
183\end{array}$ & $\begin{array}{r}2,332 \\
81 \\
146 \\
61 \\
592 \\
280 \\
741 \\
229 \\
202\end{array}$ \\
\hline $\begin{array}{l}\text { PACIFIC } \\
\text { Wash. } \\
\text { Oreg. } \\
\text { Calif. } \\
\text { Alaska } \\
\text { Hawaii }\end{array}$ & $\begin{array}{l}9 \\
- \\
3 \\
6 \\
- \\
-\end{array}$ & $\begin{array}{l}1 \\
- \\
1 \\
- \\
- \\
-\end{array}$ & $\begin{array}{l}3 \\
- \\
- \\
3 \\
- \\
-\end{array}$ & $\begin{array}{l}2 \\
- \\
- \\
1 \\
- \\
1\end{array}$ & $\begin{array}{l}1 \\
- \\
- \\
- \\
- \\
1\end{array}$ & $\begin{array}{l}1 \\
- \\
- \\
- \\
- \\
1\end{array}$ & $\begin{array}{r}5,326 \\
497 \\
354 \\
4,118 \\
79 \\
278\end{array}$ & $\begin{array}{r}5,527 \\
681 \\
281 \\
4,159 \\
50 \\
356\end{array}$ \\
\hline $\begin{array}{l}\text { Guam } \\
\text { P.R. } \\
\text { V.I. } \\
\text { Amer. Samoa } \\
\text { C.N.M.I. }\end{array}$ & $\begin{array}{l}- \\
- \\
\\
-\end{array}$ & $\begin{array}{l}- \\
- \\
\\
U\end{array}$ & $\begin{array}{l}- \\
- \\
\\
\end{array}$ & $\begin{array}{l}- \\
\\
\\
\\
U\end{array}$ & $\begin{array}{l}- \\
- \\
\\
-\end{array}$ & $\begin{array}{l}- \\
- \\
\\
U\end{array}$ & $\begin{array}{r}201 \\
\\
25\end{array}$ & $\begin{array}{r}24 \\
972 \\
\vdots \\
U\end{array}$ \\
\hline
\end{tabular}

\footnotetext{
$\mathrm{N}:$ Not notifiable. U:Unavailable. $\quad-:$ No reported cases.
}

* Incidence data for reporting year 2001 and 2002 are provisional and cumulative (year-to-date). 
TABLE II. (Continued) Provisional cases of selected notifiable diseases, United States, weeks ending December 28, 2002, and December 29, 2001 (52nd Week)*

\begin{tabular}{|c|c|c|c|c|c|c|c|c|}
\hline \multirow[b]{2}{*}{ Reporting Area } & \multicolumn{2}{|c|}{ Shigellosis } & \multicolumn{2}{|c|}{$\begin{array}{l}\text { Streptococcal Disease, } \\
\text { Invasive, Group A }\end{array}$} & \multicolumn{2}{|c|}{$\begin{array}{c}\text { Streptococcus pneumoniae, } \\
\text { Drug Resistant, Invasive }\end{array}$} & \multicolumn{2}{|c|}{$\begin{array}{c}\text { Streptococcus pneumoniae, } \\
\text { Invasive (<5 Years) }\end{array}$} \\
\hline & $\begin{array}{l}\text { Cum. } \\
2002\end{array}$ & $\begin{array}{l}\text { Cum. } \\
2001\end{array}$ & $\begin{array}{l}\text { Cum. } \\
2002\end{array}$ & $\begin{array}{l}\text { Cum. } \\
2001\end{array}$ & $\begin{array}{l}\text { Cum. } \\
2002\end{array}$ & $\begin{array}{l}\text { Cum. } \\
2001\end{array}$ & $\begin{array}{l}\text { Cum. } \\
2002\end{array}$ & $\begin{array}{l}\text { Cum. } \\
2001\end{array}$ \\
\hline UNITED STATES & 19,768 & 20,250 & 3,956 & 3,755 & 2,248 & 2,947 & 290 & 498 \\
\hline $\begin{array}{l}\text { NEW ENGLAND } \\
\text { Maine } \\
\text { N.H. } \\
\text { Vt. } \\
\text { Mass. } \\
\text { R.I. } \\
\text { Conn. }\end{array}$ & $\begin{array}{r}332 \\
12 \\
13 \\
1 \\
187 \\
17 \\
102\end{array}$ & $\begin{array}{r}312 \\
6 \\
7 \\
7 \\
208 \\
24 \\
60\end{array}$ & $\begin{array}{r}173 \\
20 \\
35 \\
10 \\
93 \\
15 \\
-\end{array}$ & $\begin{array}{r}239 \\
12 \\
\mathrm{~N} \\
16 \\
67 \\
15 \\
129\end{array}$ & $\begin{array}{r}21 \\
- \\
- \\
5 \\
N \\
16 \\
-\end{array}$ & $\begin{array}{r}150 \\
- \\
- \\
9 \\
N \\
20 \\
121\end{array}$ & $\begin{array}{r}3 \\
- \\
N \\
2 \\
N \\
1 \\
-\end{array}$ & $\begin{array}{r}52 \\
1 \\
N \\
1 \\
N \\
6 \\
44\end{array}$ \\
\hline $\begin{array}{l}\text { MID. ATLANTIC } \\
\text { Upstate N.Y. } \\
\text { N.Y. City } \\
\text { N.J. } \\
\text { Pa. }\end{array}$ & $\begin{array}{r}1,487 \\
370 \\
460 \\
403 \\
254\end{array}$ & $\begin{array}{r}1,508 \\
489 \\
410 \\
274 \\
335\end{array}$ & $\begin{array}{r}645 \\
292 \\
148 \\
136 \\
69\end{array}$ & $\begin{array}{r}687 \\
282 \\
166 \\
148 \\
91\end{array}$ & $\begin{array}{r}123 \\
96 \\
\mathrm{U} \\
\mathrm{N} \\
27\end{array}$ & $\begin{array}{r}188 \\
178 \\
U \\
N \\
10\end{array}$ & $\begin{array}{r}78 \\
75 \\
U \\
N \\
3\end{array}$ & $\begin{array}{r}123 \\
123 \\
\mathrm{U} \\
\mathrm{N} \\
-\end{array}$ \\
\hline $\begin{array}{l}\text { E.N. CENTRAL } \\
\text { Ohio } \\
\text { Ind. } \\
\text { III. } \\
\text { Mich. } \\
\text { Wis. }\end{array}$ & $\begin{array}{r}1,977 \\
681 \\
107 \\
819 \\
198 \\
172\end{array}$ & $\begin{array}{r}4,471 \\
2,979 \\
253 \\
630 \\
304 \\
305\end{array}$ & $\begin{array}{r}762 \\
217 \\
48 \\
196 \\
300 \\
1\end{array}$ & $\begin{array}{r}785 \\
199 \\
69 \\
254 \\
212 \\
51\end{array}$ & $\begin{array}{r}277 \\
107 \\
165 \\
2 \\
3 \\
\mathrm{~N}\end{array}$ & $\begin{array}{r}209 \\
3 \\
206 \\
- \\
- \\
\mathrm{N}\end{array}$ & $\begin{array}{r}123 \\
31 \\
66 \\
- \\
\mathrm{N} \\
26\end{array}$ & $\begin{array}{r}178 \\
- \\
107 \\
71 \\
\mathrm{~N} \\
-\end{array}$ \\
\hline $\begin{array}{l}\text { W.N. CENTRAL } \\
\text { Minn. } \\
\text { lowa } \\
\text { Mo. } \\
\text { N. Dak. } \\
\text { S. Dak. } \\
\text { Nebr. } \\
\text { Kans. }\end{array}$ & $\begin{array}{r}991 \\
225 \\
123 \\
201 \\
16 \\
156 \\
179 \\
91\end{array}$ & $\begin{array}{r}2,112 \\
496 \\
365 \\
321 \\
27 \\
716 \\
111 \\
76\end{array}$ & $\begin{array}{r}253 \\
132 \\
- \\
47 \\
3 \\
13 \\
18 \\
40\end{array}$ & $\begin{array}{r}409 \\
200 \\
- \\
75 \\
22 \\
17 \\
44 \\
51\end{array}$ & $\begin{array}{r}433 \\
292 \\
\mathrm{~N} \\
5 \\
1 \\
1 \\
29 \\
105\end{array}$ & $\begin{array}{r}207 \\
108 \\
\mathrm{~N} \\
11 \\
7 \\
6 \\
28 \\
47\end{array}$ & $\begin{array}{r}61 \\
60 \\
\mathrm{~N} \\
1 \\
- \\
- \\
\mathrm{N} \\
\mathrm{N}\end{array}$ & $\begin{array}{r}70 \\
58 \\
\mathrm{~N} \\
- \\
12 \\
- \\
\mathrm{N} \\
\mathrm{N}\end{array}$ \\
\hline $\begin{array}{l}\text { S. ATLANTIC } \\
\text { Del. } \\
\text { Md. } \\
\text { D.C. } \\
\text { Va. } \\
\text { W.Va. } \\
\text { N.C. } \\
\text { S.C. } \\
\text { Ga. } \\
\text { Fla. }\end{array}$ & $\begin{array}{r}7,401 \\
397 \\
1,256 \\
61 \\
1,015 \\
12 \\
638 \\
128 \\
1,354 \\
2,540\end{array}$ & $\begin{array}{r}3,440 \\
17 \\
163 \\
54 \\
784 \\
8 \\
356 \\
251 \\
752 \\
1,055\end{array}$ & $\begin{array}{r}748 \\
2 \\
149 \\
9 \\
71 \\
19 \\
122 \\
35 \\
124 \\
217\end{array}$ & $\begin{array}{r}640 \\
4 \\
\mathrm{~N} \\
22 \\
85 \\
25 \\
147 \\
14 \\
187 \\
156\end{array}$ & $\begin{array}{r}1,134 \\
3 \\
N \\
57 \\
N \\
46 \\
N \\
186 \\
196 \\
646\end{array}$ & $\begin{array}{r}1,582 \\
6 \\
N \\
11 \\
N \\
52 \\
N \\
292 \\
434 \\
787\end{array}$ & $\begin{array}{l}8 \\
N \\
N \\
1 \\
N \\
7 \\
U \\
N \\
N \\
N\end{array}$ & $\begin{array}{r}14 \\
N \\
N \\
4 \\
N \\
10 \\
\text { U } \\
N \\
N \\
N\end{array}$ \\
\hline $\begin{array}{l}\text { E.S. CENTRAL } \\
\text { Ky. } \\
\text { Tenn. } \\
\text { Ala. } \\
\text { Miss. }\end{array}$ & $\begin{array}{r}1,517 \\
201 \\
140 \\
838 \\
338\end{array}$ & $\begin{array}{r}1,772 \\
846 \\
123 \\
211 \\
592\end{array}$ & $\begin{array}{r}112 \\
21 \\
91 \\
- \\
-\end{array}$ & $\begin{array}{r}123 \\
39 \\
84 \\
- \\
-\end{array}$ & $\begin{array}{r}130 \\
18 \\
112 \\
- \\
-\end{array}$ & $\begin{array}{r}266 \\
27 \\
238 \\
1 \\
-\end{array}$ & $\begin{array}{l}- \\
N \\
N\end{array}$ & $\begin{array}{l}- \\
\mathrm{N} \\
\mathrm{N} \\
\mathrm{N} \\
-\end{array}$ \\
\hline $\begin{array}{l}\text { W.S. CENTRAL } \\
\text { Ark. } \\
\text { La. } \\
\text { Okla. } \\
\text { Tex. }\end{array}$ & $\begin{array}{r}1,847 \\
196 \\
445 \\
586 \\
620\end{array}$ & $\begin{array}{r}3,005 \\
570 \\
255 \\
147 \\
2,033\end{array}$ & $\begin{array}{r}119 \\
8 \\
- \\
48 \\
63\end{array}$ & $\begin{array}{r}322 \\
1 \\
1 \\
49 \\
271\end{array}$ & $\begin{array}{r}87 \\
12 \\
75 \\
N \\
N\end{array}$ & $\begin{array}{r}291 \\
24 \\
267 \\
N \\
N\end{array}$ & $\begin{array}{r}12 \\
- \\
4 \\
8 \\
-\end{array}$ & $\begin{array}{r}61 \\
- \\
61 \\
- \\
-\end{array}$ \\
\hline $\begin{array}{l}\text { MOUNTAIN } \\
\text { Mont. } \\
\text { Idaho } \\
\text { Wyo. } \\
\text { Colo. } \\
\text { N. Mex. } \\
\text { Ariz. } \\
\text { Utah } \\
\text { Nev. }\end{array}$ & $\begin{array}{r}1,171 \\
4 \\
22 \\
9 \\
212 \\
231 \\
604 \\
42 \\
47\end{array}$ & $\begin{array}{r}1,063 \\
9 \\
40 \\
8 \\
245 \\
122 \\
505 \\
63 \\
71\end{array}$ & $\begin{array}{r}598 \\
- \\
11 \\
7 \\
147 \\
109 \\
293 \\
31 \\
-\end{array}$ & $\begin{array}{r}461 \\
- \\
7 \\
12 \\
161 \\
91 \\
187 \\
3 \\
-\end{array}$ & $\begin{array}{r}43 \\
- \\
N \\
11 \\
- \\
31 \\
- \\
- \\
1\end{array}$ & $\begin{array}{r}50 \\
- \\
N \\
11 \\
- \\
37 \\
- \\
- \\
2\end{array}$ & $\begin{array}{r}5 \\
- \\
\mathrm{N} \\
- \\
- \\
- \\
\mathrm{N} \\
5 \\
-\end{array}$ & $\begin{array}{c}- \\
- \\
\mathrm{N} \\
- \\
- \\
- \\
\mathrm{N} \\
- \\
-\end{array}$ \\
\hline $\begin{array}{l}\text { PACIFIC } \\
\text { Wash. } \\
\text { Oreg. } \\
\text { Calif. } \\
\text { Alaska } \\
\text { Hawaii }\end{array}$ & $\begin{array}{r}3,045 \\
179 \\
117 \\
2,675 \\
6 \\
68\end{array}$ & $\begin{array}{r}2,567 \\
236 \\
116 \\
2,149 \\
7 \\
59\end{array}$ & $\begin{array}{r}546 \\
65 \\
N \\
381 \\
- \\
100\end{array}$ & $\begin{array}{r}89 \\
- \\
\mathrm{N} \\
- \\
- \\
89\end{array}$ & $\begin{array}{l}- \\
- \\
N \\
- \\
-\end{array}$ & $\begin{array}{r}4 \\
- \\
N \\
N \\
- \\
4\end{array}$ & $\begin{array}{l}- \\
N \\
N \\
N \\
-\end{array}$ & $\begin{array}{l}- \\
N \\
N \\
N \\
N\end{array}$ \\
\hline $\begin{array}{l}\text { Guam } \\
\text { P.R. } \\
\text { V.I. } \\
\text { Amer. Samoa } \\
\text { C.N.M.I. }\end{array}$ & $\begin{array}{r}- \\
8 \\
- \\
\\
18\end{array}$ & $\begin{array}{r}50 \\
21 \\
- \\
\cup \\
U\end{array}$ & $\begin{array}{r}\bar{N} \\
\bar{U} \\
-\end{array}$ & $\begin{array}{c}1 \\
N \\
- \\
U \\
U\end{array}$ & $\begin{array}{l}- \\
- \\
- \\
-\end{array}$ & $\begin{array}{l}- \\
- \\
- \\
- \\
-\end{array}$ & $\begin{array}{l}\bar{N} \\
- \\
\end{array}$ & $\begin{array}{l}\bar{N} \\
\bar{U} \\
U\end{array}$ \\
\hline
\end{tabular}

N: Not notifiable. U: Unavailable. $\quad-:$ No reported cases.

* Incidence data for reporting year 2001 and 2002 are provisional and cumulative (year-to-date). 
TABLE II. (Continued) Provisional cases of selected notifiable diseases, United States, weeks ending December 28, 2002, and December 29, 2001 (52nd Week)*

\begin{tabular}{|c|c|c|c|c|c|c|c|c|}
\hline \multirow[b]{3}{*}{ Reporting Area } & \multicolumn{4}{|c|}{ Syphilis } & \multirow{2}{*}{\multicolumn{2}{|c|}{ Tuberculosis }} & \multirow{2}{*}{\multicolumn{2}{|c|}{$\begin{array}{c}\text { Typhoid } \\
\text { Fever }\end{array}$}} \\
\hline & \multicolumn{2}{|c|}{ Primary \& Secondary } & \multicolumn{2}{|c|}{ Congenital } & & & & \\
\hline & $\begin{array}{l}\text { Cum. } \\
2002 \\
\end{array}$ & $\begin{array}{l}\text { Cum. } \\
2001\end{array}$ & $\begin{array}{l}\text { Cum. } \\
2002 \\
\end{array}$ & $\begin{array}{l}\text { Cum. } \\
2001\end{array}$ & $\begin{array}{l}\text { Cum. } \\
2002\end{array}$ & $\begin{array}{l}\text { Cum. } \\
2001\end{array}$ & $\begin{array}{l}\text { Cum. } \\
2002 \\
\end{array}$ & $\begin{array}{l}\text { Cum. } \\
2001 \\
\end{array}$ \\
\hline UNITED STATES & 6,378 & 6,095 & 359 & 497 & 12,120 & 15,492 & 266 & 368 \\
\hline $\begin{array}{l}\text { NEW ENGLAND } \\
\text { Maine } \\
\text { N.H. } \\
\text { Vt. } \\
\text { Mass. } \\
\text { R.I. } \\
\text { Conn. }\end{array}$ & $\begin{array}{r}139 \\
2 \\
9 \\
2 \\
94 \\
6 \\
26\end{array}$ & $\begin{array}{r}68 \\
1 \\
1 \\
3 \\
42 \\
9 \\
12\end{array}$ & $\begin{array}{l}1 \\
- \\
- \\
- \\
1 \\
- \\
-\end{array}$ & $\begin{array}{l}8 \\
3 \\
- \\
- \\
3 \\
- \\
2\end{array}$ & $\begin{array}{r}403 \\
20 \\
18 \\
6 \\
235 \\
37 \\
87\end{array}$ & $\begin{array}{r}498 \\
20 \\
20 \\
7 \\
270 \\
60 \\
121\end{array}$ & $\begin{array}{r}14 \\
- \\
- \\
- \\
8 \\
- \\
6\end{array}$ & $\begin{array}{r}20 \\
1 \\
2 \\
- \\
12 \\
- \\
5\end{array}$ \\
\hline $\begin{array}{l}\text { MID. ATLANTIC } \\
\text { Upstate N.Y. } \\
\text { N.Y. City } \\
\text { N.J. } \\
\text { Pa. }\end{array}$ & $\begin{array}{r}690 \\
35 \\
423 \\
157 \\
75\end{array}$ & $\begin{array}{r}538 \\
22 \\
281 \\
137 \\
98\end{array}$ & $\begin{array}{r}70 \\
12 \\
23 \\
34 \\
1\end{array}$ & $\begin{array}{r}74 \\
6 \\
33 \\
35 \\
-\end{array}$ & $\begin{array}{r}2,089 \\
287 \\
1,047 \\
496 \\
259\end{array}$ & $\begin{array}{r}2,501 \\
415 \\
1,263 \\
530 \\
293\end{array}$ & $\begin{array}{r}64 \\
9 \\
34 \\
16 \\
5\end{array}$ & $\begin{array}{r}113 \\
15 \\
49 \\
38 \\
11\end{array}$ \\
\hline $\begin{array}{l}\text { E.N. CENTRAL } \\
\text { Ohio } \\
\text { Ind. } \\
\text { Ill. } \\
\text { Mich. } \\
\text { Wis. }\end{array}$ & $\begin{array}{r}1,085 \\
167 \\
72 \\
336 \\
482 \\
28\end{array}$ & $\begin{array}{r}1,092 \\
81 \\
151 \\
409 \\
428 \\
23\end{array}$ & $\begin{array}{r}65 \\
4 \\
1 \\
33 \\
27 \\
-\end{array}$ & $\begin{array}{r}73 \\
2 \\
15 \\
45 \\
7 \\
4\end{array}$ & $\begin{array}{r}1,218 \\
173 \\
120 \\
604 \\
256 \\
65\end{array}$ & $\begin{array}{r}1,544 \\
306 \\
115 \\
707 \\
330 \\
86\end{array}$ & $\begin{array}{r}19 \\
7 \\
2 \\
1 \\
4 \\
5\end{array}$ & $\begin{array}{r}34 \\
5 \\
2 \\
18 \\
5 \\
4\end{array}$ \\
\hline $\begin{array}{l}\text { W.N. CENTRAL } \\
\text { Minn. } \\
\text { lowa } \\
\text { Mo. } \\
\text { N. Dak. } \\
\text { S. Dak. } \\
\text { Nebr. } \\
\text { Kans. }\end{array}$ & $\begin{array}{r}110 \\
57 \\
2 \\
30 \\
- \\
- \\
3 \\
18\end{array}$ & $\begin{array}{r}100 \\
33 \\
5 \\
26 \\
- \\
1 \\
10 \\
25\end{array}$ & $\begin{array}{l}1 \\
1 \\
- \\
- \\
- \\
- \\
- \\
-\end{array}$ & $\begin{array}{l}9 \\
2 \\
- \\
5 \\
- \\
- \\
- \\
2\end{array}$ & $\begin{array}{r}525 \\
226 \\
30 \\
126 \\
4 \\
12 \\
23 \\
104\end{array}$ & $\begin{array}{r}577 \\
239 \\
43 \\
157 \\
6 \\
13 \\
39 \\
80\end{array}$ & $\begin{array}{l}9 \\
3 \\
- \\
2 \\
- \\
- \\
4 \\
-\end{array}$ & $\begin{array}{r}16 \\
7 \\
- \\
9 \\
- \\
- \\
- \\
-\end{array}$ \\
\hline $\begin{array}{l}\text { S. ATLANTIC } \\
\text { Del. } \\
\text { Md. } \\
\text { D.C. } \\
\text { Va. } \\
\text { W.Va. } \\
\text { N.C. } \\
\text { S.C. } \\
\text { Ga. } \\
\text { Fla. }\end{array}$ & $\begin{array}{r}1,742 \\
11 \\
214 \\
69 \\
70 \\
2 \\
279 \\
126 \\
364 \\
607\end{array}$ & $\begin{array}{r}2,008 \\
14 \\
266 \\
43 \\
102 \\
5 \\
445 \\
235 \\
414 \\
484\end{array}$ & $\begin{array}{r}77 \\
- \\
14 \\
1 \\
1 \\
- \\
20 \\
11 \\
10 \\
20\end{array}$ & $\begin{array}{r}114 \\
- \\
5 \\
2 \\
5 \\
- \\
15 \\
21 \\
24 \\
42\end{array}$ & $\begin{array}{r}2,471 \\
15 \\
272 \\
- \\
283 \\
28 \\
417 \\
147 \\
400 \\
909\end{array}$ & $\begin{array}{r}3,005 \\
33 \\
262 \\
51 \\
306 \\
32 \\
398 \\
206 \\
572 \\
1,145\end{array}$ & $\begin{array}{r}43 \\
- \\
11 \\
- \\
7 \\
- \\
2 \\
- \\
4 \\
19\end{array}$ & $\begin{array}{r}52 \\
1 \\
10 \\
- \\
15 \\
- \\
3 \\
- \\
12 \\
11\end{array}$ \\
\hline $\begin{array}{l}\text { E.S. CENTRAL } \\
\text { Ky. } \\
\text { Tenn. } \\
\text { Ala. } \\
\text { Miss. }\end{array}$ & $\begin{array}{r}445 \\
88 \\
163 \\
151 \\
43\end{array}$ & $\begin{array}{r}661 \\
48 \\
331 \\
142 \\
140\end{array}$ & $\begin{array}{r}22 \\
3 \\
11 \\
4 \\
4\end{array}$ & $\begin{array}{r}39 \\
1 \\
24 \\
5 \\
9\end{array}$ & $\begin{array}{l}736 \\
134 \\
286 \\
207 \\
109\end{array}$ & $\begin{array}{l}884 \\
152 \\
313 \\
265 \\
154\end{array}$ & $\begin{array}{l}4 \\
4 \\
- \\
- \\
-\end{array}$ & $\begin{array}{l}1 \\
- \\
1 \\
- \\
-\end{array}$ \\
\hline $\begin{array}{l}\text { W.S. CENTRAL } \\
\text { Ark. } \\
\text { La. } \\
\text { Okla. } \\
\text { Tex. }\end{array}$ & $\begin{array}{r}841 \\
34 \\
152 \\
71 \\
584\end{array}$ & $\begin{array}{r}761 \\
49 \\
174 \\
60 \\
478\end{array}$ & $\begin{array}{r}73 \\
3 \\
- \\
3 \\
67\end{array}$ & $\begin{array}{r}85 \\
9 \\
- \\
6 \\
70\end{array}$ & $\begin{array}{r}1,569 \\
119 \\
- \\
142 \\
1,308\end{array}$ & $\begin{array}{r}2,287 \\
157 \\
294 \\
193 \\
1,643\end{array}$ & $\begin{array}{l}8 \\
- \\
- \\
2 \\
6\end{array}$ & $\begin{array}{r}20 \\
- \\
- \\
1 \\
19\end{array}$ \\
\hline $\begin{array}{l}\text { MOUNTAIN } \\
\text { Mont. } \\
\text { Idaho } \\
\text { Wyo. } \\
\text { Colo. } \\
\text { N. Mex. } \\
\text { Ariz. } \\
\text { Utah } \\
\text { Nev. }\end{array}$ & $\begin{array}{r}321 \\
- \\
9 \\
- \\
56 \\
38 \\
197 \\
8 \\
13\end{array}$ & $\begin{array}{r}243 \\
- \\
1 \\
1 \\
23 \\
19 \\
180 \\
11 \\
8\end{array}$ & $\begin{array}{r}20 \\
- \\
- \\
- \\
1 \\
- \\
19 \\
- \\
-\end{array}$ & $\begin{array}{r}35 \\
- \\
- \\
- \\
1 \\
2 \\
32 \\
- \\
-\end{array}$ & $\begin{array}{r}382 \\
12 \\
9 \\
3 \\
56 \\
28 \\
229 \\
31 \\
14\end{array}$ & $\begin{array}{r}632 \\
17 \\
9 \\
3 \\
138 \\
55 \\
289 \\
35 \\
86\end{array}$ & $\begin{array}{r}10 \\
- \\
- \\
- \\
5 \\
1 \\
- \\
2 \\
2\end{array}$ & $\begin{array}{r}11 \\
2 \\
- \\
- \\
1 \\
- \\
2 \\
2 \\
4\end{array}$ \\
\hline $\begin{array}{l}\text { PACIFIC } \\
\text { Wash. } \\
\text { Oreg. } \\
\text { Calif. } \\
\text { Alaska } \\
\text { Hawaii }\end{array}$ & $\begin{array}{r}1,005 \\
70 \\
28 \\
899 \\
- \\
8\end{array}$ & $\begin{array}{r}624 \\
57 \\
13 \\
542 \\
- \\
12\end{array}$ & $\begin{array}{r}30 \\
2 \\
1 \\
26 \\
- \\
1\end{array}$ & $\begin{array}{r}60 \\
- \\
- \\
60 \\
- \\
-\end{array}$ & $\begin{array}{r}2,727 \\
229 \\
109 \\
2,202 \\
48 \\
139\end{array}$ & $\begin{array}{r}3,564 \\
258 \\
123 \\
2,978 \\
54 \\
151\end{array}$ & $\begin{array}{r}95 \\
6 \\
2 \\
82 \\
- \\
5\end{array}$ & $\begin{array}{r}101 \\
7 \\
8 \\
82 \\
1 \\
3\end{array}$ \\
\hline $\begin{array}{l}\text { Guam } \\
\text { P.R. } \\
\text { V.I. } \\
\text { Amer. Samoa } \\
\text { C.N.M.I. }\end{array}$ & $\begin{array}{r}- \\
227 \\
1 \\
\cup \\
15\end{array}$ & $\begin{array}{r}12 \\
267 \\
- \\
U\end{array}$ & $\begin{array}{r}- \\
15 \\
- \\
U \\
-\end{array}$ & $\begin{array}{r}1 \\
15 \\
- \\
U\end{array}$ & $\begin{array}{r}- \\
75 \\
- \\
U \\
32\end{array}$ & $\begin{array}{r}63 \\
121 \\
- \\
\cup\end{array}$ & $\begin{array}{r}- \\
- \\
\end{array}$ & $\begin{array}{l}3 \\
- \\
- \\
U\end{array}$ \\
\hline
\end{tabular}

$\mathrm{N}$ : Not notifiable. U: Unavailable.

- : No reported cases.

* Incidence data for reporting year 2001 and 2002 are provisional and cumulative (year-to-date). 
TABLE III. Deaths in 122 U.S. cities, ${ }^{*}$ week ending December 28, 2002 (52nd Week)

\begin{tabular}{|c|c|c|c|c|c|c|c|c|c|c|c|c|c|c|c|}
\hline \multirow[b]{2}{*}{ Reporting Area } & \multicolumn{6}{|c|}{ All Causes, By Age (Years) } & \multirow[b]{2}{*}{$\begin{array}{l}\text { P\& }\left.\right|^{\dagger} \\
\text { Total }\end{array}$} & \multirow[b]{2}{*}{ Reporting Area } & \multicolumn{6}{|c|}{ All Causes, By Age (Years) } & \multirow[b]{2}{*}{$\begin{array}{l}\text { P\&I }{ }^{\dagger} \\
\text { Total }\end{array}$} \\
\hline & $\begin{array}{c}\text { All } \\
\text { Ages }\end{array}$ & $\geq 65$ & $45-64$ & $25-44$ & $1-24$ & $<1$ & & & $\begin{array}{c}\text { All } \\
\text { Ages }\end{array}$ & $\geq 65$ & $45-64$ & $25-44$ & $1-24$ & $<1$ & \\
\hline NEW ENGLAND & 451 & 312 & 92 & 34 & 4 & 9 & 54 & S. ATLANTIC & 852 & 544 & 179 & 83 & 30 & 16 & 62 \\
\hline Boston, Mass. & 128 & 78 & 28 & 12 & 2 & 8 & 6 & Atlanta, Ga. & 194 & 119 & 51 & 14 & 8 & 2 & 5 \\
\hline Bridgeport, Conn. & 33 & 23 & 8 & 2 & - & - & 6 & Baltimore, Md. & 103 & 60 & 20 & 14 & 4 & 5 & 10 \\
\hline Cambridge, Mass. & 14 & 10 & 3 & 1 & - & - & 1 & Charlotte, N.C. & 70 & 49 & 14 & 4 & 1 & 2 & 6 \\
\hline Fall River, Mass. & 27 & 20 & 6 & 1 & - & - & 7 & Jacksonville, Fla. & 125 & 78 & 28 & 15 & 4 & - & 12 \\
\hline Hartford, Conn. & $\mathrm{U}$ & $\mathrm{U}$ & $U$ & U & U & U & $U$ & Miami, Fla. & U & $\mathrm{U}$ & $U$ & U & $\mathrm{U}$ & $U$ & $\bar{U}$ \\
\hline Lowell, Mass. & 33 & 29 & 4 & - & - & - & 4 & Norfolk, Va. & 38 & 26 & 4 & 5 & 1 & 2 & - \\
\hline Lynn, Mass. & 12 & 8 & 2 & 2 & - & - & 1 & Richmond, Va. & 53 & 25 & 14 & 9 & 5 & - & 3 \\
\hline New Bedford, Mass. & 32 & 24 & 6 & 1 & 1 & - & 2 & Savannah, Ga. & 47 & 32 & 11 & 2 & 2 & - & 2 \\
\hline New Haven, Conn. & 42 & 28 & 9 & 4 & - & 1 & 6 & St. Petersburg, Fla. & 56 & 42 & 6 & 5 & 1 & 2 & 3 \\
\hline Providence, R.I. & $\mathrm{U}$ & $U$ & $U$ & U & $U$ & U & $U$ & Tampa, Fla. & 158 & 106 & 31 & 14 & 4 & 3 & 17 \\
\hline Somerville, Mass. & 10 & 8 & 2 & - & - & - & 1 & Washington, D.C. & U & U & U & U & $U$ & $U$ & $U$ \\
\hline Springfield, Mass. & 48 & 32 & 12 & 3 & 1 & - & 6 & Wilmington, Del. & 8 & 7 & - & 1 & - & - & 4 \\
\hline Waterbury, Conn. & 19 & 14 & 3 & 2 & - & - & 1 & E.S. CENTRAL & 530 & 352 & 120 & 36 & 14 & 8 & 56 \\
\hline Worcester, Mass. & 53 & 38 & 9 & 6 & - & - & 13 & Birmingham, Ala. & $\begin{array}{l}530 \\
104\end{array}$ & $\begin{array}{r}352 \\
67\end{array}$ & $\begin{array}{r}120 \\
26\end{array}$ & $\begin{array}{r}36 \\
6\end{array}$ & 1 & 4 & 18 \\
\hline MID. ATLANTIC & 2,034 & 1,456 & 388 & 125 & 35 & 30 & 118 & Chattanooga, Tenn. & 44 & 32 & 9 & 2 & - & 1 & 2 \\
\hline Albany, N.Y. & 61 & 45 & 14 & 1 & 1 & - & 2 & Knoxville, Tenn. & U & $\bar{U}$ & $U$ & $\bar{U}$ & $U$ & U & $\bar{U}$ \\
\hline Allentown, $\mathrm{Pa}$. & 31 & 27 & 2 & 1 & 1 & - & 3 & Lexington, Ky. & 72 & 50 & 14 & 5 & 3 & - & 6 \\
\hline Buffalo, N.Y. & 83 & 60 & 17 & 3 & 1 & 2 & 9 & Memphis, Tenn. & 197 & 129 & 46 & 14 & 6 & 2 & 20 \\
\hline Camden, N.J. & 24 & 13 & 5 & 1 & 1 & 4 & 4 & Mobile, Ala. & 20 & 14 & 5 & 1 & - & - & 1 \\
\hline Elizabeth, N.J. & 22 & 17 & 4 & - & 1 & - & - & Montgomery, Ala. & U & $\mathrm{U}$ & $U$ & $\mathrm{U}$ & $U$ & $\mathrm{U}$ & $U$ \\
\hline Erie, $\mathrm{Pa}$. & 33 & 27 & 3 & 3 & - & - & 2 & Nashville, Tenn. & 93 & 60 & 20 & 8 & 4 & 1 & 9 \\
\hline Jersey City, N.J. & 56 & 40 & 9 & 5 & 2 & - & - & WS CENTRAL & 416 & 278 & 87 & 25 & 16 & 10 & 37 \\
\hline New York City, N.Y. & 1,037 & 738 & 202 & 66 & 19 & 12 & 52 & $\begin{array}{l}\text { W.S. CENIRAL } \\
\text { Austin, Tex. }\end{array}$ & $\begin{array}{r}410 \\
61\end{array}$ & $\begin{array}{r}210 \\
34\end{array}$ & $\begin{array}{l}01 \\
20\end{array}$ & $\begin{array}{r}25 \\
5\end{array}$ & $\begin{array}{r}10 \\
2\end{array}$ & 10 & $\begin{array}{r}37 \\
5\end{array}$ \\
\hline Newark, N.J. & 35 & 12 & 16 & 5 & 1 & 1 & 2 & $\begin{array}{l}\text { Austin, lex. } \\
\text { Baton Rouge, La. }\end{array}$ & 28 & 17 & 5 & 1 & 3 & 2 & $\begin{array}{l}5 \\
1\end{array}$ \\
\hline Paterson, N.J. & 14 & 6 & 3 & 2 & - & 3 & - & $\begin{array}{l}\text { Baton Rouge, La. } \\
\text { Corpus Christi. Tex. }\end{array}$ & $\begin{array}{l}20 \\
41\end{array}$ & 32 & 5 & 1 & 1 & 2 & $\begin{array}{r}1 \\
11\end{array}$ \\
\hline Philadelphia, $\mathrm{Pa}$. & 255 & 163 & 62 & 23 & 4 & 3 & 11 & $\begin{array}{l}\text { Corpus Christl, Iex. } \\
\text { Dallas. Tex. }\end{array}$ & $\begin{array}{r}41 \\
U\end{array}$ & U & $\hat{U}$ & U & u & U & $\begin{array}{r}11 \\
U\end{array}$ \\
\hline Pittsburgh, $\mathrm{Pa} .^{\S}$ & 27 & 19 & 6 & 1 & - & 1 & - & $\begin{array}{l}\text { Dallas, lex. } \\
\text { ElPaso Tex }\end{array}$ & 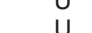 & U & 4 & U & U & U & U \\
\hline Reading, $\mathrm{Pa}$. & 24 & 19 & 4 & 1 & - & - & 3 & El Paso, lex. & 75 & 50 & 14 & 4 & 3 & 4 & $\begin{array}{l}0 \\
7\end{array}$ \\
\hline Rochester, N.Y. & 125 & 107 & 11 & 5 & 1 & 1 & 9 & Ft.Worth, Tex. & 15 & 50 & 14 & $\begin{array}{c}4 \\
11\end{array}$ & $\overrightarrow{3}$ & 4 & 7 \\
\hline Schenectady, N.Y. & 18 & 16 & 2 & - & - & - & 3 & Houston, lex. & 0 & 0 & 0 & 0 & 0 & u & U \\
\hline Scranton, Pa. & 27 & 19 & 4 & 3 & - & 1 & 1 & Little Rock, Ark. & 57 & 37 & 15 & 2 & 2 & 1 & 3 \\
\hline Syracuse, N.Y. & 91 & 73 & 11 & 2 & 3 & 2 & 11 & New Orleans, La. & 30 & 17 & 8 & 4 & 1 & - & - \\
\hline Trenton, N.J. & 27 & 20 & 6 & 1 & - & - & 4 & San Antonio, Tex. & $\mathrm{U}$ & $U$ & $U$ & U & $\mathrm{U}$ & $\mathrm{U}$ & $U$ \\
\hline Utica, N.Y. & 21 & 14 & 6 & 1 & - & - & $\begin{array}{l}4 \\
-\end{array}$ & Shreveport, La. & $\mathrm{U}$ & $\mathrm{U}$ & $\mathrm{U}$ & $U$ & $\mathrm{U}$ & $\mathrm{U}$ & $U$ \\
\hline Yonkers, N.Y. & 23 & 21 & 1 & 1 & - & - & 2 & Tulsa, Okla. & 124 & 91 & 20 & 8 & 4 & 1 & 10 \\
\hline E.N. CENTRAL & 1,227 & 775 & 287 & 106 & 38 & 21 & 87 & MOUNTAIN & 730 & 499 & 143 & 51 & 20 & 17 & 52 \\
\hline Akron, Ohio & 56 & 42 & 8 & 1 & 3 & 2 & 78 & Albuquerque, N.M. & 82 & 62 & 12 & 6 & - & 2 & 12 \\
\hline Canton, Ohio & 24 & 16 & 7 & 1 & - & - & 6 & Boise, Idaho & $\mathrm{U}$ & U & U & $U$ & $\mathrm{U}$ & $\bar{U}$ & $\mathrm{U}$ \\
\hline Chicago, III. & 408 & 232 & 101 & 54 & 18 & 3 & $\begin{array}{r}6 \\
28\end{array}$ & Colo. Springs, Colo. & 57 & 38 & 9 & 7 & 3 & - & 3 \\
\hline Cincinnati, Ohio & U & U & $\mathrm{U}$ & U & 10 & 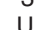 & 28 & Denver, Colo. & 104 & 66 & 27 & 4 & 5 & 2 & 10 \\
\hline Cleveland, Ohio & 106 & 65 & 31 & 7 & 2 & 1 & 7 & Las Vegas, Nev. & 241 & 157 & 57 & 16 & 5 & 6 & 15 \\
\hline Columbus, Ohio & 155 & 101 & 36 & 7 & 3 & 8 & 7 & Ogden, Utah & 15 & 11 & 4 & - & - & - & - \\
\hline Dayton, Ohio & $U$ & $\mathrm{U}$ & $U$ & U & $U$ & U & $\mathrm{U}$ & Phoenix, Ariz. & $U$ & U & $U$ & $U$ & U & $U$ & $U$ \\
\hline Detroit, Mich. & 111 & 65 & 29 & 12 & 4 & 1 & 7 & Pueblo, Colo. & 18 & 14 & 4 & - & - & - & 1 \\
\hline Evansville, Ind. & 19 & 13 & 3 & 1 & 1 & 1 & 3 & Salt Lake City, Utah & 82 & 53 & 10 & 11 & 4 & 4 & 5 \\
\hline Fort Wayne, Ind. & 56 & 42 & 12 & 2 & - & - & 3 & Tucson, Ariz. & 131 & 98 & 20 & 7 & 3 & 3 & 6 \\
\hline Gary, Ind. & 5 & 2 & - & - & 1 & 2 & - & PACIFIC & 1,000 & 690 & 201 & 58 & 32 & 19 & 73 \\
\hline Grand Rapids, Mich. & 48 & 36 & 6 & 6 & - & - & 6 & Berkeley, Calif. & 18 & 11 & 6 & 1 & - & - & - \\
\hline Indianapolis, Ind. & 138 & 87 & 34 & 10 & 6 & 1 & 9 & Fresno, Calif. & 108 & 72 & 19 & 6 & 7 & 4 & 9 \\
\hline Lansing, Mich. & $U$ & U & U & $\mathrm{U}$ & $U$ & $\mathrm{U}$ & $\mathrm{U}$ & Glendale, Calif. & 14 & 11 & 1 & - & 2 & - & 1 \\
\hline Milwaukee, Wis. & $U$ & U & U & U & $U$ & U & $U$ & Honolulu, Hawaii & 53 & 35 & 11 & 5 & 1 & 1 & 4 \\
\hline Peoria, III. & 47 & 34 & 10 & 2 & - & 1 & 2 & Long Beach, Calif. & 61 & 40 & 17 & 3 & - & 1 & 5 \\
\hline Rockford, III. & 54 & 40 & 10 & 3 & - & 1 & 2 & Los Angeles, Calif. & 119 & 73 & 24 & 10 & 7 & 5 & 3 \\
\hline South Bend, Ind. & $U$ & $U$ & U & $\mathrm{U}$ & U & $\mathrm{U}$ & $\mathrm{U}$ & Pasadena, Calif. & 19 & 16 & 1 & 1 & 1 & - & - \\
\hline Toledo, Ohio & $U$ & $\mathrm{U}$ & U & U & U & U & $U$ & Portland, Oreg. & 132 & 97 & 21 & 10 & 3 & 1 & 10 \\
\hline Youngstown, Ohio & $U$ & $U$ & $U$ & $U$ & $U$ & $U$ & $U$ & Sacramento, Calif. & $\mathrm{U}$ & U & $U$ & $U$ & $U$ & U & $U$ \\
\hline W.N. CENTRAL & & & & & 7 & 10 & 16 & San Diego, Calif. & 114 & 72 & 29 & 9 & 2 & 2 & 6 \\
\hline Des Moines, lowa & U & U & U & U & 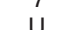 & u & 10 & San Francisco, Calif. & U & $\mathrm{U}$ & $U$ & $U$ & $\bar{U}$ & $\bar{U}$ & $\mathrm{U}$ \\
\hline Duluth, Minn. & 21 & 17 & 4 & - & - & - & 1 & San Jose, Calif. & 155 & 112 & 32 & 3 & 6 & 2 & 19 \\
\hline Kansas City, Kans. & $U$ & U & U & $\mathrm{U}$ & $U$ & $U$ & $\begin{array}{l}1 \\
\mathrm{U}\end{array}$ & Santa Cruz, Calif. & 27 & 21 & 5 & 1 & - & - & 2 \\
\hline Kansas City, Mo. & 89 & 62 & 14 & 8 & 2 & 3 & 4 & Seattle, Wash. & 97 & 67 & 21 & 5 & 1 & 3 & 6 \\
\hline Lincoln, Nebr. & 20 & 16 & 3 & 1 & - & - & - & Spokane, Wash. & $U$ & U & $U$ & U & $\mathrm{U}$ & $\mathrm{U}$ & $U$ \\
\hline Minneapolis, Minn. & 52 & 36 & 11 & 3 & 1 & 1 & 4 & Tacoma, Wash. & 83 & 63 & 14 & 4 & 2 & - & 8 \\
\hline Omaha, Nebr. & 81 & 56 & 11 & 7 & 3 & 4 & 6 & TOTAL & $7,552^{\Uparrow}$ & 5,127 & 1,550 & 539 & 196 & 140 & 555 \\
\hline St. Louis, Mo. & U & U & U & U & U & $\mathrm{U}$ & $U$ & & & & & & & & \\
\hline St. Paul, Minn. & 49 & 34 & 10 & 2 & 1 & 2 & 1 & & & & & & & & \\
\hline Wichita, Kans. & U & U & U & U & U & $\mathrm{U}$ & U & & & & & & & & \\
\hline
\end{tabular}

\section{U: Unavailable. -:No reported cases.}

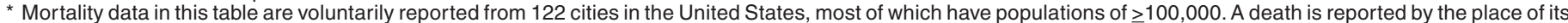
occurrence and by the week that the death certificate was filed. Fetal deaths are not included.

t Pneumonia and influenza.

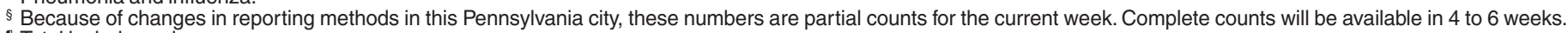

ๆ Total includes unknown ages. 
All $M M W R$ references are available on the Internet at http://www.cdc.gov/mmwr. Use the search function to find specific articles.

Use of trade names and commercial sources is for identification only and does not imply endorsement by the U.S. Department of Health and Human Services.

References to non-CDC sites on the Internet are provided as a service to $M M W R$ readers and do not constitute or imply endorsement of these organizations or their programs by CDC or the U.S. Department of Health and Human Services. CDC is not responsible for the content of these sites. URL addresses listed in $M M W R$ were current as of the date of publication. 
The Morbidity and Mortality Weekly Report (MMWR) Series is prepared by the Centers for Disease Control and Prevention (CDC) and is available free of charge in electronic format and on a paid subscription basis for paper copy. To receive an electronic copy each week, send an e-mail message to listserv@listserv.cdc.gov. The body content should read SUBscribe mmwr-toc. Electronic copy also is available from CDC's World-Wide Web server at http://www.cdc.gov/mmwr or from CDC's file transfer protocol server at ftp://ftp.cdc.gov/pub/publications/ mmwr. To subscribe for paper copy, contact Superintendent of Documents, U.S. Government Printing Office, Washington, DC 20402; telephone 202-512-1800.

Data in the weekly MMWR are provisional, based on weekly reports to CDC by state health departments. The reporting week concludes at close of business on Friday; compiled data on a national basis are officially released to the public on the following Friday. Address inquiries about the $M M W R$ Series, including material to be considered for publication, to Editor, $M M W R$ Series, Mailstop C-08, CDC, 1600 Clifton Rd., N.E., Atlanta, GA 30333; telephone 888-232-3228.

All material in the MMWR Series is in the public domain and may be used and reprinted without permission; citation as to source, however, is appreciated.

预U.S. Government Printing Office: 2003-533-155/69084 Region IV 